\title{
Sistema de produção Neuro-Fuzzy em tempo real para a ITAIPU Binacional
}

\section{Teresinha Arnauts}

Orientadora: Profa. Dra. Roseli Aparecida Francelin Romero

Dissertação apresentada ao Instituto de Ciências Matemáticas e de Computação - ICMC-USP, como parte dos requisitos para obtenção do título de Mestre em Ciências de Computação e Matemática Computacional. 
A Comissão Julgadora:

Profa. Dra. Roseli Ap. Francelin Romero

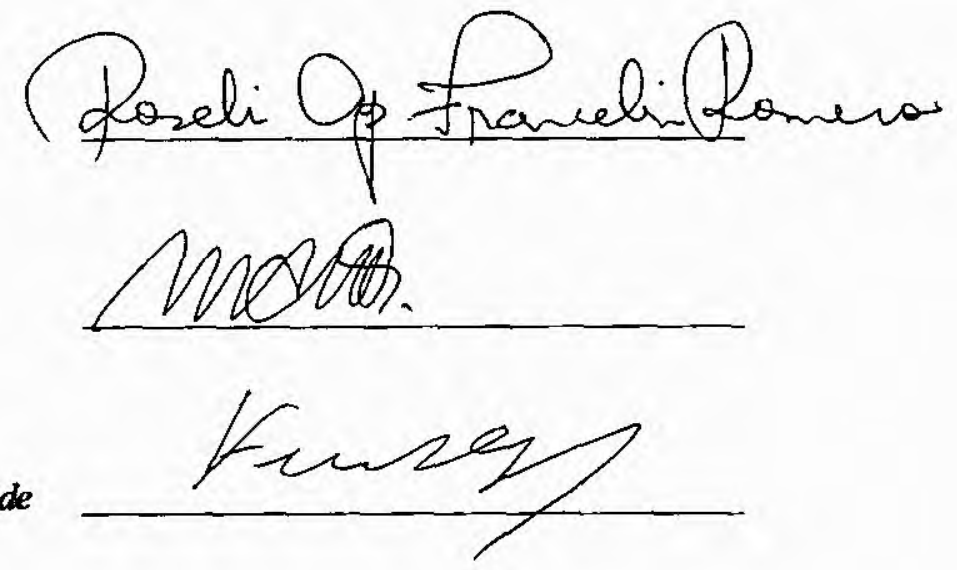

Profa. Dra. Maria Carolina Monard

Prof. Dr. Fernando Antonio Campos Gomide 


\section{Agradecimentos}

- A Deus, que guiou meus passos até aqui.

- A Professora Doutora Roseli Aparecida Francelin Romero, orientadora deste trabalho, pela orientação e atenção dedicada durante o desenvolvimento deste trabalho.

- Aos Eng. Jorge Habib Hanna El Khouri e João Ricardo Camargo, pelo apoio e incentivo, fundamentais à realização deste trabalho.

- Aos colegas do LABIC e da ITAIPU Binacional, que ajudaram com seus conhecimentos e amizade.

- À USP de São Carlos e seus professores, pela oportunidade de estudar num centro de formação de conhecimento.

- Ao CNPq pelo apoio à formação discente.

- A Antonio Marcos Massao Hachisuca, pelo amor, colaboração e apoio durante todos os instantes desta jornada.

- A Renato Bobsin Machado, pela atenção e ajuda, que ajudaram à realização deste trabalho.

- Aos meus pais, Stanislau e Lucia, que sempre apoiaram minhas decisões e sonhos. 


\section{Resumo}

Nos últimos anos, tem-se dado grande enfoque à resolução de problemas utilizando-se redes neurais artificiais, principalmente devido às suas características de aprendizado e adaptação, generalização, processamento paralelo e distribuído, etc... Pesquisadores também têm proposto o desenvolvimento de sistemas híbridos, que consiste na união de mais de um paradigma, por exemplo, redes neurais, sistemas especialistas e sistemas fuzzy, num mesmo sistema, provendo uma solução melhor para um determinado problema.

Neste trabalho, uma técnica para a modelagem de sistemas de produção através dos paradigmas conexionista e fuzzy está sendo proposta. Um sistema de produção neurofuzzy, que utiliza esta técnica para a detecção e previsão de falhas na Hidrelétrica de Itaipu, foi desenvolvido. Este sistema, chamado de Sistema de Produção NEUFI (NEUro Fuzzy para a Itaipu), permite a rápida tomada de decisões em emergências e melhor monitoração do sistema Itaipu em situações normais.

Para este propósito, uma base de conhecimento baseada em regras, já em uso na operação da Usina pelo sistema R-TESE (Real Time Expert System Environment), foi utilizada como referência inicial. Além disso um simulador, denominado Simulador Neuro-Fuzzy, foi também desenvolvido para facilitar a modelagem das regras.

A abor dagem proposta, quando comparada com o sistema R-TESE, tem as seguintes vantagens. Primeiro, a incorporação de técnicas de redes neurais dá ao sistema NEUFI maior flexibilidade e fácil manutenção. Segundo, possibilidade de visualizar às regras através de estruturas neurais. Outra vantagem é a redução do número de regras devido a similaridade de algumas delas, que têm seu conhecimento implicitamente representado durante o treinamento da rede. 


\section{Abstract}

In the last years, neural networks have been widely used for solving problems, mainly due to their learning, adaptation, generalization, parallel and distributed processing characteristics. In addition, researchers have proposed the development of hybrid systems which consist in the combination of more than one paradigm, for example, neural networks, expert systems and fuzzy systems in the same system, providing a better solution for the problem given.

In this work, a technique for modeling of production systems by using connectionist and fuzzy paradigms has been proposed. A neuro-fuzzy production system, that uses this technique, for fault detection and prediction in the Itaipu Hydroelectric, has been developed. This system, called by NEUFI Production System (NEUro Fuzzy for Itaipu), allows a faster making decision in emergencies and improves the Itaipu System monitoring in normal situations.

For this purpose, rule-based knowledge already in use on Itaipu operation by system R-TESE (Real Time Expert System Environment) has been taken as initial reference. Furthermore, a simulator entitled Neuro-Fuzzy Simulator has also been developed for the modeling of the rules to be easier.

The proposed approach when compared with the system R-TESE has the following advantages. First, the incorporation of neural network techniques in NEUFI provides the system more flexibility and easier maintenance. Second, it allows to take a view of the rules through neural networks. Another improvement is the reduction of the number of rules, due to the similarity of some rules, which have their knowledge implicitly represented during the network training process. 


\section{Conteúdo}

1 Introdução 1

2 Delimitação do Espaço do Problema 6

2.1 Sistemas em Tempo Real . . . . . . . . . . . . . . . . 6

2.2 A ITAIPU Binacional . . . . . . . . . . . . . . . . . 8

2.3 Sistemas em Operação na Usina . . . . . . . . . . . . . . . . . 10

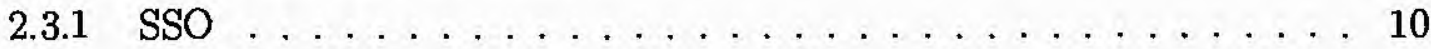

2.3 .2 R-TESE ............................ 14

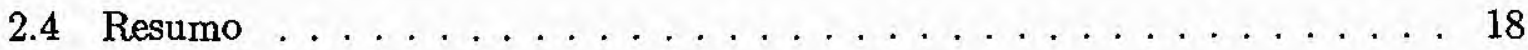

3 Sistemas Híbridos $\quad 19$

3.1 Redes Neurais Artificiais . . . . . . . . . . . . . . . . . . 20

3.1 .1 Aprendizado . . . . . . . . . . . . . . 21

3.1 .2 Redes Neurais Multicamadas . . . . . . . . . . . . . . . . 22

3.2 Sistemas Especialistas Conexionistas . . . . . . . . . . . . . 23

3.3 Sistemas Fuzzy . . . . . . . . . . . . . . . . . . . 28

3.4 Redes Neurais Fuzzy . . . . . . . . . . . . . . . . . 31

3.4 .1 Modelo FuNN . . . . . . . . . . . . . . . . 32

3.4 .2 Neurônios Fuzzy. . . . . . . . . . . . . . . . . 34

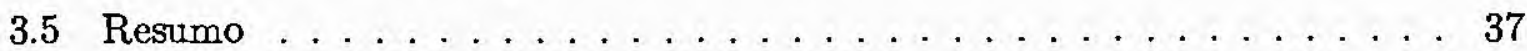

4 Simulador Neuro-Fuzzy 38

4.1 Desenvolvimento do Simulador Neuro-Fuzzy . . . . . . . . . . . . . 38

4.1.1 Projeto de uma Base de Conhecimento Neuro-Fuzzy . . . . . . . . 39 
4.1 .2 Base de Conhecimento Final . . . . . . . . . . . . . . 47

4.2 Formalização das Regras . . . . . . . . . . . . . . . . . 48

4.2 .1 Base de Regras . . . . . . . . . . . . . . . . . 48

4.2 .2 Regras modeladas . . . . . . . . . . . . . . . 50

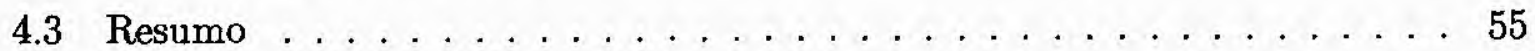

5 Sistema NEUFI $\quad \mathbf{5 7}$

5.1 Interfaces com os Usuários . . . . . . . . . . . . . . 57

5.1 .1 Interface de Variáveis . . . . . . . . . . . . . . . . . . 58

5.1 .2 Edição de Mensagens . . . . . . . . . . . . . . . . 59

5.1 .3 Apresentação do Resultado . . . . . . . . . . . . . . . . . 59

5.2 Características de Implementação . . . . . . . . . . . . . . . 61

5.2 .1 TNeuronioBinario ........................ 64

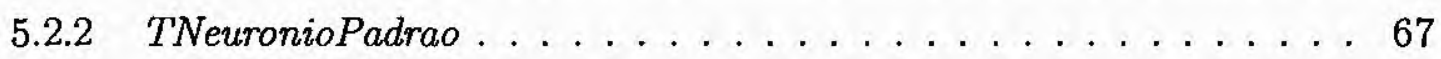

5.2 .3 TNeuronioFuzzy..................... 67

5.2 .4 TConexao ......................... 70

5.2 .5 TSubNet.............................. 71

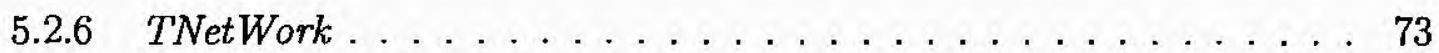

5.2 .7 TVariavel ......................... 74

5.2 .8 TSaida............................. 75

5.2 .9 TThFiles........................ 77

5.2 .10 TThExecute ......................... 78

5.3 Testes e Validação dos Resultados . . . . . . . . . . . . . . . . . . 80

5.3 .1 Testes de Unidade . . . . . . . . . . . . . . . . 80

5.3 .2 Testes de Interação entre o SSO e o NEUFI . . . . . . . . . . . . 81

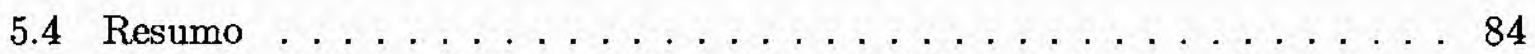

6 Conclusões e Trabalhos Futuros $\quad 85$

A Base de Conhecimento Real (notação no R-TESE) 92 


\section{Lista de Figuras}

2.1 Localização Geográfica da Usina Hidrelétrica de ITAIPU Binacional . . . : 8

2.2 Componentes do SSO . . . . . . . . . . . . . . . . . . 11

2.3 Estrutura Típica do Ambiente Especialista R-TESE . . . . . . . . . . . . 15

2.4 Arquitetura do R-TESE . . . . . . . . . . . . . . . 16

3.1 Neurônio natural . . . . . . . . . . . . . . . . . . . 21

3.2 Modelo Simplificado (neurônio artificial) . . . . . . . . . . . . . 21

3.3 Função de ativação Degrau . . . . . . . . . . . . . . . . 21

3.4 Função de ativação Sigmoid . . . . . . . . . . . . . . . . . 21

3.5 Estrutura de uma rede neural do tipo multicamadas . . . . . . . . . 23

3.6 Exemplos de Neurônios Binários (AND e OR) . . . . . . . . . . 26

3.7 Rede Neural com Regras Simples . . . . . . . . . . . . . . . . 27

3.8 Modelo Genérico, regras mais complexas . . . . . . . . . . . . . 27

3.9 Função de pertinência para o conjunto "perto" . . . . . . . . . . . . . 29

3.10 Conjuntos fuzzy representando "temperatura" . . . . . . . . . . . . . 29

3.11 Arquitetura Geral de uma FNN . . . . . . . . . . . . . . . 32

3.12 Neurônio Fuzzy AND . . . . . . . . . . . . . . . . . 34

3.13 Neurônio Fuzzy $O R \ldots \ldots \ldots \ldots \ldots \ldots \ldots \ldots \ldots$

3.14 Neurônio Neo-Fuzzy . . . . . . . . . . . . . . . . . 36

3.15 Função de pertinência uniformemente distribuída sobre o universo de X . . 36

4.1 Simulador Neuro-Fuzzy . . . . . . . . . . . . . 40

4.2 Interface das sub-redes do Projeto . . . . . . . . . . . . . . 40

4.3 Edição das características da sub-rede Selecionada . . . . . . . . . . . 41

4.4 Formulário de uma sub-rede . . . . . . . . . . . . . . . . 41 


\section{Lista de Tabelas}

2.1 Pontos Monitorados . . . . . . . . . . . . . . . . . 12

2.2 Formato do Pacote . . . . . . . . . . . . . . . . 12

2.3 Status dos Pontos do SSO . . . . . . . . . . . . . . . 14

5.1 Formato do Arquivo de Mensagens . . . . . . . . . . . 60

5.2 Classe TNeuronioBinario . . . . . . . . . . . . . 65

5.3 Classe das Variáveis . . . . . . . . . . . . . . . . . 67

5.4 Classe TNeuronioFuzzy . . . . . . . . . . . . . . 67

5.5 Classe TFuncaoPertinencia . . . . . . . . . . . . . . 68

5.6 Classe TGrausPertinencia . . . . . . . . . . . . . 70

5.7 Classe TConexao . . . . . . . . . . . . . . . 70

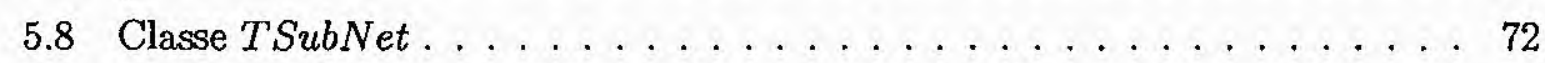

5.9 Classe TNetWork . . . . . . . . . . . . . . . . 73

5.10 Classe das Variáveis . . . . . . . . . . . . . . . . . . . 74

5.11 Registro TInformacao . . . . . . . . . . . . . . . 76

5.12 Classe TSaida . . . . . . . . . . . . . . . . . . 76

5.13 Classe TListaEspera . . . . . . . . . . . . . . . . . 77

5.14 Classe TThFiles . . . . . . . . . . . . . . . . . . 77

5.15 Classe TThExecute . . . . . . . . . . . . . . . 78

5.16 Períodos de Carga . . . . . . . . . . . . . . . . 82 


\section{Lista de Abreviaturas}

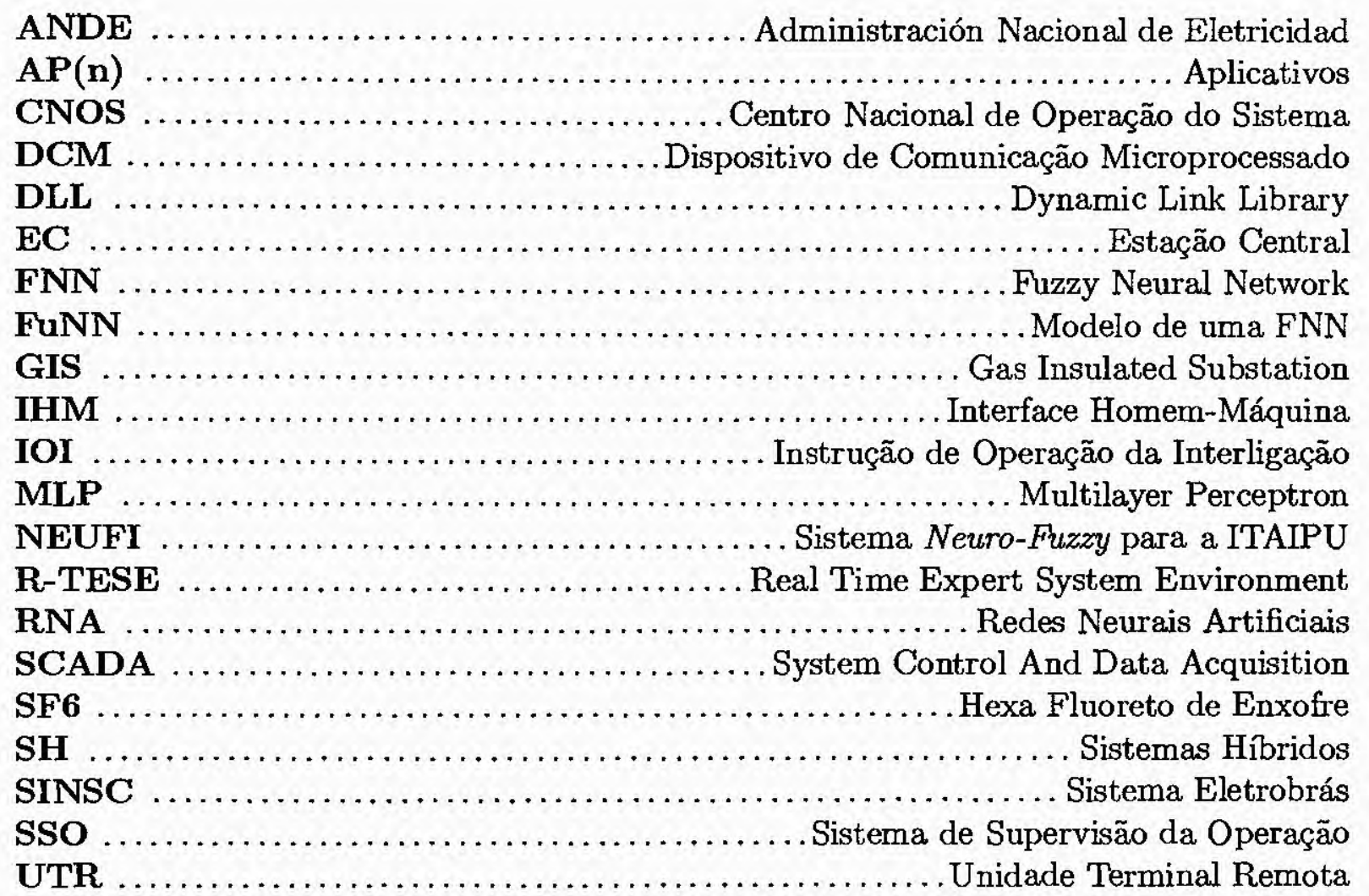




\section{Capítulo 1}

\section{Introdução}

O setor elétrico tem recebido grande enfoque nos estudos que envolvem novas tecnologias, devido ao papel estratégico que as fontes de energia e todo o seu aparato desempenham no suporte ao desenvolvimento de um país (Capanema, 1997).

De modo mais específico, pode ser citada a automatização crescente nas atividades de geração, transmissão e distribuição de energia. Algumas companhias do setor elétrico brasileiro já passaram pela barreira da consolidação de seus serviços e se defrontam, atualmente, com o aprimoramento dos seus procedimentos e processos operacionais, em busca da qualidade total. Esta busca pela qualidade representa pesquisar e implantar técnicas modernas de apoio e execução de atividades essenciais ao funcionamento do sistema interligado, em todas as suas etapas (Khouri, 1993).

A geração e transmissão de energia elétrica envolvem uma estrutura extremamente complexa de componentes interligados: usinas, subestações, linhas, operadores, despachantes, sendo que os esforços despendidos para assegurar a continuidade no fornecimento desta energia constituem tarefas críticas para a qualidade dos serviços prestados (Khouri, 1991).

Com a finalidade de manter a qualidade dos serviços prestados diversos projetos estão sendo desenvolvidos, principalmente, os voltados à área de aquisição, supervisão e controle.

A ITAIPU Binacional, fonte estratégica da energia brasileira e paraguaia, também está sensível a este contexto, necessitando constantemente da utilização de novas fontes tecnológicas que ajudem na tomada de decisōes de forma mais rápida e confiável, para um mercado consumidor que cada vez se torna mais exigente. 
Essa situação implica num maior investimento no treinamento e na pesquisa de novas tecnologias para facilitar à tomada de decisões. Em sistemas elétricos um grande número de mensagens e alarmes precisam ser analisados em caso de distúrbios. Estes distúrbios estão associados à falhas que podem ser de diferentes tipos e que podem ocorrer em qualquer lugar no sistema (Rodrigues et al., 1999). Nestas situações há a necessidade de se localizar as falhas e suas causas, para restabelecer ao sistema as suas condições normais de operação. Então, é essencial que a localização da falha seja determinada num espaço de tempo muito curto. Numa sala de controle o operador deve chegar a uma conclusão através de um grande número de informações, o que pode consumir muito tempo.

Muitas aplicações de sistemas inteligentes para diagnóstico e restauração de falhas, estão baseados em sistemas especialistas. Mas, o maior problema destes sistemas é quando se trabalha com dados novos ou que tenham ruídos, pois eles não tem a capacidade de generalização, ou seja, encontrar a saída em que melhor se enquadra a entrada fornecida. As Redes Neurais Artificiais (RNA) têm sido usadas com sucesso para solucionar problemas deste tipo em sistemas elétricos nos últimos anos (Rodrigues et al., 1999). Uma vez treinada elas são capazes de generalizar e apresentar resultados num espaço de tempo muito curto (Braga et al., 1999). Além disso, elas são capazes de processar um grande número de informações e obter respostas em tempo compatível com os requisitos de sistemas em tempo real (Rodrigues et al., 1999). E, para melhorar a solução do problema, pode-se combiná-las com outros paradigmas, tais como sistemas especialistas e sistemas fuzzy (Haykin, 1999), culminando numa solução mais abrangente para o problema.

O sistema, atualmente em uso pela ITAIPU Binacional, e que é citado devido ao papel estratégico que ele desempenha neste projeto, é o Sistema de Supervisão da Operação (SSO). O SSO é responsável pela aquisição e monitoramento, em tempo real, de grandezas analógicas e digitais dos mais diversos pontos de aquisição. A tarefa de monitoração das grandezas obtidas inclui: um tratamento quanto à validade e violação de limites; realização de cálculos matemáticos; exteriorização das informações em diagramas; apresentação de gráficos de tendências; registro dos dados referentes a eventos; além de montar pacotes referentes aos pontos monitorados, sumarizando a conclusão obtida. Esses pacotes são disponibilizados a todos os subsistemas externos que deles necessitam. Já os subsistemas externos, quando precisam enviar informações ao SSO, geram pacotes e os enviam ao SSO, caracterizando assim, o protocolo de comunicação entre eles. Outras características do SSO são apresentadas no capítulo 2, item 2.3.1.

Os operadores/despachantes observam o comportamento do SSO, coordenando todos os procedimentos estabelecidos pelas instruções de operação da planta, pois o SSO 
tem por característica processar cada ponto monitorado (analógico ou digital) individualmente sem considerar o sistema interligado, ou seja, sem considerar a relação que existe entre os componentes de um sistema elétrico e o que isto implica. Essas relações estão especificadas nas Instrução de Operação da Interligação (IOIs) ${ }^{1}$.

Desta forma, percebe-se a possibilidade de ampliar a automatização disponível, através de um sistema inteligente que ajude na tomada de decisões, proporcionando maior confiabilidade e rapidez na ações/decisōes dos despachantes.

No presente trabalho é proposta uma técnica de modelagem de sistemas de produção utilizando os paradigmas conexionista e fuzzy, e um sistema de produção neuro-fuzzy que a utiliza para a deteçãa e previsão de falhas na Usina Hidrelétrica de ITAIPU Binacional. Para isto é utilizado um subconjunto de regras de produção, que faz parte da base de conhecimento do sistema especialista R-TESE (Real Time Expert System Environment) (Capanema, 1999). Devido às características deste subconjunto, o mesmo foi considerado suficiente para representar todas as regras.

O sistema proposto tem como característica a capacidade de analisar o estado das linhas de transmissão de energia, barras, disjuntores, seccionadoras e com base nesta análise, informar ao operador do Sistema ITAIPU sugestões de como interagir com estes elementos.

Estas informações permitem melhorar a configuração do sistema elétrico, quando ele estiver operando em condições normais, e uma agilidade maior em situações de emergência, levando-se em consideração o grande volume de dados que precisam ser analisados até que se encontre(m) a(s) causa(s) do problema.

Para o desenvolvimento do sistema neuro-fuzzy as seguintes tarefas foram necessárias:

- Desenvolvimento de um ambiente de construção de bases de conhecimento neurofuzzy, intitulado Simulador Neuro-Fuzzy. Esta ferramenta permite a modelagem de diversas redes concorrentes ou dependentes, criação de prioridades entre estas (quanto dependentes), treinamento das mesmas, e por fim, junção de todas as redes numa única, compondo a base de conhecimento utilizada por outros sistemas;

- Construção de uma base de conhecimento neuro-fuzzy fundamentada nas Instruções de Operação da Interligação do setor de $60 \mathrm{~Hz}$, que já foram organizadas em forma de regras para utilização no sistema especialista R-TESE;

\footnotetext{
${ }^{1}$ Estudos de Procedimentos Operativos feito por operadores da ITAIPU
} 
- Implementação de um sistema que realiza a inferência sobre a base de conhecimento neuro-fuzzy construída - Sistema NEUFI (NEUro Fuzzy para a Itaipu). Este sistema recebe do SSO, em tempo real, informações sobre a configuração do sistema elétrico. A partir destas informações, o sistema realiza a inferência sobre a rede neuro-fuzzy e a resposta é dada pelos neurônios da camada de saída que foram ativados. Estas saídas são as causas de uma eventual anormalidade ocorrida, bem como as ações pertinentes previstas nas Instruções de Operação;

- Atendimento dos requisitos funcionais e de desempenho (tempo de resposta) de sistemas de tempo real.

Para apresentar as tarefas e estudos realizados, organizou-se este trabalho da seguinte forma:

No Capítulo 1 é destacada a importância da utilização dos paradigmas conexionista, fuzzy e sistemas especialistas para a resolução de problemas nos setores elétricos. Além disto, uma visão geral do conteúdo deste trabalho também é apresentada.

O Capítulo 2 é dedicado ao estudo de sistemas em tempo real, uma das grandes características deste trabalho. Descreve-se a Hidrelétrica de ITAIPU e dois sistemas em tempo real, um deles voltado à área de supervisão e controle e o outro à área de apoio à operação.

O Capítulo 3 é iniciado com uma introdução a sistemas híbridos. Após esta breve introdução, é dada uma visão geral do que são redes neurais artificiais, sistemas de produção conexionistas, sistemas fuzzy e redes neurais fuzzy.

O simulador Neuro-Fuzzy proposto no presente trabalho, bem como a modelagem das regras a partir do mesmo são apresentados no Capítulo 4. Todo o processo de modelagem de redes no simulador é apresentado, deste o particionamento das mesmas, especificação de dependência entre elas, definição das variáveis que representam dados de entrada e de saída, bem como das variáveis que ligam as redes que possuem relacionamento, até o treinamento e criação da base que contém todas as redes². Além disso, as regras contidas no Apêndice A são apresentadas numa arquitetura neuro-fuzzy, de acordo com suas respectivas modelagens no simulador.

No Capítulo 5 é proposto o sistema NEUFI, detalhando suas interfaces com os usuários; explicando como associar os dados de entrada com variáveis; explicando como atribuir mensagens aos neurônios das camadas de saída e apresentando as principais

\footnotetext{
${ }^{2}$ União de todas as redes numa única, rede esta utilizada pelo sistema NEUFI.
} 
classes de objetos utilizadas na implementação deste sistema. Alguns dos testes efetuados para a validação do sistema NEUFI e das regras são também apresentados.

No Capítulo 6 são expostas às conclusões e trabalhos futuros relacionados a este trabalho.

O Apêndice A contém as regras de produção que foram modeladas numa base de regras neuro-fuzzy. 


\section{Capítulo 2}

\section{Delimitação do Espaço do Problema}

Neste capítulo serão apresentados alguns dos estudos que foram realizados para a elaboração deste trabalho.

Em primeira análise será dado enfoque a sistemas em tempo real, suas principais características.

Posteriormente serão apresentados os principais aspectos da Usina Hidrelétrica de ITAIPU Binacional e dois sistemas em tempo real considerados fundamentais para a elaboração deste trabalho.

\subsection{Sistemas em Tempo Real}

Sistemas computacionais estão presentes na maioria dos dispositivos modernos, desde um equipamento industrial até o mais simples aparelho doméstico. Por exemplo, um avião usa uma seqüência de registros para determinar sua posição atual. Além disso, outros sistemas requerem respostas "imediatas" para eventos que ocorrem sem conhecimento prévio e, a princípio sem razão conhecida. Esses problemas necessitam sistemas que apresentem soluções em tempo real para que seja possível a rápida tomada de decisões.

Os primeiros sistemas considerados em tempo real foram desenvolvidos no final da década de 40 e início da década de 50 . O primeiro, o projeto Whirlwind, era um simulador de vôo desenvolvido pela IBM para a Marinha Norte-Americana (1949) e o segundo, SAGE, era um sistema de defesa aéreo desenvolvido pela Força Aérea NorteAmericana (década de 50). Só a partir dos anos 60 começou a haver algum interesse em aplicações em tempo real para soluções de problemas (Weber, 1997). 
Segundo Pressman (Pressman, 1995), este tipo de sistema deve monitorar informações em tempo contínuo de algum processo do mundo real, ou seja, interagir com o mundo real num limite de tempo ditado pelo mundo real. Como exemplo de aplicações destes sistemas pode-se citar a de aviões, utilizada em aeronaves, o controle de processos de produção, os produtos de consumo e a instrumentação industrial.

Sistemas em tempo real são freqüentemente reativos ou sistemas embedded (embutidos). Sistemas reativos são aqueles que têm alguma interação com o ambiente, por exemplo, sistemas de controle de incêndios que, constantemente reagem a botões acionados pelo piloto de um avião. Sistemas embutidos são aqueles sistemas usados para controlar hardware especializado, no qual o sistema computacional está instalado, por exemplo, o sistema microprocessador usado para controlar a mistura combustível/ar no carburador de alguns carros.

Normalmente, sabe-se que sistemas em tempo real são sistemas que devem reagir rapidamente à ocorrência de eventos, especialmente eventos críticos. $\mathrm{Na}$ realidade, a visão mais correta destes sistemas é que, além de fornecer respostas logicamente corretas, estas respostas devem ser fornecidas dentro dos limites de tempo que garantam a integridade do sistema (Weber, 1997).

As tarefas dos sistemas em tempo real, não apresentam somente restrições de tempo, elas têm que respeitar também às restrições de precedência e de recursos.

Apesar dos diferenciais dos sistemas em tempo real em relação aos sistemas tradicionais, o projeto de software em tempo real, conforme Pressman (Pressman, 1995), envolve todos os aspectos do projeto de um software convencional, introduzindo, ao mesmo tempo, um conjunto novo de critérios e preocupações de um projeto, uma vez que o sistema em tempo real deve reagir a eventos do mundo real, em um tempo ditado por esses eventos, tornando todas as classes do seu projeto mais complexas.

A aplicabilidade dos sistemas em tempo real, tiveram por muito tempo, como principais consumidores, os militares. Hoje, porém, significativas diminuições nos custos de hardware tornaram possivel que a maioria das empresas se dêem ao luxo de possuir sistemas e produtos em tempo real para aplicações diversas.

Existem duas grandes forças impulsionando a próxima geração de sistemas em tempo real: o rápido desenvolvimento de hardware e a necessidade de técnicas inteligentes nas aplicações. Por estes motivos novas abordagens são necessárias para garantir o bom funcionamento e o alcance dos objetivos destes sistemas, ou seja, serem rápidos, confiáveis, adaptativos e apresentar um comportamento previsível. 


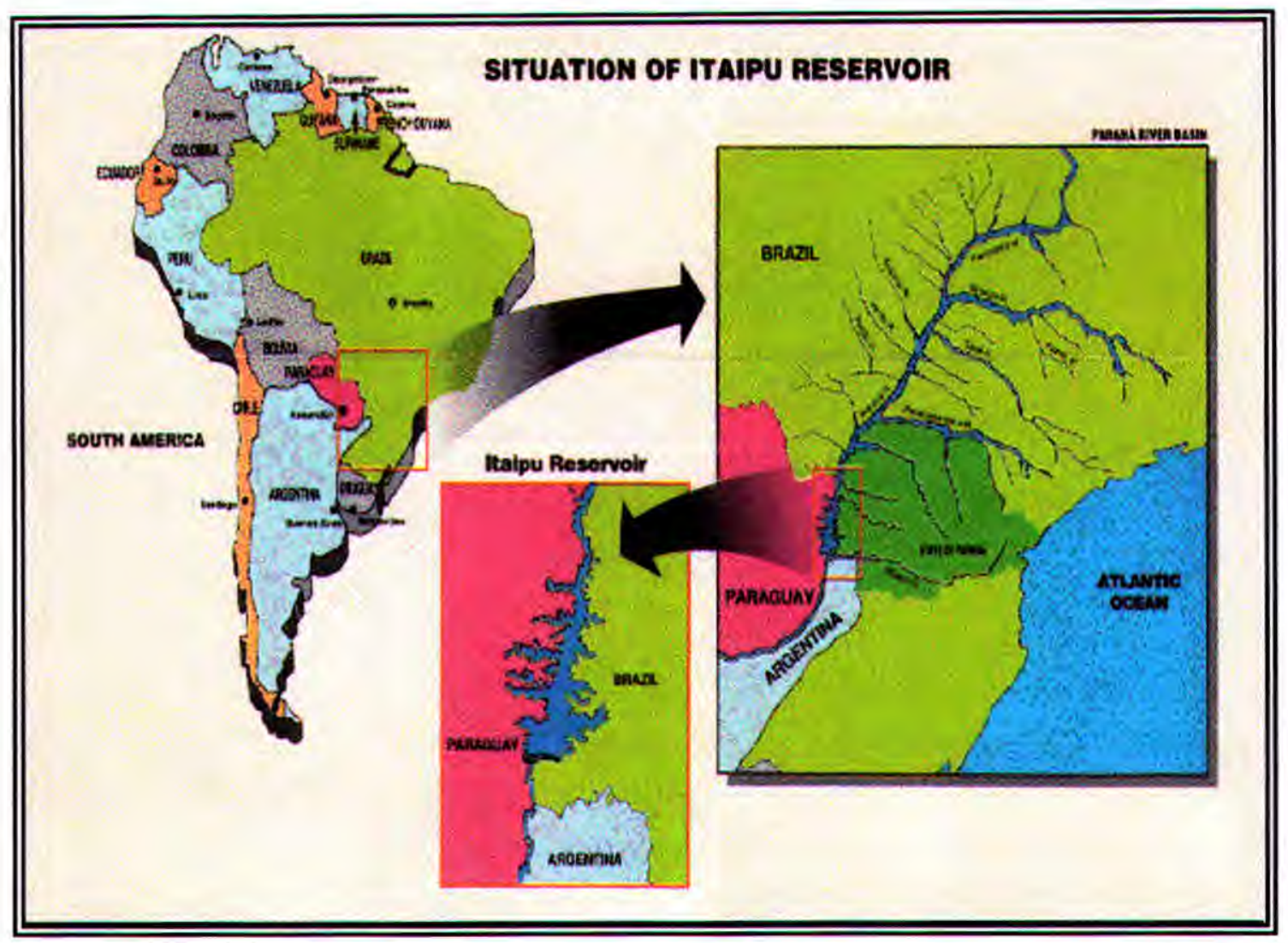

Figura 2.1: Localização Geográfica da Usina Hidrelétrica de ITAIPU Binacional

Nos dias atuais vê-se a crescente utilização de sistemas em tempo real, principalmente na automação industrial.

\subsection{A ITAIPU Binacional}

A Usina Hidrelétrica de ITAIPU é uma empresa binacional. Está localizada no rio Paraná, na fronteira entre Brasil e Paraguai. A Figura 2.1 mostra a localização geográfica da mesma.

A usina de ITAIPU é responsável pelo abastecimento de $78 \%$ da energia consumida no Paraguai e por $25 \%$ da energia consumida no Brasil. A energia gerada é transportada de duas formas: corrente alternada (tensão de $750 \mathrm{kV}$ ) e corrente contínua (tensão de 600 kV). Ambas partem da Subestação de Foz do Iguaçu, e conduzem a energia à região de São Paulo, onde é colocada no Sistema Sudeste, o qual abastece os centros consumidores de São Paulo, Minas Gerais e Rio de Janeiro. 
A energia destinada à Regiāo Sul é composta apenas de corrente alternada, a partir de Ivaiporã, onde uma Subestação da Eletrosul recebe, em $500 \mathrm{kV}$, a parcela destinada aos estados do Paraná, Santa Catarina e Rio Grande do Sul.

O Sistema de Transmissão em Corrente Contínua é composto pelos seguintes elementos: Subestação Conversora de Foz do Iguaçu, Subestação Conversora de Ibiúna, duas linhas de transmissão ligando estas duas subestações $(800 \mathrm{Km})$ e duas linhas de eletrodos em cada uma.

O Sistema de Transmissão em Corrente Alternada é constituído de: Subestação Elevadora de Foz do Iguaçu, Subestação Elevadora de Ivaiporã, Subestação Intermediária de Itaberá, Subestação Abaixadora de Tijuco Preto e três linhas de transmissão em circuito simples, interligando as quatro subestações.

A ITAIPU é composta basicamente dos seguintes equipamentos e instalações:

- Casa de Força e Unidades Geradoras: A Casa de Força possui 20 unidades geradoras, sendo que 18 estão instaladas, uma está em fase de instalação e a outra aguardando futuras instalações, cada uma com capacidade de $700 \mathrm{MW}$. As unidades numeradas de 1 a 9 e $9 \mathrm{~A}^{1}$ possuem freqüência de geração de $50 \mathrm{~Hz}$, enquanto que as numeradas de 10 a 18 e $18 \mathrm{~A}^{2}$ operam em freqüência de $60 \mathrm{~Hz}$. As unidades geradoras da ITAIPU estão interligadas com a Subestação Isolada a Gás (GIS), também localizada na Casa de Força.

- Subestação GIS: A alta tensão das unidades geradoras (500 kV), linhas de transmissão e transformadores está concentrada em uma subestação blindada, isolada a gás SF6 (Hexa Fluoreto de Enxofre). Este gás elimina a necessidade de longas distâncias para isolamento. A GIS é dividida em dois setores: setor de $60 \mathrm{~Hz}$, ligada à Subestação de Furnas, e setor de $50 \mathrm{~Hz}$, ligado à Subestação da Margem Direita, através de quatro linhas de $500 \mathrm{kV}$.

- Subestação da Margem Direita: Localizada na margem direita do Rio Paraná, a dois quilômetros da Casa de Força. A comunicação entre as duas é feita através de duas linhas de transmissão independentes. É responsável pela interligação entre o Sistema ANDE (Administración Nacional de Eletricidad - Paraguai) e Furnas (Brasil).

- Barragem Principal: Localizada acima da Casa de Força, tem como função, direcionar a água do reservatório para as turbinas.

\footnotetext{
${ }^{1} \mathrm{Em}$ fase de instalação

${ }^{2}$ Instalação futura
} 
- Vertedouro: O vertedouro está localizado na margem direita do Rio Paraná, e é responsável pela descarga da água que não é consumida pelas turbinas.

A operação da ITAIPU é realizada em dois níveis hierárquicos: despacho de carga e operação da usina.

O despacho de carga é responsável pela coordenação e supervisão da operação com as companhias ligadas às áreas de energia. São gerenciados todos os equipamentos ligados ao Sistema ITAIPU, com tensão maior ou igual a $18 \mathrm{kV}$. A área de operação da usina é responsável pela supervisão e execução de chaveamento e ações de controle em todos os equipamentos da ITAIPU. Ou seja, a execução de ações de controle e chaveamento normais (sobre equipamentos com tensão acima de $18 \mathrm{kV}$ ) é realizada apenas por requisição do despacho, enquanto que os chaveamentos e ações de controles emergenciais (ou em equipamentos que funcionam abaixo de $18 \mathrm{kV}$ ) são realizados pela área de operação da usina.

\subsection{Sistemas em Operação na Usina}

Nas próximas seções serão apresentados dois dos sistemas, em tempo real, que estão em operação na Usina de ITAIPU: Sistema de Supervisão da Operação (SSO) e Real Time Expert System Environment (R-TESE).

O SSO é responsável pela execução de funções de acompanhamento e monitoração, em tempo real, de grandezas analógicas e digitais. Já o R-TESE é uma shell voltada para o setor de geração e transmissão de energia, que permite o desenvolvimento modular de Bases de Conhecimento.

\subsubsection{SSO}

O principal objetivo do SSO é prover a ITAIPU com um sistema de supervisão moderno que incorpore algumas das características básicas do SCADA ${ }^{3}$ (Supervisory Control And Data Acquisition).

\footnotetext{
${ }^{3}$ O SCADA será um sistema de supervisão e controle capaz de automatizar a aquisição de, aproximadamente, 17500 pontos da Hidrelétrica de ITAIPU Binacional. Monitorará o estado das chaves, disjuntores, compressores, bombas, válvulas, e supervisionará variáveis analógicas (tensão, potência, freqüência, nível de abertura do vertedouro, entre outros), sendo capaz de efetuar até 2000 controles. Este sistema somente será disponibilizado a médio/longo prazo.
} 


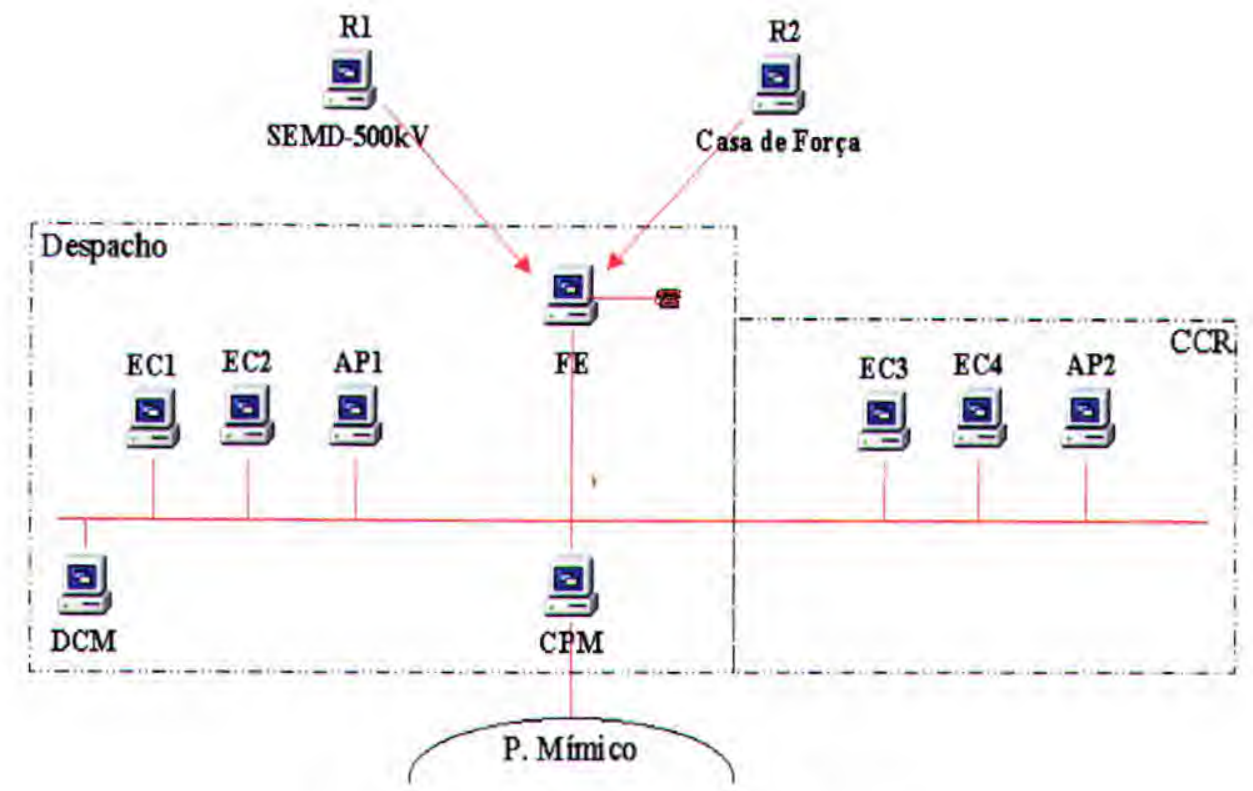

Figura 2.2: Componentes do SSO

Após indefiniçōes nos contratos que previam o fornecimento do SCADA, viu-se a necessidade de suprir o despacho e a operação da usina com uma ferramenta que proporcionasse o acompanhamento das principais grandezas de seu sistema elétrico. Assim, deu-se início a um projeto próprio, que incorporasse tais funcionalidades, o SSO.

Sua primeira versão foi operacionalizada em maio de 1991, e a partir de então ele não parou de evoluir.

Atualmente o SSO é composto por uma série de subsistemas, sendo eles: Unidades terminais remotas; Front-End; Estação Central e Subsistemas Externos. Os componentes desta estrutura podem ser vistos na Figura 2.2.

A seguir cada um dos componeutes do SSO são descritos mais detalhadamente.

\section{Unidades Terminais Remotas}

As Unidades Terminais Remotas R1 e R2 estão situadas, respectivamente, na Subestaçâo da Margem Direita e na Casa de Força, e têm por objetivo o interfaceamento do Sistema de Supervisão com as grandezas analógicas e digitais.

As unidades remotas são responsáveis pela aquisição dos dados disponibilizados pelos transdutores, sendo constituídas por placas montadas em plataforma de PC. Estas 
placas realizam a aquisição e a conversão dos sinais analógicos em digitais, para serem armazenadas no PC, que os envia ao processador de comunicação denominado Front-End.

\section{Front-End}

O Front-End é responsável pelo gerenciamento e sincronização do recebimento e da transmissão dos pacotes com as informações vindas das Unidades Terminais Remotas (UTRs), incluindo a administração tanto do protocolo de comunicação, essencial ao SSO, como da comunicação via linhas telefônicas, para o recebimento dos dados das UTRs.

\section{Estação Central}

A Estação Central (ECn), que contém o Software de Supervisão, está conectada ao FrontEnd, e recebe todas as informações relativas às grandezas a serem supervisionadas na usina, apresentando-as aos despachantes e operadores, de forma a instruí-los sobre o estado dos disjuntores, seccionadoras, geradores, filtros, pólos e as grandezas analógicas do sistema, cujos valores são exteriorizados em diagramas unifilares.

A Tabela 2.1 mostra a quantidade de informações, atualmente, supervisionadas em tempo real.

\begin{tabular}{|l|c|c|c|c|}
\hline \hline Características do Ponto & Procedência & Analógicos & Digitais & Total \\
\hline \hline \multirow{2}{*}{ Analógicos e Digitais } & Margem Direita & 32 & 216 & 248 \\
\cline { 2 - 5 } & Casa de Força & 64 & 72 & 136 \\
\hline Calculados & & 50 & 2 & 52 \\
\hline Manuais & - & 95 & 490 & 585 \\
\hline Total & - & 241 & 780 & 1021 \\
\hline \hline
\end{tabular}

Tabela 2.1: Pontos Monitorados

Além dessas informações serem mostradas aos operadores, elas também são disponibilizadas em pacotes (Tabela 2.2) e estes enviados a outros sistemas que deles necessitam para outras funcionalidades.

\begin{tabular}{|l|l|l|}
\hline Cabeçalho & Vetor de Pontos Analógicos & Vetor de Pontos Digitais \\
\hline
\end{tabular}

Tabela 2.2: Formato do Pacote

A estrutura apresentada na Tabela 2.2 é descrita abaixo:

- Cabeçalho: os primeiros dados do pacote constituem o cabeçalho do mesmo, e possuem o formato mostrado abaixo: 


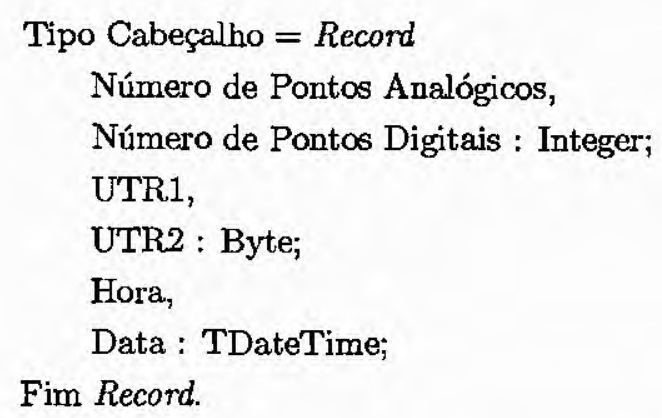

O cabeçalho contém o número de pontos analógicos e digitais supervisionados na Usina, o status (operante ou não) das Unidades Terminais Remotas da Casa de Força e da Margem Direita (UTR1 e UTR2), a hora e a data em que o pacote foi criado.

- Vetor de Pontos Analógicos: está situado logo após o cabeçalho. Seu tamanho é determinado pelo campo Número de Pontos Analógicos presente no cabeçalho. Cada elemento do vetor possui a seguinte estrutura:

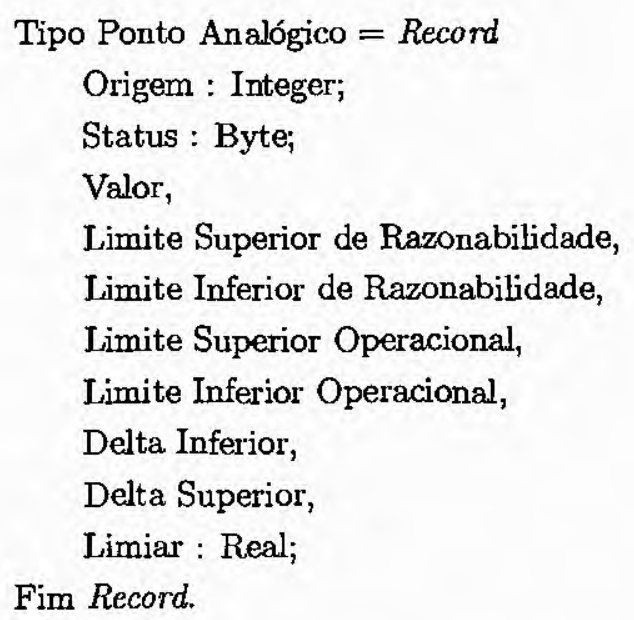

onde os pontos analógicos têm limites de razonabilidade, isto é, limites que abrangem uma faixa maior de valores se comparados aos limites operacionais, e são utilizados para verificação da validade do ponto analógico.

- Vetor de Pontos Digitais: este está localizado após o Vetor de Pontos Analógicos e seu tamanho é determinado pelo campo Número de Pontos Digitais do cabeçalho. Cada elemento do vetor possui a estrutura mostrada a seguir:

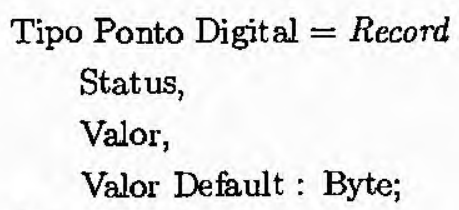

Fim Record. 
O status destes dois tipos de pontos é definido em um byte, estruturado conforme a Tabela 2.3 .

\begin{tabular}{|c|c|}
\hline Status & \\
\hline Bit O & Modo de Aquisiçāo \\
\hline 0 & Manual \\
\hline 1 & Automático \\
\hline$\overline{\text { Bit } 1}$ & Acesso aos Dados do FE \\
\hline$\overline{0}$ & Inibido \\
\hline 1 & Ativo \\
\hline Bit $\overline{2}$ & Estado do Ponto \\
\hline 0 & Normal \\
\hline 1 & Alarmado \\
\hline
\end{tabular}

\begin{tabular}{|c|c|}
\hline Status & \\
\hline \hline Bit 3 & Validade do Ponto \\
\hline 0 & $\begin{array}{c}\text { Inválido } \\
\text { Válido }\end{array}$ \\
\hline \hline Bit 4 & $\begin{array}{c}\text { Reconhecimento } \\
\text { do Ponto }\end{array}$ \\
& Não Reconhecido \\
0 & Reconhecido \\
\hline 1 & Alarmado \\
\hline \hline Bit 5-6-7 & Sempre 0 \\
\hline \hline
\end{tabular}

Tabela 2.3: Status dos Pontos do SSO

Pacotes de dados, gerados com este formato, sāo disponibilizados pelo SSO. Estes pacotes podem ser acessados por outros softwares que fazem uso de seus dados, a fim de processar aplicativos que auxiliam nas atividades do despacho e da operação.

\section{Subsistemas Externos}

O módulo DCM (Dispositivo de Comunicação Microprocessado) é responsável pelo gerenciamento da comunicação com o Centro Nacional de Operação do Sistema (CNOS), onde se realiza a supervisão ao nível de Sistema Eletrobrás (SINSC). A cada vinte segundos, os dados da Usina são enviados para Brasília, e os dados do sistema elétrico brasileiro são enviados para a ITAIPU.

Além do DCM, existem outros aplicativos (APn) que necessitam dos dados vindos do SSO, dentre estes pode-se citar os sistemas especialistas de 50 e $60 \mathrm{~Hz}$, que auxiliam nas atividades do despacho e da operação.

\subsubsection{R-TESE}

O R-TESE (Capanema, 1999) é uma shell voltada ao setor de geração e transmissão de energia, a qual permite que, a partir dela, sejam construídos sistemas especialistas.

Para sua validação foi construído o Sistema Especialista de $60 \mathrm{~Hz}$, que consistiu em formalizar as informações contidas nas IOIs, através de um conjunto de regras de produção que resultaram na formação da Base de Conhecimento apresentada no Apêndice A.

O R-TESE foi criado de modo a permitir, ao próprio projetista do conhecimento, 


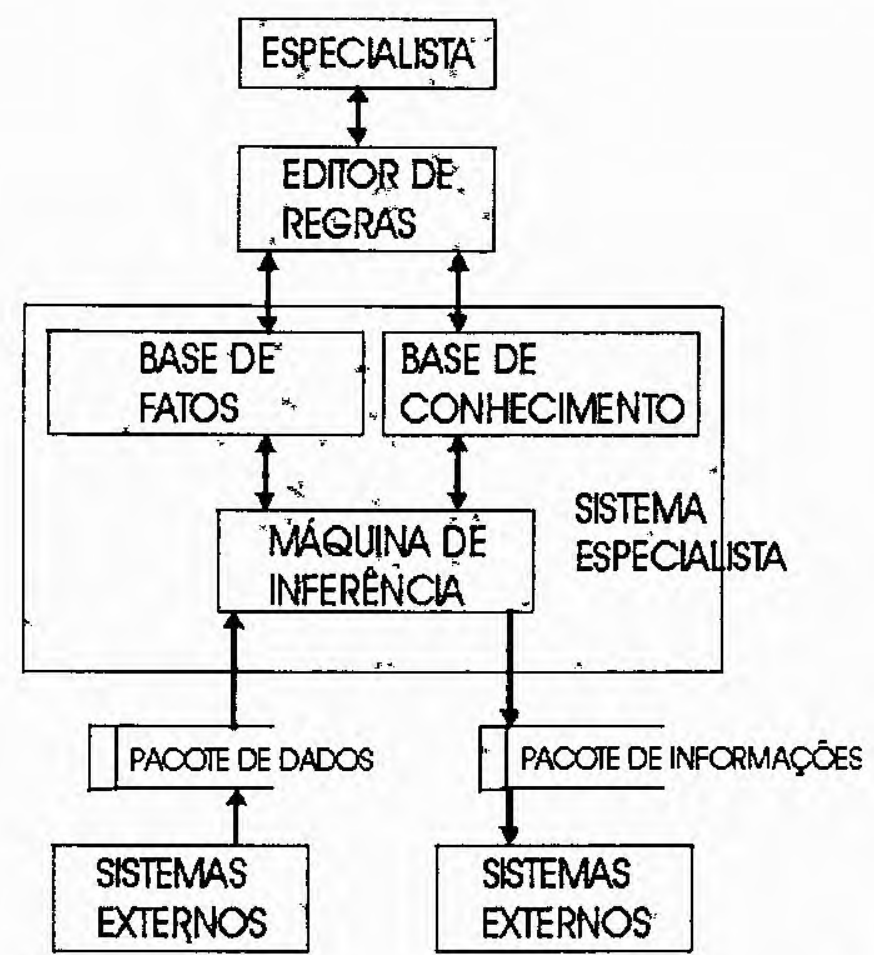

Figura 2.3: Estrutura Típica do Ambiente Especialista R-TESE

a implementação das bases desejadas. Sua estrutura é apresentada na Figura 2.3, sendo um ambiente típico para o desenvolvimento de Sistemas Especialistas.

Como em sistemas especialistas típicos, aqueles implementados utilizando o RTESE constituem-se de uma Base de Fatos, uma Base de Conhecimento e um Mecanismo de Inferência, onde:

- Base de Conhecimento e Base de Fatos: armazenam as informações (regras e fatos) que um especialista utiliza, representadas computacionalmente;

- Máquina de Inferência: parte do Sistemas Especialista responsável pelas deduções sobre a Base de Conhecimento;

- Editor de Regras: meio pelo qual a shell permite a implementação das bases desejadas.

Sistemas Externos enviam pacotes de dados ao ambiente, atualizando sua Base de Fatos. Com o auxílio de um perito, responsável pela apresentação de lógicas consistentes que caracterizam o projeto em questão, forma-se uma Base de Conhecimento consistente. 


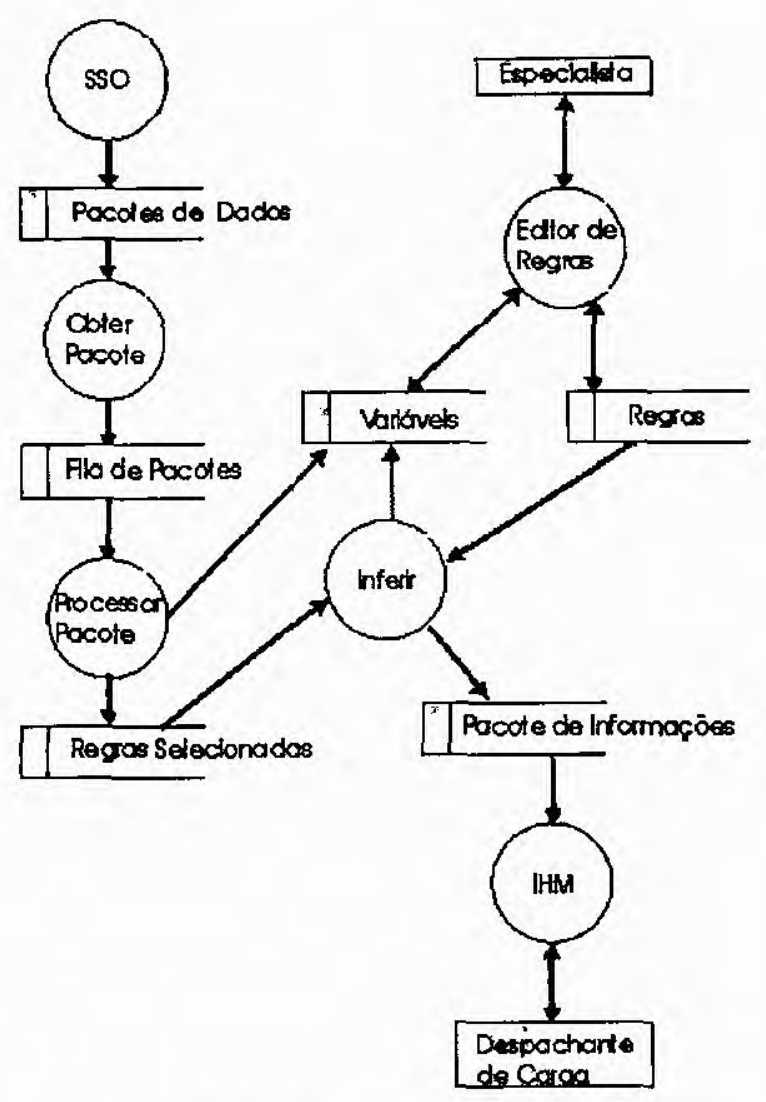

Figura 2.4: Arquitetura do R-TESE

O Mecanismo de Inferência, por sua vez, utiliza as informações contidas nas Bases de Fatos e Conhecimento para gerar informações pertinentes ao problema a ser solucionado. Por fim, pacotes contendo estas informações são enviados a Sistemas Externos, que os usam para fins específicos.

A arquitetura do R-TESE pode ser vista na Figura 2.4, cuja descrição sintetiza seu funcionamento.

Detalhando-se a Figura 2.4, o R-TESE executa os seguintes procedimentos:

1. Processamento dos pacotes de dados vindos do SSO, atualizando a Base de Fatos do sistema

O SSO envia, a cada três segundos, um pacote de dados ao R-TESE, contendo informações sobre os pontos analógicos e digitais supervisionados pela ITAIPU.

O R-TESE, através de um mecanismo de thread, armazena este pacote em um banco 
de dados de memória (método Obter Pacote). Cada novo pacote disponibilizado ao sistema é inserido em uma fila de pacotes.

Outra thread, paralela a esta, acessa cada pacote recebido, retirando-o da fila, e disponibilizando seus dados ao sistema. O dados de cada pacote são processados (método Processar Pacote), atualizando a Base de Fatos do sistema, que contém o valor e o estado de todas as variáveis envolvidas na supervisão da operação.

Esta configuração produtor-consumidor garante que não haja perda de pacotes, fazendo com que todos os dados enviados ao SSO sejam acessados pelo ambiente inteligente. A definição deste modo de funcionamento foi necessária, pois considerando-se alguma interferência de processos externos, ou uma inferência acima do limite de tempo definido (causada por um problema eventual), poderiam ocorrer perdas de pacotes, comprometendo a análise do estado do sistema interligado.

\section{Verificação das regras aptas ao disparo}

As regras aptas ao disparo são aquelas cujas variáveis, relacionadas às suas premissas, sofreram alguma alteração em seu estado ou valor, quando analisadas as informações provenientes do SSO. Estas regras são armazenadas em uma coleção na memória (Regras Selecionadas), obedecendo à ordem crescente de prioridade de cada regra.

\section{Processamento das regras selecionadas}

São disparadas todas as regras habilitadas. Avalia-se o estado das premissas e executa-se a ação correspondente.

A interpretação das regras também pode ocasionar a mudança do estado ou valor de outras variáveis que compõem o processo, ativando novas regras e criando, assim, o encadeamento necessário.

Estas etapas caracterizam um ciclo de execução. O processo de inferência encerrase quando não houverem mais regras aptas ao disparo. Neste momento, a memória de trabalho conterá as informações desejadas, resultantes desta inferência. Estas são estruturadas em pacotes, e enviadas a uma Interface Homem-Máquina, na forma de instruções operacionais, disponibilizando ao despachante de carga o acesso às mesmas. 


\subsection{Resumo}

Este Capítulo mostrou alguns dos elementos impulsionadores deste projeto, enfocando alguns conceitos de sistemas em tempo real e descrevendo dois sistemas em tempo real em uso pela Usina Hidrelétrica de ITAIPU Binacional, além de contextualizar a mesma.

O Capítulo seguinte tratará de sistemas híbridos, que são derivados de abordagens diferentes com o intuito de solucionar um mesmo problema de forma mais rápida e efetiva. 


\section{Capítulo 3}

\section{Sistemas Híbridos}

Neste capítulo será abordado um dos temas de pesquisa mais recentes na área de Inteligência Artificial, que é o desenvolvimento de Sistemas Hibridos (Goonatilake and Khebbal, 1995; Braga et al., 1999; Fullér, 1995; Kasabov, 1996). Após caracterizar o que vem a ser sistemas híbridos, as técnicas de Redes Neurais Artificias, Sistemas de Produção Conexionistas, Sistemas Fuzzy e Redes Neurais Fuzzy serão brevemente apresentadas.

Observando o ser humano pode-se dizer que, suas ações são comandadas por uma combinação de informações genéticas que foram adquiridas através do treinamento. As informações em seus genes são resultantes de métodos que têm sido treinados e testados através de milhões de anos de evolução. $O$ aprendizado humano consiste de uma variedade de processos que usam informações adquiridas através de interações com o ambiente. É a combinação destes diferentes tipos de métodos de processamento de informações que têm possibilitado aos humanos sucesso em sua interação com o ambiente.

De acordo com Goonatilake e Khebbal (Goonatilake and Khebbal, 1995), este tipo de processamento de informações híbridas está agora sendo aplicado em uma nova geração de máquinas. O coração destas máquinas são sistemas computacionais inteligentes, alguns dos quais são inspirados nos mecanismos da natureza. Redes neurais, por exemplo, são inspiradas no funcionamento das células nervosas da memória. Igualmente aos humanos, as redes neurais podem aprender a reconhecer padrões através da exposição repetitiva a muitos exemplos diferentes. Elas são boas no reconhecimento de padrões complexos, tais como caracteres escritos a mão, empréstimos bancários, decisões financeiras, etc...

Todas as técnicas inteligentes têm uma propriedade computacional particular à técnica (por exemplo, habilidade para apreender, explicar decisões) que as tornam aceitáveis para alguns tipos de problemas e não para outros. Por exemplo, enquanto as redes neurais 
são boas no reconhecimento de padrões, elas não são boas em explicar como tomam suas decisões. Sistemas de lógica fuzzy, que podem raciocinar com informações imprecisas, são bons em explicar suas decisões, mas eles não podem adquirir automaticamente as regras usadas na tomada de decisões. Estas limitações são a força motriz que leva à criação de sistemas híbridos inteligentes, onde duas ou mais técnicas são combinadas de maneira a superar as limitações das técnicas individuais. Sistemas híbridos também são importantes quando se considera uma natureza variada de domínios de aplicações. Domínios muito complexos têm muitos componentes diferentes de problemas, cada um dos quais pode requerer diferentes tipos de processamento (Goonatilake and Khebbal, 1995; Fullér, 1995; Braga et al., 1999).

Os princípios básicos de redes neurais artificias, sistemas fuzzy e redes neurais fuzzy serão abordados nas próximas seções.

\subsection{Redes Neurais Artificiais}

Redes neurais artificiais são modelos computacionais construídos a partir do estudo de sistemas neurobiológicos encontrados nos animais e nos seres humanos. O mais notável e estudado destes sistemas é o próprio cérebro humano, composto por conexões entre suas células básicas, os neurônios. Estes elementos possuem um grande número de vias de entrada (os dentritos), um corpo celular (soma), e uma única via de saída (o axônio), que pode estar conectada a inúmeras outras entradas de diferentes neurônios (Fabro, 1998a).

Um modelo da estrutura e do funcionamento de um neurônio foi primeiramente apresentado por McCulloch e Pitts em 1943 (McCulloch and Pitts, 1943), e deu origem às pesquisas sobre redes neurais artificiais.

As Figuras 3.1 e 3.2 mostram um modelo de neurônio artificial, em comparação a um neurônio real. Neste modelo simplificado, proposto por McCulloch e Pitts, vêem-se $p$ sinais de entrada $X_{1}, X_{2}, \ldots, X_{p}, w_{1}, w_{2}, \ldots, w_{p}$ pesos e uma função de transferência ou ativação $t$, assumindo valores lógicos ( 0 ou 1 ). Neste modelo, o nível de atividade $a$ é dado por:

$$
a=w_{1} X_{1}+w_{2} X_{2}+\ldots+w_{p} X_{p}
$$

O nível de atividade $a$ obtido é processado por uma função $f$ de ativação do tipo Degrau (Figura 3.3), que define o valor de saída do neurônio. 


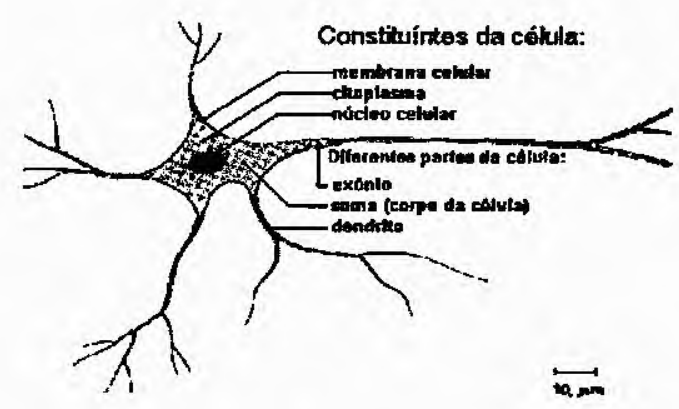

Figura 3.1: Neurônio natural

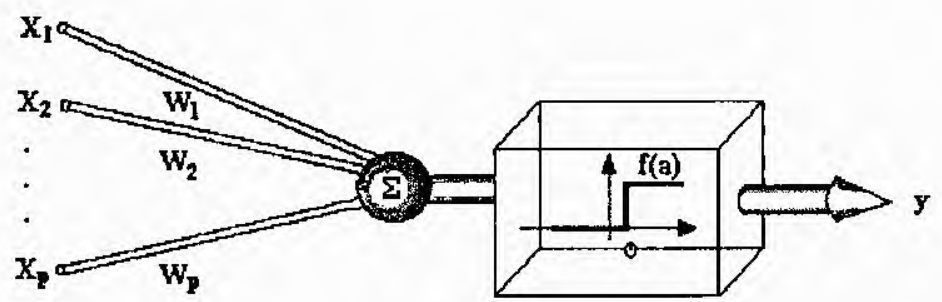

Figura 3.2: Modelo Simplificado (neurônio artificial)

Existem muitas funções de ativação, a escolha das funções a serem usadas depende muito das características do problema. A função de ativação de um neurônio é geralmente uma função não linear. Elas podem induzir tanto uma saída binária, por exemplo, $y \in$ $\{0,1\}$, como na Figura 3.3 , quanto valores contínuos em um intervalo, por exemplo $y \in$ $[0,1]$, como na Figura 3.4.

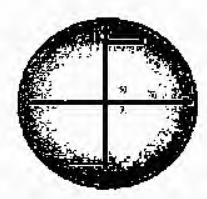

Figura 3.3: Função de ativação Degrau

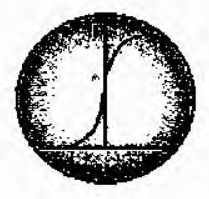

Figura 3.4: Função de ativação Sigmoid

\subsubsection{Aprendizado}

Uma das principais características das redes neurais artificiais é sua capacidade de aprender. O conhecimento de uma rede neural está armazenado nos pesos das conexões entre os neurônios. O conhecimento da rede é automaticamente atualizado, quando os pesos 
são modificados. O processo de modificação dos pesos é denominado treinamento.

O aprendizado ocorre quando a rede neural atinge uma solução generalizada para uma classe de problemas (Carvalho, 1999). Ou seja, ao se aplicar um vetor $x$ em sua entrada, esta retorne o vetor $y$ desejado.

Dependendo da forma como a rede neural se relaciona com o ambiente, tem-se os seguintes paradigmas de aprendizado (Braga et al., 1999):

- Aprendizado Supervisionado, onde as entradas e saídas desejadas para a rede são fornecidas por um supervisor (professor) externo. O objetivo é ajustar os parâmetros da rede, de forma a encontrar uma função, que dada a entrada da rede, esta retorna a saída desejada;

- Aprendizado Não Supervisionado (auto-organização), quando não existe uma agente externo indicando a resposta desejada para os padrões de entrada, a única informação fornecida está no conjunto de padrões de entrada. Desta forma, estas redes definem seus parâmetros por si próprias, sem auxílio externo. A estrutura do sistema de aprendizado não-supervisionado pode tomar diversas formas. Ela pode, por exemplo, consistir de uma camada de entrada, uma camada de saída, conexões da camada de entrada para a de saída e conexões laterais entre os neurônios da camada de saída;

- Reforço, quando um crítico externo avalia a resposta fornecida pela rede. Se a resposta fornecida estiver correta então os pesos associados à entrada serão reforçados, caso contrário, penalizados.

Os exemplos mais conhecidos de algoritmos para aprendizado supervisionado são a regra delta (Widrow and Hoff, 1960) e a sua generalização para redes multicamadas, o algoritmo backpropagation (Rumelhart et al., 1986).

\subsubsection{Redes Neurais Multicamadas}

Uma rede neural multicamadas ou $\mathrm{MLP}^{1}$, tem seus neurônios divididos em subgrupos. Cada subgrupo compõe uma das camadas da rede neural. Há redes neurais de uma, duas, três ou mais camadas, depende muito da aplicação a que se destina.

As redes de uma só camada resolvem apenas problemas que são linearmente separáveis, mas as soluções para a maioria dos problemas não são linearmente separáveis.

\footnotetext{
${ }^{1}$ Do inglês multilayer perceptron
} 


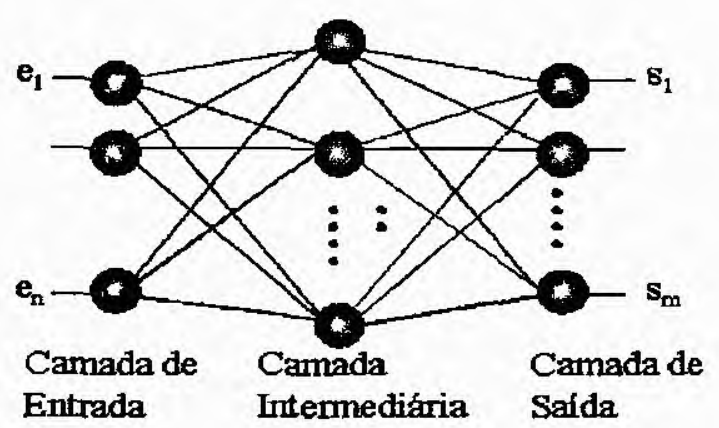

Figura 3.5: Estrutura de uma rede neural do tipo multicamadas

Teoricamente, redes neurais com duas camadas intermediárias podem implementar qualquer função, seja ela linearmente separável ou não (Cybenko, 1989). A Figura 3.5 apresenta uma rede MLP típica, com uma camada intermediária.

Usualmente, as camadas são classificadas em três grupos (Carvalho, 1999):

- Camada de Entrada: onde os padrões são apresentados à rede;

- Camadas Intermediárias ou Escondidas: onde é feita a maior parte do processamento, através das conexões ponderadas; podem ser consideradas como extratoras de características. Elas geram uma combinação interna dos padrões de entrada, que é então utilizada para a definição da saída da rede;

- Camada de Saŕda: onde o resultado final é concluído e apresentado.

As redes neurais multicamadas formam uma das estruturas artificiais mais utilizadas. Estas redes podem ser treinadas para reconhecer padrões ou aproximar funções.

Utilizando treinamento supervisionado, basta apresentar o padrão a ser reconhecido nas entradas da rede e alterar os pesos proporcionalmente ao erro encontrado entre as saídas desejadas e as apresentadas. Por meio desta alteração nos pesos, a rede pode aprender o mapeamento correto, e efetuar o reconhecimento (Fabro, 1998a).

\subsection{Sistemas Especialistas Conexionistas}

Esta seção tem por objetivo apresentar uma nova abordagem para o uso de Redes Neurais: inserção de regras numa arquitetura conexionista. 
Existem sistemas especialistas que têm sua base de conhecimento representada numa estrutura conexionista (Kasabov, 1996). As propriedades das redes neurais de aprendizado e generalização, adaptação, armazenarnento associativo da informação, processamento paralelo e distribuído, entre outras, fazem delas instrumentos de grande porte para a construção de sistemas especialistas baseados em conhecimento.

Qualquer que seja o sistema especialista em pauta, ele sempre terá um módulo de conhecimento. Em sisternas especialistas conexionistas este módulo é conhecido como Módulo Baseado em Conhecimento Conexionista. Quatro abordagens são possíveis para a geração deste módulo:

1. Dados Passados: dados históricos são usados para treinar a rede. Depois do treinamento a rede conterá o conhecimento do sistema;

2. Conhecimento existente (1): por exemplo, regras. Uma forma de se fazer isso é gerar um conjunto de treinamento através das regras e treinar uma rede corn este conjunto;

3. Conhecimento existente (2): por exemplo, regras. Neste caso as regras são usadas para prever uma topologia para uma rede neural e para calcular os pesos das conexões, antes de seu respectivo treinamento;

4. Todos os métodos acima são usados para construir o sistema: onde uma estrutura de rede neural é gerada de acordo como um conjunto de regras existentes e então treinada com dados (com dados passados ou com dados atuais obtidos enquanto o sistema está rodando, isto é, on-line).

Um conjunto inicial de regras pode ser usado para prever uma topologia para a rede neural antes do treinamento com dados reais. Uma forma de ser fazer essa tarefa é montar uma arquitetura de rede neural e inicializar os pesos das conexões antes do treinamento. É o que será apresentado nas próximas seções.

\section{Sistemas de Produção Conexionistas}

Construir uma base de regras conexionista é possível não somente através do treinamento de uma rede neural com um conjunto de exemplos, mas também pela inserção de regras existentes numa estrutura de rede neural. Usar uma representação conexionista do problema possui todas as vantagens dos sistemas conexionistas. 
Modelos padrões de redes neurais têm sido desenvolvidos para resolver problemas baseados no aprendizado através de exemplos. Eles são inspirados na fisiologia da memória humana e no que é conhecido de sua estrutura e organização.

De outra forma, existem muitos métodos para representar o conhecimento que são psicologicamente plausíveis. O gap entre o processo fisiológico na memória e o processo cognitivo ainda não é totalmente entendido. Mas do ponto de vista da engenharia, é possível projetar neurônios artificiais e redes neurais que são dedicados à representação e processamento de estruturas de conhecimento existentes.

Uma rede neural construída para representar conhecimento estruturado pode ter conexões com valores fixos, ou seja, a rede não pode aprender e improvisar seu conhecimento; ou adaptáveis, onde a rede pode aprender e atualizar a estrutura de conhecimento que foi previamente inserida nela, podendo ajustar-se durante o treinamento.

Uma grande vantagem no uso de redes neurais para a implementação de sistemas baseados em regras é a capacidade de generalização. Mas isso somente é possível quando os neurônios usados na rede possuem conexões que são adaptáveis, ou seja, podem se ajustar de acordo com o problema. Se, por exemplo, elas forem fixas, somente um determinado conjunto de exemplos pode ser classificado.

As próximas seçōes demonstram como é feita a inserção de regras numa arquitetura conexionista. Primeiramente é apresentado um modelo para inserção de regras simples numa rede neural, seguido de um modelo genérico, o qual permite a inserção de regras com mais termos em suas partes antecedentes.

\section{Representação de Regras numa Rede Neural}

Uma regra é considerada simples quando é formada por conectivos iguais, como a regra proposicional abaixo:

$$
\text { IF } x_{1} \text { and } x_{1} \text { and } \ldots \text { and } x_{n} \text { THEN } y \text {, }
$$

onde $x_{i}(i=1,2, \ldots, n)$ e $y$ são proposições lógicas.

Esta regra pode ser representada por neurônios de entrada binária - saída binária, com uma função de entrada que somente realiza a soma das entradas e uma função de ativação thresholding $(\theta)$. Os exemplos (a) e (c), Figura 3.6, mostram duas das possíveis representações do neurônio AND. Nestas, C1 e C2 representam proposições lógicas, portanto, podem somente assumir valores falsos (0) ou verdadeiros (1). 


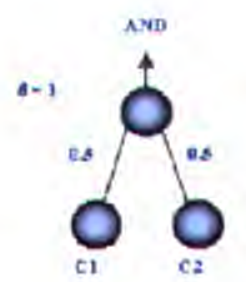

(a)

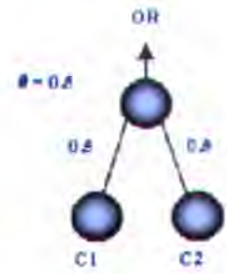

(⿻)

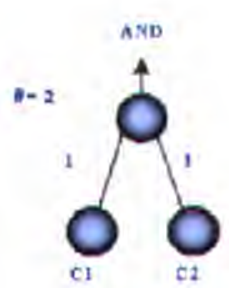

(e)

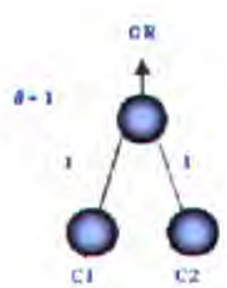

(d)

Figura 3.6: Exemplos de Neurônios Binários (AND e OR)

Ao trabalhar-se com conectivos AND todos os valores de entrada precisam ser verdadeiros para que o resultado assim o seja, $\log \theta=1$ no exemplo (a) e $\theta=2$ no exemplo (c), onde o threshold é resultado da soma dos pesos de todas as entradas do neurônio atual, se verdadeiras.

Da mesma forma, a regra proposicional:

$$
\text { IF } x_{1} \text { or } x_{1} \text { or } \ldots \text { or } x_{n} \text { THEN } y
$$

poderia ser processada num neurônio binário similar, mas com diferentes pesos nas conexões ou diferentes thresholds. Os exemplos (b) e (d), Figura 3.6, ilustram possíveis representações para o neurônio OR.

No neurônio OR, somente uma das conexões precisa ser verdadeira para que a saída do neurônio seja ativada, se os pesos das conexões possuem valores distintos então o threshold conterá o valor do menor peso.

Uma rede neural que representa um conjunto de proposições simples é mostrada na Figura 3.7.

Regras proposicionais construídas com mais termos nas suas partes antecedentes também podem ser representadas de forma similar. Um modelo genérico de um sistema conexionista que possui regras mais complexas é dado na Figura 3.8, onde:

- Camada 1: refere-se aos valores de entrada do sistema, ou seja, aos fatos de um sistema de produção comum;

- Camada 2: compōe os termos da regra;

- Camada 3: cada elemento desta camada é responsável pela união dos termos das 


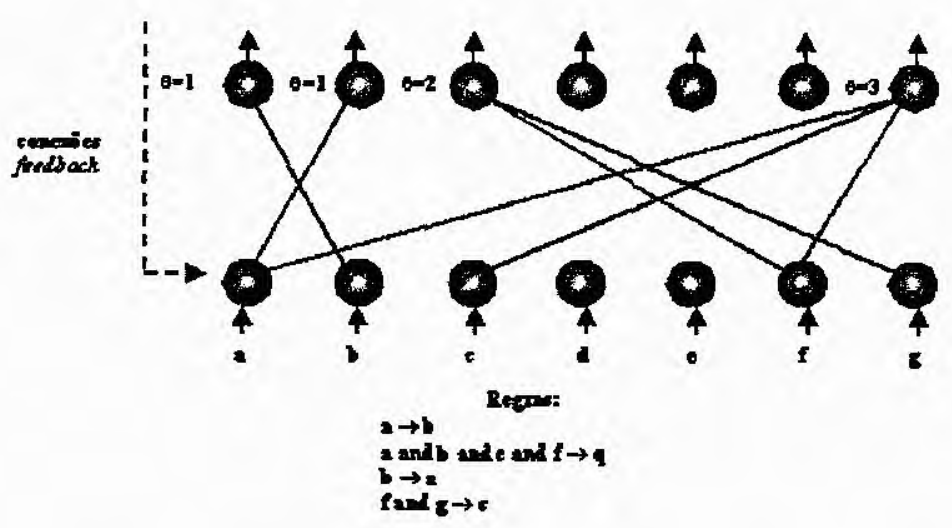

Figura 3.7: Rede Neural com Regras Simples
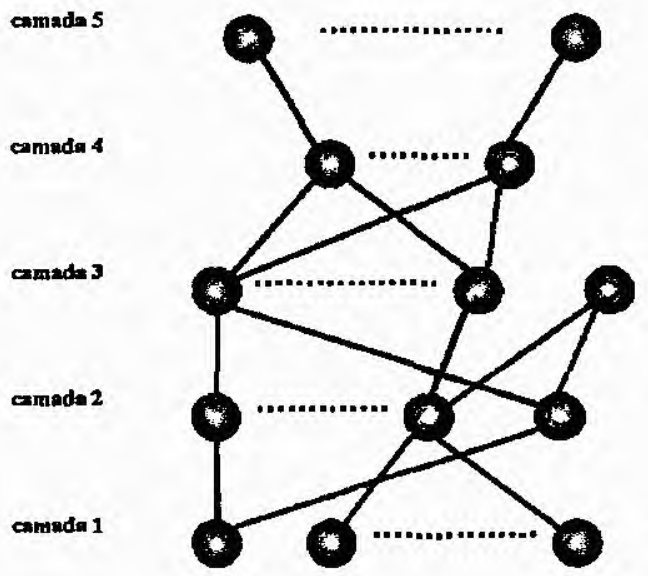

conclusties (novos fatos)

regrad

condiffies

termos

fatos de entrada

Figura 3.8: Modelo Genérico, regras mais complexas

regras, resultando nas condições. Ou seja, cada neurônio representa uma proposição da regra, por exemplo: SE $A>5$ ENTÄO..., onde $A>5$ representa uma proposição e terá um neurônio da camada de condição executando esta função;

- Camada 4: nesta camada os elementos condicionais da regra são unidos, de forma a resultar na respectiva regra;

- Camada 5: resposta do sistema. Os neurônios que foram ativados corresponderão ao diagnóstico do sistema.

Como é apresentado no próximo capítulo, este modelo genérico serve de base para a modelagem das regras listadas no Apêndice A, pois, através de uma análise feita sobre 
as regras, verificou-se que este modelo é o que mais se adequa às suas representações.

\subsection{Sistemas Fuzzy}

A lógica fuzzy consiste em uma forma de representar o conhecimento sem a rigidez da lógica tradicional de considerar que só existem proposições totalmente verdadeiras ou totalmente falsas. A lógica fuzzy permite que conjuntos sejam definidos para quantizar uma variável lingüística e que graus de pertinência sejam designados a cada elemento do conjunto, de forma a representar o "quão verdadeira" é a proposição de " $x$ " pertencer ao conjunto fuzzy.

Ressalta-se também, sua habilidade em tratar problemas do cotidiano através da utilização de variáveis lingüísticas que muito se aproximam do vocabulário humano.

A definição teórica de sistemas fuzzy foi formalizada e definida pelo professor Lotfi A. Zadeh da universidade da Califórnia em 1965 (Zadeh, 1965), a partir da observação de que o mundo não se comporta sob os conceitos lógicos Aristotelianos onde só existem valores totalmente verdadeiros ou totalmente falsos. A primeira implementação foi realizada por Mamdani e Assilian em 1974 (Yager, 1992; Brule, 1985).

O grau de pertinência de um elemento pertencente a um determinado conjunto é representado por um número real no intervalo $[0,1]$, que representa o "quão verdadeira" é a afirmação de que este elemento pertence a este conjunto. Um grau de pertinência de 1 equivale ao clássico símbolo de pertinência $\in$, e um grau de pertinência de 0 equivale ao clássico símbolo $\notin$. Entretanto, graus intermediários também podem ser tratados com idêntica facilidade (Fabro, 1998b).

O grau de pertinência é definido através de uma característica generalizada chamada função de pertinência:

$$
\mu_{A}(u): U \rightarrow[0,1]
$$

onde $U$ é chamado de universo, e $A$ é um subconjunto fuzzy de $U$.

Na Figura 3.9 é apresentada uma função de pertinência para o conjunto fuzzy "perto", em relação à medidas de distância genéricas. Nesta função, distâncias entre 0 e 20 unidades possuem valor de pertinência $\mu(x)=1.0$, significando que estas distâncias possuem total compatibilidade com o conceito "perto". Distâncias maiores de 20 e menores de 250 unidades apresentam valores de pertinência deçescentes, representando afi- 


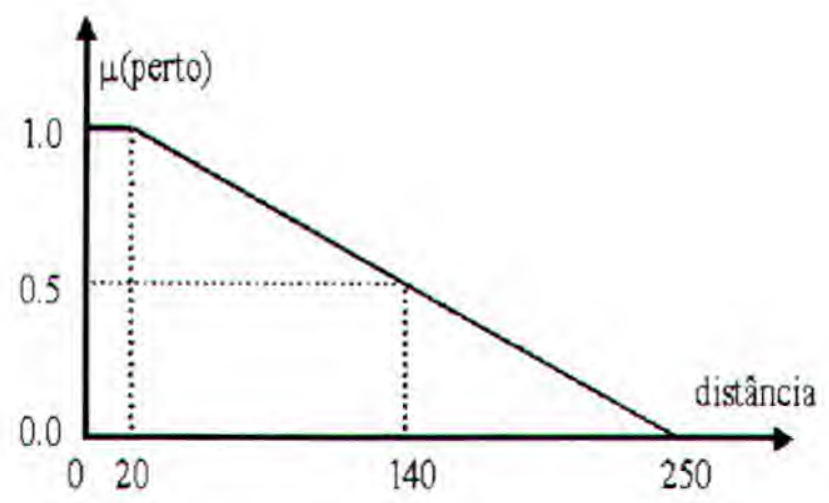

Figura 3.9: Função de pertinência para o conjunto "perto"

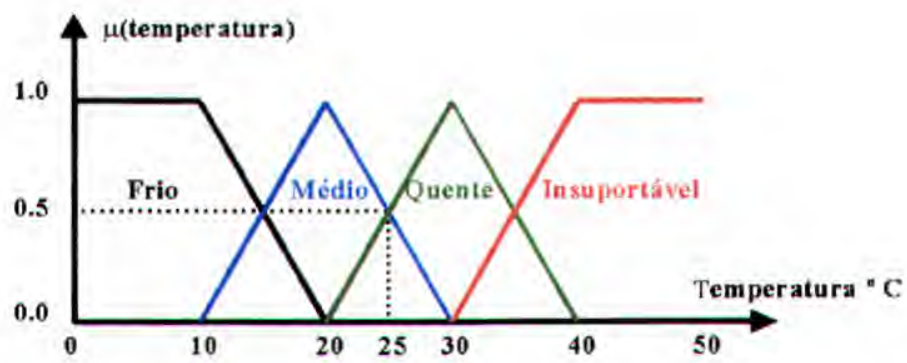

Figura 3.10: Conjuntos fuzzy representando "temperatura"

cada vez menores com o conceito "perto". Distâncias acima de 250 unidades possuem grau de pertinência $\mu(x)=0.0$, ou seja, uão são consideradas como tendo qualquer compatibilidade com o conceito representado. Os conceitos da teoria dos conjuntos fuzzy aproximam-se muito dos utilizados na linguagem e no raciocínio humano.

\section{Conjuntos Fuzzy e Variáveis Lingüísticas}

Os conjuntos fuzzy representam uma informação imprecisa de maneira direta, através dos graus de pertinência $\mu(x)$ de cada elemento $x$ de um conjunto fuzzy (Fabro, 1998b). Um exemplo clássico que pode facilmente ser demonstrado é a análise da temperatura, em que o ser humano não precisa de muita precisão para tirar conclusões se está "Frio", "Médio", "Quente" ou "Insuportável". Isso poderia ser transformado em conjuntos fuzzy como ilustra a Figura 3.10.

Esta representação não só utiliza a linguagem humana, mas também a forma como que se raciocina. Assim, sempre que a temperatura estiver abaixo de $10^{\circ} \mathrm{C}$ ter-se-á 
$\mu(x)=1.0$ para temperatura "Frio". Da mesma forma, sempre que a temperatura estiver acima de $40^{\circ} \mathrm{C}$ produzir-se-á o valor a $\mu(x)=1.0$ para temperatura "Insuportável". Nos demais casos, nota-se que há faixas de limites fornecendo uma conclusão mais precisa a partir de dados imprecisos. Isso se evidencia na Figura 3.10, quando temos uma temperatura de $25^{\circ} \mathrm{C}$, onde, ao contrário da lógica clássica.que daria uma resposta "Médio" ou "Quente", a resposta Fuzzy é 0.5/"Médio" + 0.5/"Quente", ou seja, a temperatura não é totalmente quente nem totalmente média, mas uma temperatura intermediária a ambas. Cabe observar que a distribuição dos conjuntos sobre o universo de discurso pode ser arbitrária, que as funções podem tomar quaisquer formato (trapezoidal e triangular, como no exemplo, e também gaussiana), e que pode ou não haver sobreposição de conjuntos. Toda esta generalidade proporciona uma alta capacidade de representação e de adequação ao problema a ser tratado.

Variável lingüística é um termo relacionado com conjuntos fuzzy. Entende-se por variável um identificador que pode assumir um dentre vários valores. Deste modo, uma variável lingüística pode assumir um valor lingüístico dentre vários em um conjunto de termos lingüísticos (Fabro, 1998b). No exemplo da Figura 3.10, a variável poderia ser denominada "temperatura", e assumir um dos seguintes valores: "frio", "médio", "quente" ou "insuportável", elementos do conjunto $\mathrm{T}=\{$ "frio", "médio", "quente", "insuportável" $\}$.

Em termos formais, uma variável lingüística é formada pela quíntupla $\{X, T(X)$, $\mathrm{U}, \mathrm{G}, \mathrm{M}\}$, onde:

- $X$ : Nome do conjunto de termos ("temperatura", no exemplo);

- $T(X)$ : Gerado através de G;

- G: Gramática para gerar os termos $\mathrm{T}(\mathrm{X})$;

- $U$ : Universo de discurso;

- $M$ : Significado dos termos lingüísticos, representado pelos conjuntos fuzzy.

Em geral, valores de variáveis lingüísticas podem ser gerados a partir de termos primários, por exemplo, "quente" é antônimo de "frio". Ainda pode-se acrescentar inúmeros modificadores, tais como: não, muito, pouco, mais ou menos, raramente, não muito, etc e conectivos "e" e "ou". Um exemplo que pode ser citado é para temperatura média que seria representado por "não muito frio" e "não muito quente".

Para se trabalhar com os conectivos citados pode-se utilizar propriedades matemáticas. Um exemplo tradicional é o modificador "não" em que se pode aplicar à operação de 
operação de "Complemento". O modificador "muito" freqüentemente é utilizado pela operação de elevar ao quadrado todos os $\mu(x)$ do intervalo.

\subsection{Redes Neurais Fuzzy}

Para possibilitar que um sistema trabalhe com incertezas cognitivas de uma forma mais parecida aos humanos, pode-se incorporar o conceito de lógica fuzzy numa rede neural.

As redes neurais fuzzy são usadas para ajustar funções de pertinência de sistemas fuzzy que são empregadas em sistemas de tomada de decisões para controle de equipamentos. Através da lógica fuzzy pode-se codificar conhecimento especialista diretamente, usando regras com variáveis lingüísticas. Geralmente, gasta-se um grande tempo para projetar e ajustar as funções de pertinência que, quantitativamente, definem estas variáveis lingüísticas. As técnicas de aprendizado de redes neurais podem automatizar este processo e reduzir substancialmente o tempo de desenvolvimento e o custo, enquanto ganha-se "performance" (Kasabov, 1996; Fullér, 1995).

Em teoria, redes neurais e sistemas fuzzy sāo equivalentes, ainda que na prática cada um tem suas próprias vantagens e desvantagens (Kasabov, 1996; Omlin et al., 1998). Para as redes neurais multicamadas, o conhecimento pode ser adquirido automaticamente pelo algoritmo backpropagation, mas o processo de aprendizado é relativamente lento e a análise da rede treinada é relativamente difícil (caixa preta) (Braga et al., 1999). Por outro lado, é possível extrair conhecimento estruturado (regras) de uma rede neural treinada, e também pode-se introduzir informações específicas sobre o problema na rede neural para simplificar o processo de aprendizado (Fullér, 1995).

Sistemas fuzzy são mais favoráveis visto que seu conhecimento pode ser explicado baseado nas regras fuzzy e sua "performance" pode ser melhorada pelo ajuste das regras. Em geral, a aquisição do conhecimento é difícil, pois o universo de discurso de cada variável de entrada precisa ser dividido em diversos intervalos, por isso aplicaçôes de sistemas fuzzy são restritas para os campos onde o conhecimento dos especialistas está acessível e o número de variáveis de entrada é pequeno. Para resolver o problema de aquisição do conhecimento, as redes neurais são projetadas para automaticamente extrair regras fuzzy de dados numéricos. Abordagens corporativas usam redes neurais para otimizar os parâmetros de sistemas fuzzy, ou para pré-processar dados e depois extrair regras fuzzy (Kasabov, 1996). Mas não há necessidade de se extrair regras da rede treinada, com isso o processo de inferência visto nos sistemas fuzzy será realizado por uma arquitetura neural (Lin and Cumningham, 1995; Keller et al., 1992; Wang and Keerthipala, 1998). 


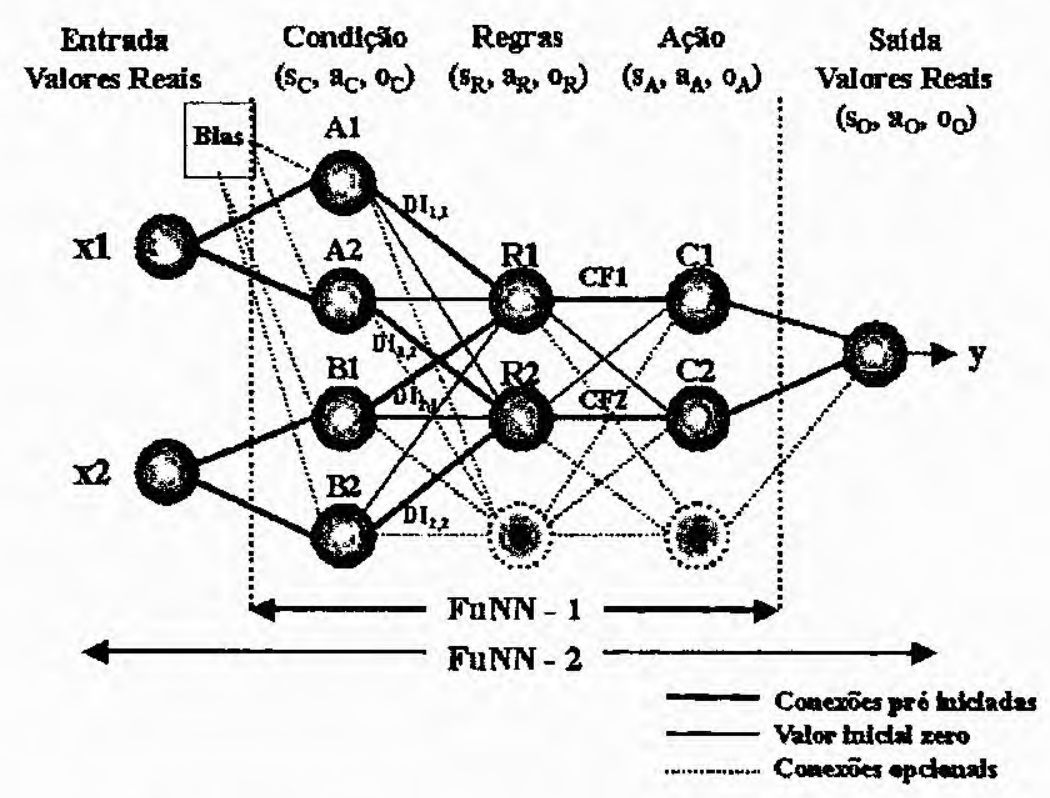

Figura 3.11: Arquitetura Geral de uma FNN

Diferentes tipos de redes neurais fuzzy $\left(\mathrm{FNN}^{2}\right)$ estão sendo desenvolvidos e aplicados em diferentes tarefas. A forma apresentada neste trabalho é a proposta por Kasabov (Kasabov, 1996).

Uma FNN é um modelo conexionista para implementar regras fuzzy e inferência, possuindo uma grande variedade de arquiteturas e funcionalidades. A seguir um dos modelos de FNN, o modelo FuNN, proposto por Kasabov (Kasabov, 1996) é apresentado.

\subsubsection{Modelo FuNN}

O modelo FuNN facilita o aprendizado dos dados, extração de regras fuzzy, e raciocínio aproximado. Usa uma rede multicamadas e o algoritmo de treinamento backpropagation. Ela é uma FNN adaptável, com funções de pertinência e predicados fuzzy, as regras fuzzy são inseridas antes do treinamento e podem se adaptar e mudar de acordo com o treinamento. Sua arquitetura geral consiste de cinco camadas (Figura 3.11):

1. Camada de entrada: cada nó representa uma variável de entrada;

2. Camada de condição: cada nó representa um predicado fuzzy de uma variável de entrada. O valor de ativação do nó representa o grau de pertinência das variáveis

\footnotetext{
${ }^{2}$ Do inglês Fuzzy Neural Network
} 
de entrada;

3. Camada de regras: cada nó representa ou uma regra existente ou uma regra atualizada. Quando o modelo FuNN é usado para implementar um conjunto de regras, as conexões entre os elementos da camada de condição e a camada de regras são inicializados de acordo com os graus de importância $\left(D I_{i, j}{ }^{3}\right)$ anexados nos antecedentes das regras $\left(w_{i j}=D I_{i, j}\right)$. Se não há $D I$ anexado à regra, então:

$$
w_{i, j}=N e t_{i} / n
$$

onde $n$ é o número de elementos condicionais da regra $R_{i}$ e $N e t_{i}$ é igual a 1, constante definindo a entrada que a rede deveria ter para que a regra fosse ativada. Quanto mais representativa a regra maior deve ser $N e t_{i}$. Por exemplo, para regras fortes o $N e t_{i}$ poderia ser 5 , já para regras mais fracas o $N e t_{i}$ poderia ser 1 , os pesos das outras conexões podem ser inicializados com zero. Nós adicionais podem ser inseridos para permitir o aprendizado de novas regras, onde suas conexões são inicializadas com zero;

4. Camada de ação: cada nó representa um predicado fuzzy nos conseqüentes das regras. As conexões entre a camada de regras e a de ação são inicializadas de acordo com os fatores de confiança $\left(\mathrm{CF}^{4}\right)$ das regras; as restantes são inicializadas com zero. Nós adicionais podem ser usados para obter predicados de novas ações (conclusões) durante o treinamento (adaptação);

5. Camada de saída: representa as variáveis de saída do sistema.

A arquitetura mostrada na Figura 3.11 é referente às seguintes regras:

$$
\begin{aligned}
& R_{1}: \text { Se } x_{1} \text { é } A_{1}\left(D I_{1,1}\right) \text { e } x_{2} \text { é } B_{1}\left(D I_{2,1}\right) \text {, então } y \text { é } C_{1}\left(C F_{1}\right) \\
& R_{2}: \text { Se } x_{1} \text { é } A_{2}\left(D I_{1,2}\right) \text { e } x_{2} \text { é } B_{2}\left(D I_{2,2}\right) \text {, então } y \text { é } C_{2}\left(C F_{2}\right)
\end{aligned}
$$

Os princípios de inserção de conhecimento apresentados aqui são utilizados para a modelagem das regras de produção apresentadas no Apêndice A.

\footnotetext{
${ }^{3}$ Do inglês Degrees of Importance

${ }^{4}$ Do inglês Confidence Factors
} 


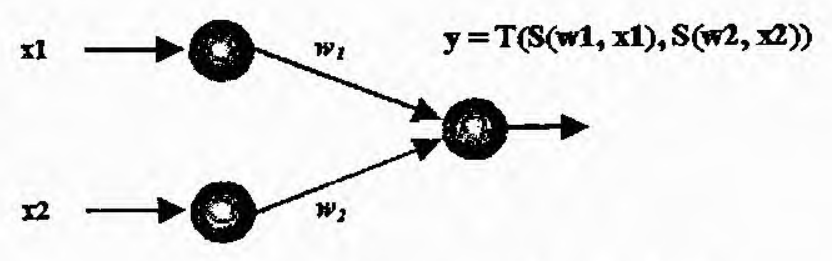

Figura 3.12: Neurônio Fuzzy $A N D$

\subsubsection{Neurônios Fuzzy}

Uma rede neural padrão emprega multiplicações, adições, funções de ativação, etc... Ao empregar-se outras operações sobre esta rede neural, por exemplo, as operações "e" e "ou" usadas nos sistemas fuzzy, obtém-se uma rede neural fuzzy ou, também chamada, rede neural hibrida.

Cada elemento de processamento de uma rede neural híbrida pode ser formado por um neurônio fuzzy. A seguir são apresentados três modelos de neurônios fuzzy. $\mathrm{O}$ terceiro modelo é o utilizado no projeto.

\section{Primeiro Modelo: Neurônio Fuzzy AND}

Neste neurônio (Fullér, 1995) os sinais $x_{i}$ e $w_{i}$ são combinados por uma operação $S$ para produzir:

$$
p_{i}=S\left(w_{i}, x_{i}\right), i=1,2
$$

A informação de entrada $p_{i}$ é agregada por uma operação $T$ para produzir a saída:

$$
y=A N D\left(p_{1}, p_{2}\right)=T\left(p_{1}, p_{2}\right)=T\left(S\left(w_{1}, x_{1}\right), S\left(w_{1}, x_{1}\right)\right)
$$

do neurônio.

Assim, com $T=\min$ e $S=\max$ o neurônio AND (Figura 3.12) realizará a seguinte composição:

$$
y=\min \left\{w_{1} \vee x_{1}, w_{1} \vee x_{1}\right\}
$$

OBS: Na lógica fuzzy as operações de União (V) e $\max$ são equivalentes. 


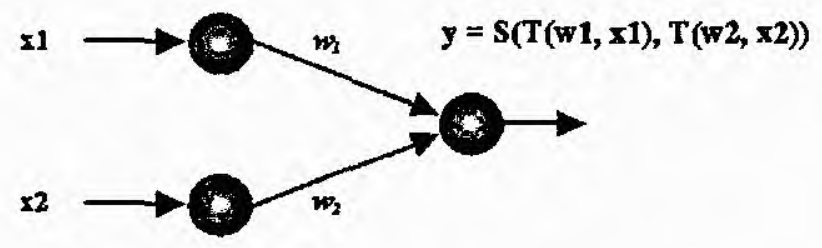

Figura 3.13: Neurônio Fuzzy OR

\section{Segundo Modelo: Neurônio Fuzzy $O R$}

Os sinais $x_{i}$ e $w_{i}$ deste neurônio (Fullér, 1995) são combinados por uma operação $T$ para produzir:

$$
p_{i}=T\left(w_{i}, x_{i}\right), i=1,2 \text {. }
$$

A informação de entrada $p_{i}$ é agregada por uma operação $S$ para produzir a saída:

$$
y=O R\left(p_{1}, p_{2}\right)=T\left(p_{1}, p_{2}\right)=S\left(T\left(w_{1}, x_{1}\right), T\left(w_{1}, x_{1}\right)\right)
$$

do neurônio.

Assim, com $T=\min$ e $S=\max$ o neurônio OR (Figura 3.13) realizará a seguinte composição :

$$
y=\max \left\{w_{1} \wedge x_{1}, w_{1} \wedge x_{1}\right\}
$$

OBS: Na lógica fuzzy as operações de Intersecção $(\wedge)$ e min são equivalentes.

\section{Terceiro Modelo: Neurônio Neo-Fuzzy}

O neurônio Neo-Fuzzy (Yamakawa et al., 1992) foi desenvolvido a partir do neurônio fuzzy. A Figura 3.14 mostra o diagrama detalhado de seus nós e funções de pertinência. Suas características são:

- As entradas $x_{1}, x_{2}, \ldots, x_{n}$ são representadas por variáveis fuzzy,

- Cada segmento fuzzy $x_{i j}$ associado a cada uma das variáveis $x_{i}, i=1, m ; j=1, n$ são representados por conexões entre a entrada $i$ e a saída; 


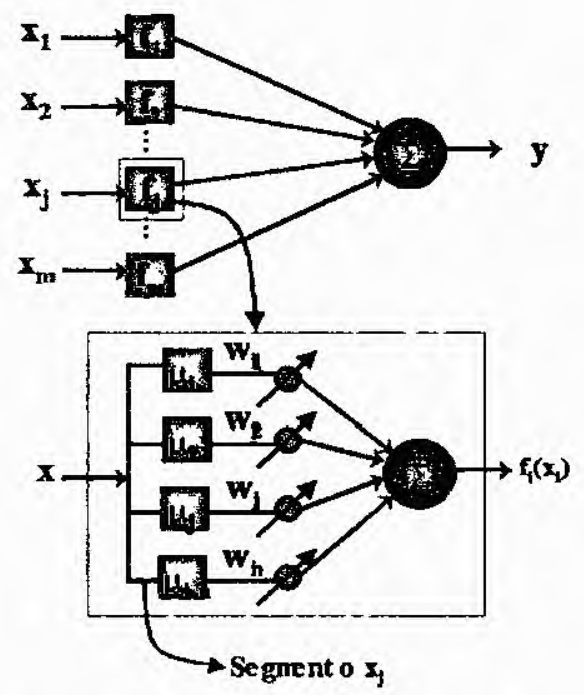

Figura 3.14: Neurônio Neo-Fuzzy

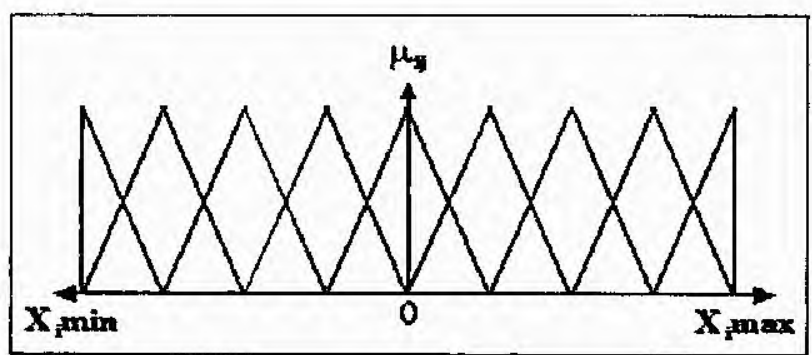

Figura 3.15: Função de pertinência uniformemente distribuída sobre o universo de X

- Adicionalmente à função de pertinência $\mu_{i}$, pesos $w_{i j}$ são atribuídos ao neurônio, sujeitos a treinamento;

- Os segmentos $x_{i 1}, x_{i 2}, \ldots, x_{i l}$ têm função de pertinência de padrão triangular. Com isso uma entrada somente ativa duas funções de pertinência simultaneamente (ver Figura 3.15), pois a soma dos graus de cada valor de entrada $x_{i}^{\prime}$ pertencentes a quaisquer duas funções de pertinência vizinhas $\mu_{i k}\left(x_{i}^{\prime}\right)$ e $\mu_{i, k+1}\left(x_{i}^{\prime}\right)$ serão sempre iguais a 1. Desta forma, a saída do neurônio poderia ser expressa pela equação:

$$
f_{i}\left(x_{i}^{\prime}\right)=\mu_{i k}\left(x_{i}^{\prime}\right) * \omega_{i k}+\mu_{i, k+1}\left(x_{i}^{\prime}\right) * \omega_{i, k+1} .
$$

Existem alguns algoritmos de treinamento aplicáveis ao neurônio neo-fuzzy. Um deles é conhecido como Atualização Incremental. Sẹ'q neurônio neo-fuzzy deve aprender 
pela associação de um padrão de entrada $x^{(k)}=\left(x_{1}^{k}, x_{2}^{k}, \ldots, x_{m}^{k}\right)$ com um valor de saída $y^{(k)}$, então as mudanças dos pesos pode ser feita pela equação abaixo:

$$
\Delta \omega_{i j}=-\alpha\left(y^{k}-d^{k}\right) \mu\left(x_{i}^{k}\right), \text { para } i=1,2 . ., \text { ne } j=1,2, \ldots, 1
$$

onde $\alpha$ é o fator de aprendizado, $\mu$ é o grau de pertinência, $y^{k}$ é a saída atual do neurônio e $d^{k}$ é a saída desejada para o padrão de entrada $x^{k}$.

Antes do treinamento todos os pesos são inicializados com zero.

Exemplos de uso deste neurônio estão expostos no capítulo 4, seção 4.2 .

\subsection{Resumo}

Muitas vezes a solução de um problema requer a união de mais de uma técnica computacional, tal como redes neurais e lógica fuzzy, podendo receber então, a denominação de sistemas híbridos, tema principal deste capítulo. Este tipo de abordagem está ganhando seu espaço no mercado, pois com ele ganha-se eficiência, generalização, e outras características inerentes das redes neurais artificiais.

No capítulo seguinte é apresentado o simulador neuro-fuzzy desenvolvido, além de ser abordada a modelagem de regras de produção neste simulador. 


\section{Capítulo 4}

\section{Simulador Neuro-Fuzzy}

Nos capítulos anteriores foram apresentados os conceitos teóricos necessários à realização deste trabalho.

Como o conhecimento disponível do domínio (Usina Itaipu) era uma base de regras montada a partir de um sistema especialista R-TESE construído para a detecção e previsão de falhas na Usina de Itaipu, surgiu a necessidade de modelar essas regras através de RNAs e Lógica Fuzzy. Para facilitar a modelagem dessas regras e de outras que poderão ser incorporadas à medida que o sistema vai sendo atualizado, decidiu-se por construir um simulador para a modelagem das regras.

Assim sendo, este capítulo tem como meta descrever o processo de implementação do simulador e a modelagem das regras neste simulador.

\subsection{Desenvolvimento do Simulador Neuro-Fuzzy}

O desenvolvimento do simulador, denominado Neuro-Fuzzy, deu-se ao fato de não se encontrar disponível um simulador que possuísse as características desejadas.

De acordo com os estudos realizados sobre a base de regras existente, decidiu-se dividir as regras em grupos, conforme suas semelhanças. Cada grupo criado foi modelado numa mesma rede, chamada de sub-rede.

O simulador permite modelar e treinar cada uma das sub-redes previstas individualmente, onde cada uma delas tem seu conjunto de treinamento. Além disso, é possível criar níveis de dependências entre as sub-redes, ou seja, as saídas de uma sub-rede podem servir de entrada para outra sub-rede. 
A representação de cada sub-rede está baseada no modelo genérico para representação de regras apresentado no capítulo 3, Figura 3.8, pois, com base numa análise das regras, visando escolher o melhor modelo de representação, verificou-se que este modelo é o que mais se adequa às regras.

Aprofundando-se mais em suas características, cada sub-rede pode ser formada pelos seguintes neurônios: Neurônio Binário, Neurônio Fuzzy e Neurônio Padrão.

Com o término da modelagem e treinamento de todas as sub-redes do projeto, pode-se gerar a base de conhecimento final. Esta base é a que contém todas as subredes projetadas. No presente trabalho, o simulador foi desenvolvido especificamente para auxiliar na geração desta base de conhecimento, que é utilizada pelo Sistema de Produção NEUFI (Capítulo 5).

As próximas seções apresentam, de forma detalhada, as funções que constituem o simulador e o seu funcionamento. Para isto, será mostrado como se modela um projeto de rede neural no simulador, abrangendo desde a criação do projeto, suas sub-redes, elaboração do conjunto de treinamento, treinamento, até a determinação de níveis de prioridade e a geração da base de conhecimento final. Por último, as regras modeladas neste simulador são apresentadas.

\subsubsection{Projeto de uma Base de Conhecimento Neuro-Fuzzy}

Inicialmente, o desenvolvedor tem a opção de criar uma nova base de conhecimento neurofuzzy ou abrir uma já existente, alterando suas informações. Para isso, o simulador cria como padrão arquivos de projeto com a extensão .SPR. Estes arquivos gerenciam todas as sub-redes que compõem o projeto, desde o nome da sub-rede, do conjunto de treinamento até a definição da prioridade de execução da sub-rede com relação as demais.

$\mathrm{O}$ arquivamento de cada sub-rede é feito em arquivos individuais do tipo TStream, que possibilita o armazenamento dos elementos que compõem a sub-rede em formato de objetos, facilitando assim a manipulação das informações.

A interface principal do simulador é apresentada na Figura 4.1, onde as seguintes funcionalidades encontram-se disponíveis:

Novo Projeto: Permite criar um novo projeto de rede neural;

Abrir Projeto: Permite abrir um projeto já existente;

Salvar Projeto: Para salvar o arquivo de projeto; 


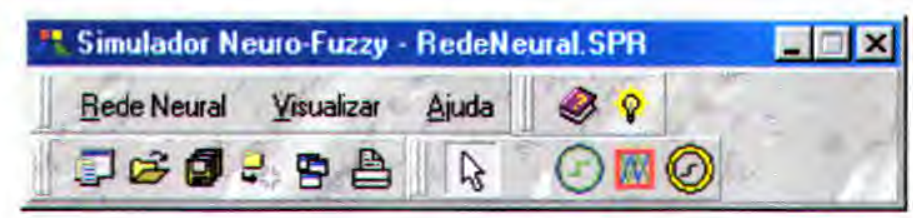

Figura 4.1: Simulador Neuro-Fuzzy

\begin{tabular}{|c|c|c|c|c|}
\hline \multicolumn{5}{|c|}{ Visualizar Sub-Rede } \\
\hline 0 & SB1. rxa & I1.pat & 4 & \& Nova \\
\hline-1 & Sb2.rna & T2.pat & - & \\
\hline-1 & Sb3.rna & T3. PAT & & $\sqrt{\text { Editar }}$ \\
\hline-1 & Sb4.rna & T4. PAT & & \\
\hline 1 & $\mathrm{Sb} 5 . \mathrm{rna}$ & T5. PAT & & - Excluit \\
\hline-1 & SB6. RNA & $\mathrm{T} 6 . \mathrm{PAT}$ & & (ख) Moter \\
\hline-1 & SB7. RNA & T7. PAT & & Him Mustar \\
\hline-1 & SR8. RNA & T8, PAT & & 裙 Oculta \\
\hline-1 & SB9. RNA & T9.PAT & $=$ & \\
\hline
\end{tabular}

Figura 4.2: Interface das sub-redes do Projeto

\section{Fechar Projeto: Fechar o projeto;}

sub-redes: Mostrar/Ocultar o Formulário de SubRedes (Figura 4.2):

皿 Imprimir: Imprimir as características do projeto, ou seja, nome das sub-redes, dos arquivos de treinamento e prioridades das sub-redes;

Ajuda: Ajuda on-line;

Q Sobre...: Informações sobre os desenvolvedores do sistema;

Desmarcar: Desmarcar o neurônio selecionado;

Neurônio Binário: Selecionar neurônio Binário;

Neurônio Fuzzy: Selecionar neurônio Fuzzy,

(5) Neurônio Padrão: Selecionar neurônio Padrão.

A Figura 4.2 mostra o formulário que permite gerenciar todas as sub-redes que pertencem ao projeto. Neste formulário têm-se as seguintes opçôes: 


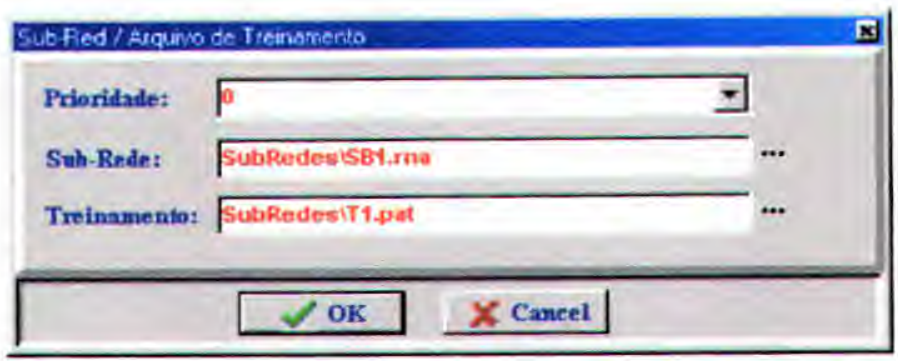

Figura 4.3: Edição das características da sub-rede Selecionada

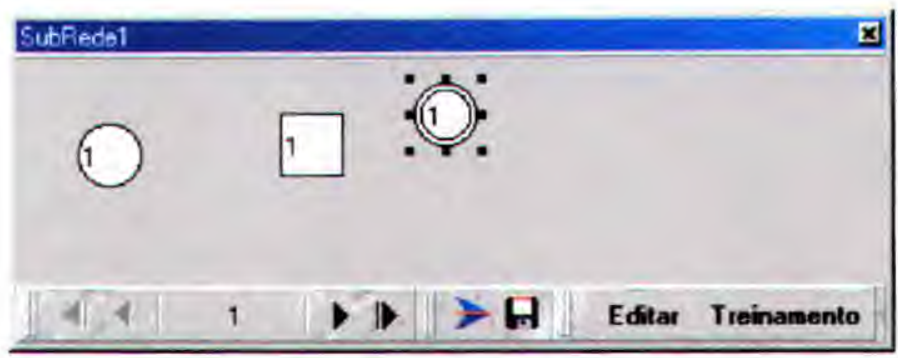

Figura 4,4: Formulário de uma sub-rede

\$ Nova: Permite criar uma nova sub-rede;

Editar: Permite editar as informações relacionadas à sub-rede, tais como nome para a sub-rede, nome do arquivo que contém os padrões de treinamento e prioridade de execução da rede. A Figura 4.3 apresenta o formulário que contém estas informações;

- Excluir: Permite excluir uma sub-rede do projeto. Os arquivos que contêm as sub-redes não são excluídos fisicamente, seus nomes são apenas excluídos do projeto, se houver necessidade pode-se adicioná-los novamente;

Mostrar: Exibe o Formulário de Ediçâo de sub-redes (Figura 4.4);

鼠 Ocultar: Fecha o Formulário de sub-redes.

\section{Modelagem de uma sub-rede}

A Figura 4.4 mostra o formulário para edição de sub-redes. Este formulário disponibiliza as seguintes opções: 
\ Primeiro: Ir para o primeiro conjunto de treinamento;

Anterior: Ir para o conjunto de treinamento anterior;

Número: Selecionar o número do conjunto de treinamento;

- Próximo: Ir para o próximo conjunto de treinamento;

| Último: Ir para o último conjunto de treinamento;

Executar: Executar a rede com o conjunto de dados que se encontra em sua entrada;

口 Salvar: Salvar a sub-rede, cada sub-rede é armazenada em arquivos individuais;

Editar: Editar conjunto de treinamento;

Treinamento: Treinar a rede.

Para inserir neurônios na sub-rede deve-se escolher um neurônio (Formulário Principal) e clicar na posição desejada do Formulário da sub-rede.

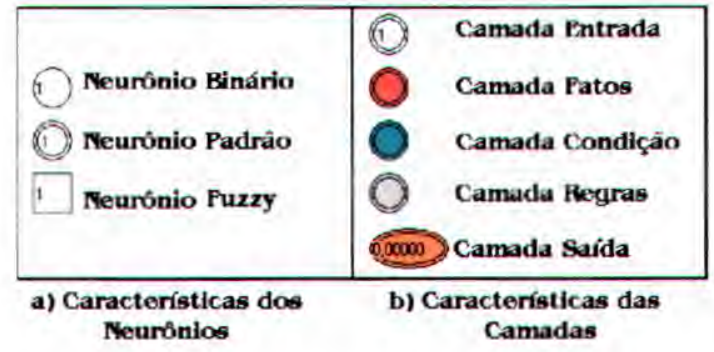

Figura 4.5: Representação dos Neurônios e das Camadas

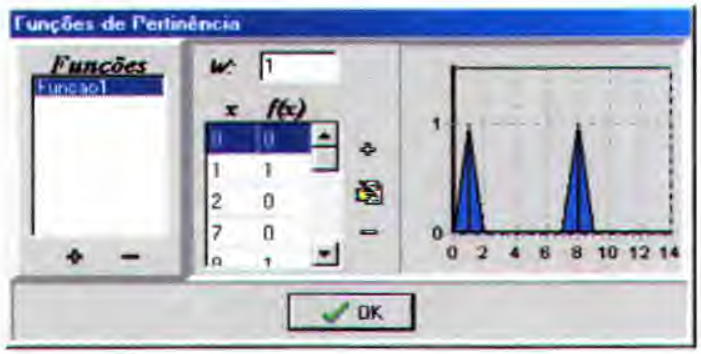

Figura 4.6: Funções de Pertinência e Graus de Pertinência

O Formulário Propriedades é responsável por apresentar, em sua interface, os atributos de um determinado objeto.

Desta forma, quando um neurônio é selecionado, com o clicar do mouse, suas propriedades são apresentadas no Formulário Propriedades (Figuras $4.7[a, b, c$ e $d]$ ). A Figura 4.7 apresenta, respectivamente, as propriedades dos neurônios: Binário, Fuzzy, Padrão e Opção Conexão. Se dois neurônios estiverem selecionados aparecerão mais duas propriedades: Conexão e Peso. A propriedade Peso somente poderá ser modificada se a propriedade Conexâo estiver com valor True.

Cada neurônio utilizado no simulador pode ser de diferentes tipos: Neurônio Binário; Neurônio Fuzzy e Neurônio Padrão. Suas propriedades podem ser alteradas através do Formulário Propriedades. 


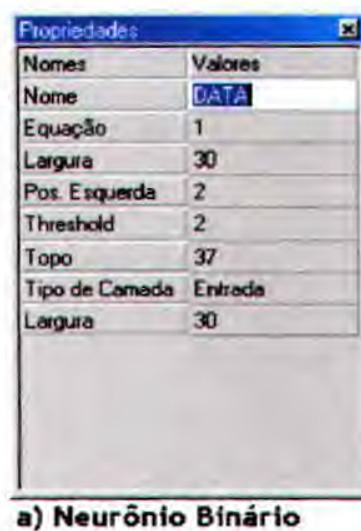

a) Neurônio Binário

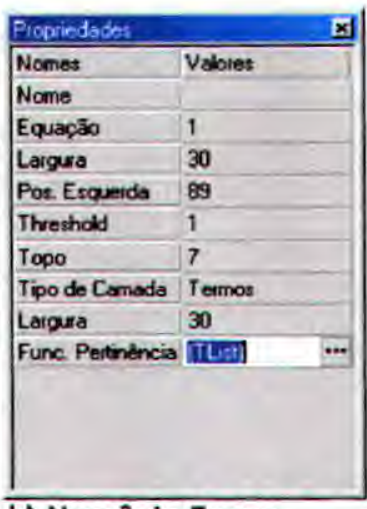

b) Neurônio Fuzzy

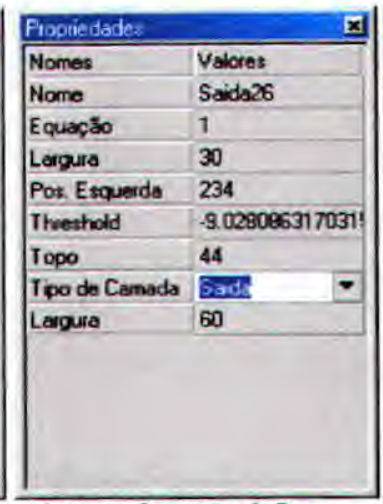

c) Neurônio Padrão

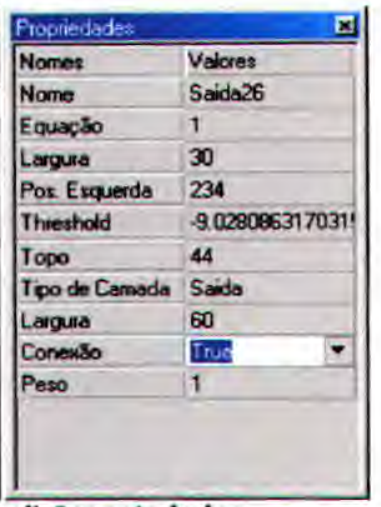

d) Propriedades

Conexão e Peso

Figura 4.7: Propriedades dos Neurônios

Quando um neurônio Fuzzy for selecionado aparecerá mais uma propriedade - Func. Pertinência, a qual refere-se a uma lista de todas as funções de pertinência atribuídas ao neurônio. A escolha desta opção disponibiliza o Formulário apresentado na Figura 4.6. Cada função de pertinência tem um peso associado e vários graus de pertinência.

O peso da função de pertinência é atualizado de acordo com o treinamento. Durante a inserção/exclusão de graus de pertinência a função resultante vai sendo desenhada.

A Figura 4.5 mostra a forma na qual os neurônios são apresentados no simulador, onde:

- Neurônio Binário: Representado por uma elipse;

- Neurônio Padrão: Representado por duas elipses:

- Neurônio Fuzzy: Representado por um retângulo.

Adicionalmente, têm-se as características representativas de cada camada que compõem a sub-rede:

- Camada Entrada: Os neurônios desta camada são representados na cor branca, rotulados com o valor de entrada;

- Camada Termos: Representado na cor vermelha;

- Camada Condição: Representado na cor verde;

- Camada Regras: Representado na cor cinza; 
- Camada Saída: Os neurônios pertencentes a esta camada são apresentados na cor laranja. Seu valor de saída é apresentado em seu interior.

Nas próximas seçôes são apresentados como editar o conjunto de treinamento e como treinar uma sub-rede.

\section{Edição do Conjunto de Treinamento}

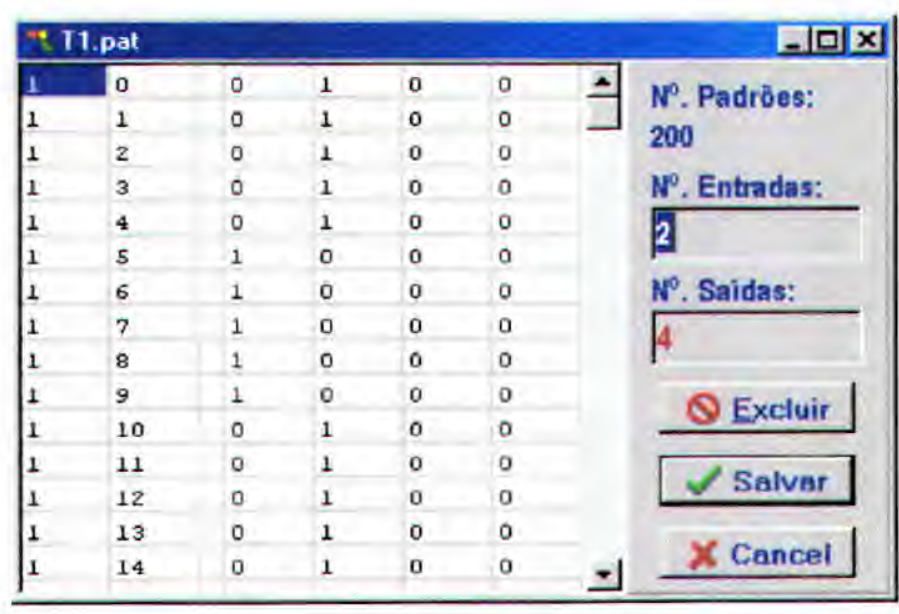

Figura 4.8: Editor de Padrões de Treinamento

$\begin{array}{ll}\text { Ireinsmenlo } & \\ \text { NE.Ciclos: } & 1000 \\ \propto & 0.4 \\ \text { Limpar } & \text { Embaralhar } \\ \text { Inicializar } & \\ \text { Treinar } & \text { Gráfico } \\ \text { Parar } & \text { MSE }\end{array}$

Figura 4.9: Treinamento da Rede

Para editar os padrões de treinamento da sub-rede deve-se, primeiramente, indicar o número de neurônios que compõem a camada de entrada e de saída (Figura 4.8). As colunas necessárias para a edição dos padrões de treinamento serão então disponibilizadas. Uma coluna é adicionada automaticamente entre os valores de entrada e os de saída para separá-los.

Para excluir um padrâo deve-se posicionar o cursor sobre a linha em que o padrão se encontra para então excluí-lo.

O número total de padrões é obtido automaticamente pelo sistema, de acordo com o número de linhas criadas. Linhas excedentes devem ser excluídas manualmente.

\section{Treinamento}

Montada a arquitetura e definido o conjunto de treinamento, poderá ser iniciado o processo de treinamento. Para isto as seguintes opções estão disponíveis (Figura 4.9): 
- No Ciclos: Número de ciclos de treinamento;

- $\alpha$ : Fator de aprendizado;

- Limpar: Inicializar a rede (pesos e thresholds) com zero;

- Inicializar: Inicializar a rede (pesos e thresholds) com valores aleatórios;

- Treinar: Iniciar treinamento;

- Parar: Parar treinamento;

- Embaralhar: Apresentar os padrōes de treinamento de forma aleatória;

- Gráfico: Visualizar gráfico de erros (Figura 4.10),

- MSE: Visualizar os erros obtidos durante o treinamento (Figura 4.11).

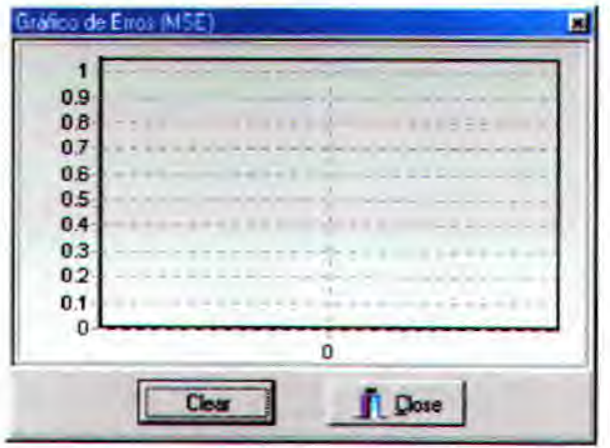

Figura 4.10: Gráfico de Erros obtido durante o treinamento

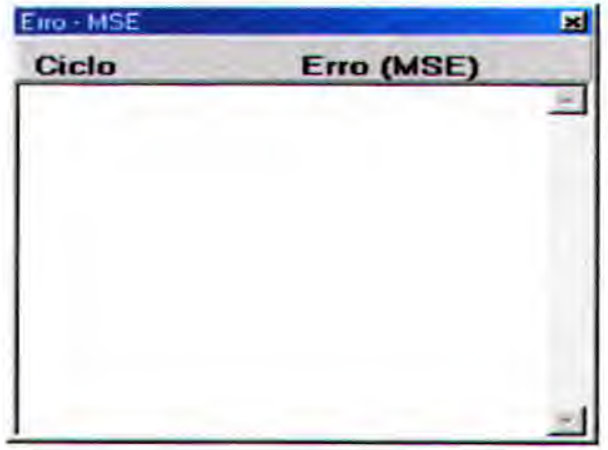

Figura 4.11: Erro MSE obtido durante o treinamento

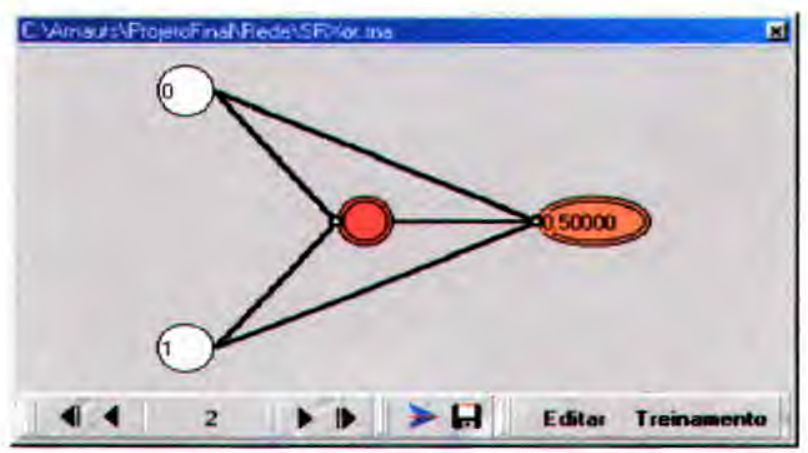

Figura 4.12: Neurônio XOR, modelagem usando o Simulador Neuro-Fuzzy 


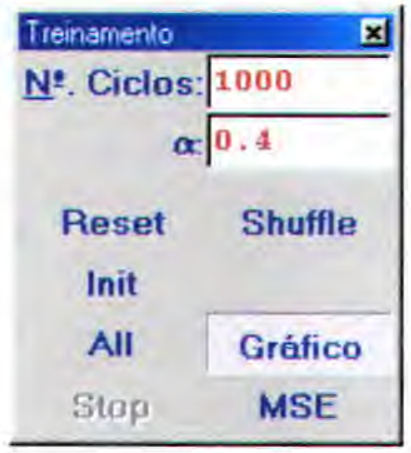

Figura 4.13: Opções de treinamento de 11ma sub-rede

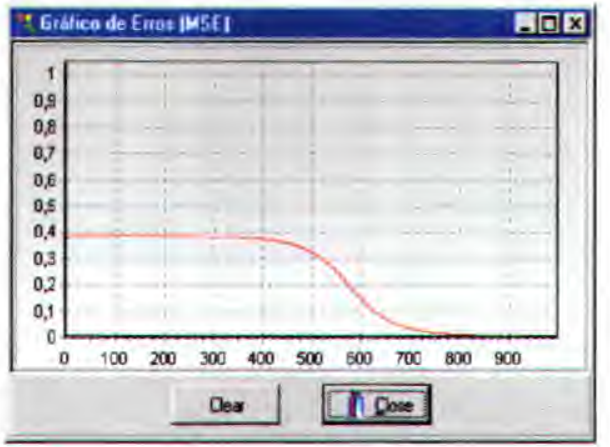

Figura 4.14: Gráfico de Erros obtido durante o treinamento

Após carregado o conjunto de treinamento, definido o número de ciclos e o fator de aprendizado, pode-se iniciar o treinamento da rede. Este é realizado em background. por uma Thread, possibilitando que o usuário continue interagindo com o sistema.

O treinamento da rede neuro-fuzzy é realizado segundo o algoritmo backpropagation (Rumelhart et al., 1986) na sua versão mais simples.

O exemplo apresentado na Figura 4.12 refere-se ao treinamento de uma rede neural que representa a função $X O R$, usando-se o simulador Neuro-Fuzzy. Para o treinamento da função XOR utilizou-se na 1a camada neurônios binários e nas demais neurônios padrão. As Figuras 4.13 e 4.14 mostram as opções de inicialização da rede e o gráfico de erros obtido durante o treinamento.

\section{Prioridades}

Este simulador também permite a criação de níveis de dependência entre as sub-redes. onde as saídas de algumas podem servir de entradas para outras. Para que este processo seja efetuado de forma correta, é necessário indicar qual o nível de prioridade das subredes. Redes cujas entradas dependem das saídas de outras devem ter níveis de prioridade inferiores.

Pode-se alterar o nível de prioridade da sub-rede através do Formulário sub-redes, na opção Editar. A escolha desta opção apresenta o Formulário da Figura 4.3. Neste formulário tem-se o campo Prioridade, o qual indica a prioridade de execnção da subrede, quanto mais baixo este número maior será esta prioridade.

Quatro (4) níveis são possíveis, variando de -1 a 2 , onde -1 indica que não há dependência desta sub-rede com as demais, ou seja, a sub-rede atual não depende de nenhuma outra para que possa ser processada. 
Além de indicar que há sub-redes dependentes dentro do projeto, precisa-se indicar quais neurônios de saída de uma sub-rede estão ligados aos neurônios de entrada de outras. No próximo item é explicado como isso é realizado.

\section{Variáveis}

Uma variável de entrada é definida através da propriedade Variável presente em todos os neurônios, mas somente utilizada pelos neurônios da camada de entrada e de saída de cada sub-rede.

Apesar das variáveis terem todas as mesmas propriedades, elas podem ser divididas nos seguintes grupos:

- Variáveis de Entrada: Usadas por neurônios da camada de entrada cujas entradas não são dependentes das saídas de outras sub-redes. Elas representam os novos a serem apresentados à rede;

- Variáveis de Saída: Variáveis associadas aos neurônios da camada de saída e que não são utilizadas como entradas para outras sub-redes. São elas que fornecem o valor de saída do neurônio, possibilitando assim saber se ele foi ativado ou não. Todos os neurônios da camada de saída devem ter variáveis associadas;

- Variáveis de Ligação: Variáveis que ligam duas sub-redes. Cada neurônio da camada de entrada, dependente de um neurônio da camada de saída, deve ter o mesmo nome de variável atribuído ao neurônio da camada de saída do qual ele é dependente.

\subsubsection{Base de Conhecimento Final}

Após o término da modelagem, treinamento, definição de prioridades e de variáveis, podese gerar a base de conhecimento final, com a utilização do simulador Neuro-Fuzzy desenvolvido.

A geração de uma base de conhecimento conexionista fundamentada nas Instruções de Operação da Interligação do setor de $60 \mathrm{~Hz}$ é explicada de forma detalhada a seguir. 


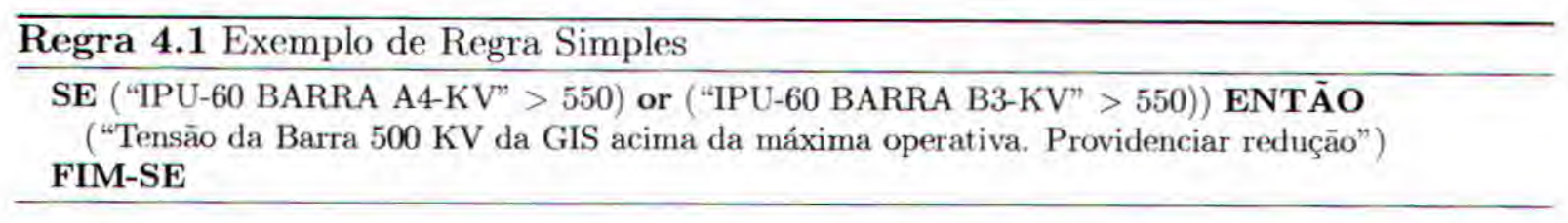

\subsection{Formalização das Regras}

Em primeiro lugar, nesta seção, são apresentados os estudos realizados sobre a base de regras de produção e em seguida as regras modeladas no simulador são expostas de forma detalhada.

\subsubsection{Base de Regras}

A base de regras que foi utilizada para a realização deste trabalho foi adquirida junto à Usina Hidrelétrica de Itaipu Binacional, e estas correspondem às IOIs do Setor de 60 $\mathrm{Hz}$ (Instruções de Operação da Interligação do Setor de $60 \mathrm{~Hz}$ da Usina), organizadas na forma de regras de produção.

Nos exemplos mostrados a seguir, a representação gráfica dos neurônios é a mesma adotada no Simulador Neuro-Fuzzy, ou seja, o neurônio binário é representado por uma elipse, o neurônio padrão por duas e o neurônio fuzzy por um retângulo.

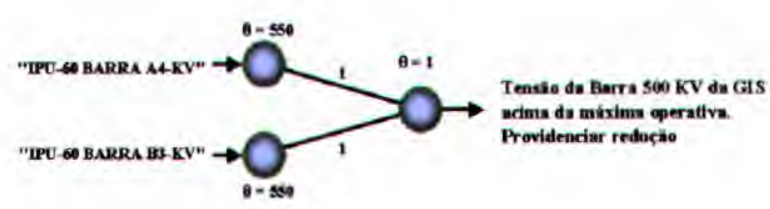

Figura 4.15: Exemplo de Modelagem de uma Regra Simples

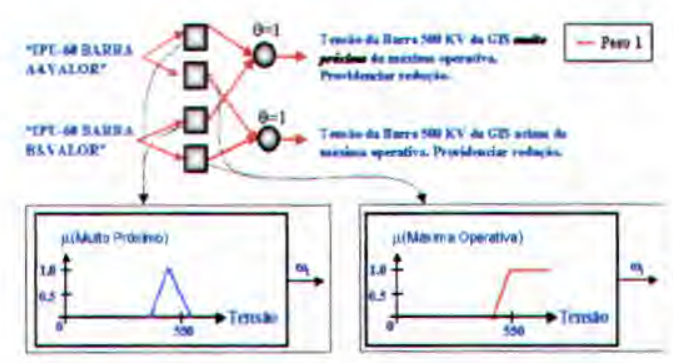

Figura 4.16: Regra Simples sendo modelada com Neurônio Fuzzy

A Figura 4.15 mostra a Regra 4.1 sendo modelada somente com neurônios binários.

Já a Figura 4.16 ilustra a modelagem da mesma regra (Regra 4.1), agora usando também o neurônio fuzzy. Nesta estrutura, a tensão da barra não deve ultrapassar o limiar de 550 V. Então, se ela ultrapassar este valor, será enviada uma mensagem indicando ao Usuário que a tensão está acima da Máxima Operativa. Mas, quando a tensão estiver Muito Próxima da Máxima Operativa, poderá também, ser gerada uma meusagem indicando ao Usuário que esta proximidade está ocorrendo. 


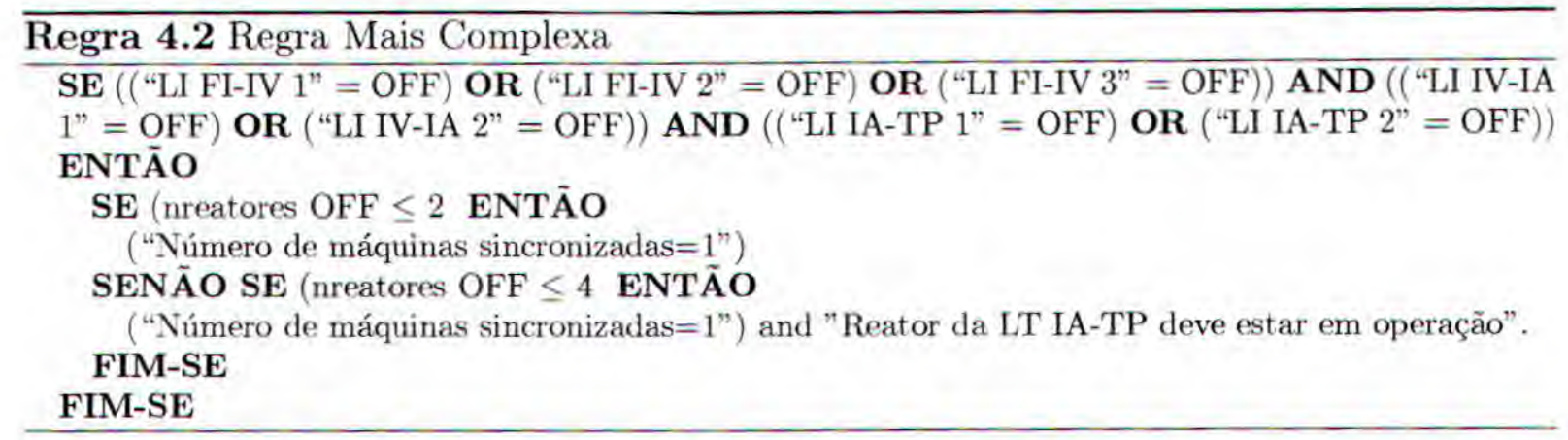

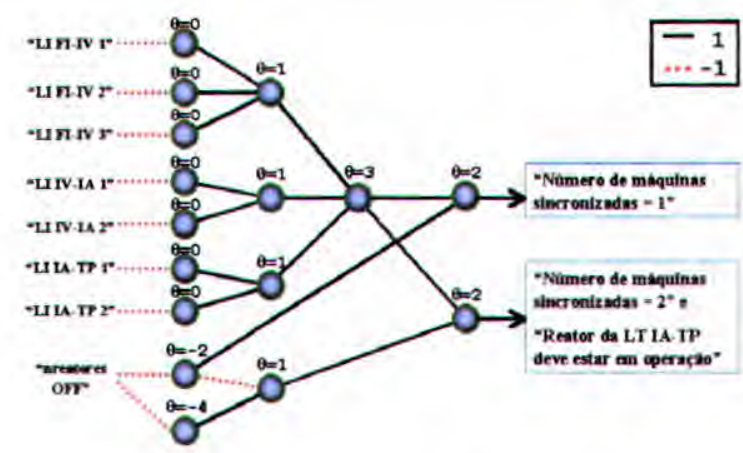

Figura 4.17: Exemplo de Modelagem de uma Regra Simples

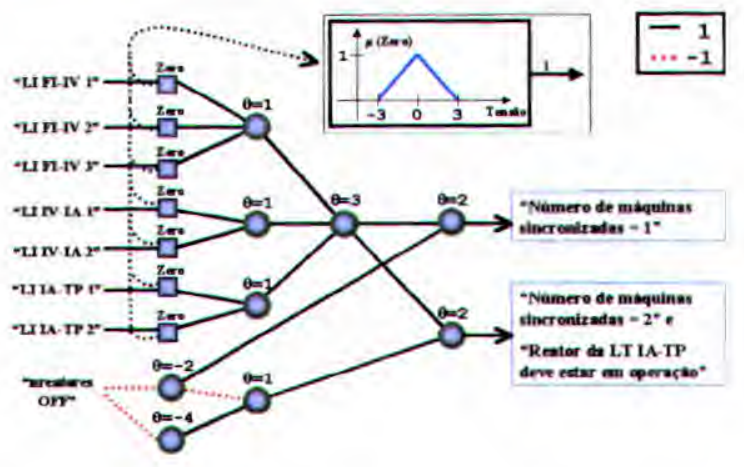

Figura 4.18: Regra Complexa sendo modelada com Neurônio Fuzzy

Regras mais complexas, como a Regra 4.2, também podem ser representadas por neurônios binários (Figura 4.17). A Figura 4.18 mostra esta mesma regra sendo modelada também com neurônios fuzzy e a Figura 4.19 apresenta-a em uma estrutura que requer posterior treinamento.

A vantagem de se utilizar esta última forma de modelagem, combinando os diferentes tipos de neurônios, é que o conhecimento sobre as regras fica intrínseco à rede de acordo com o processo de treinamento, diminuindo sua complexidade de modelagem.

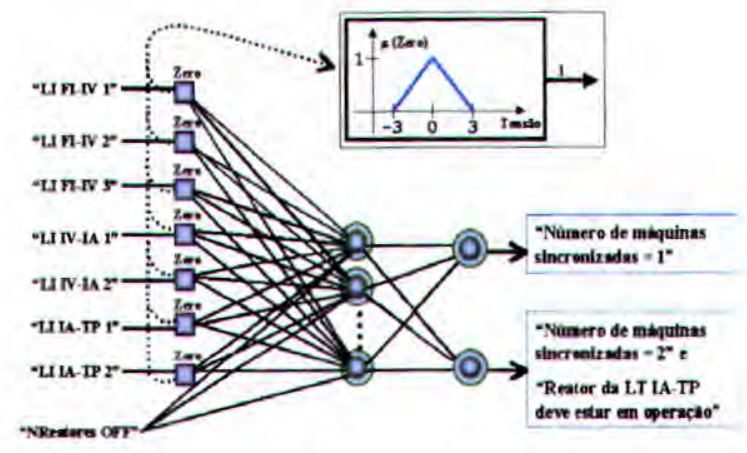

Figura 4.19: Exemplo de Regra Complexa com Aprendizado 
Além disso, utilizar somente neurônios binários na modelagem significa que a rede somente classificará as regras inseridas em sua estrutura.

A utilização de neurônios fuzzy é útil para modelar regiões de proximidade, principalmente representando aquelas que determinam os status (ligada/desligada) de uma linha de transmissão de energia. Isto é, quando uma linha não está em operação pode haver a interferência de outros fatores (ruído) no sinal recebido, e esse sinal pode não ser o esperado (zero), mas estar próximo a ele.

\subsubsection{Regras modeladas}

As regras apresentadas no Apêndice A foram particionadas em 17 (quinze) sub-redes, de acordo com suas características. Estas 17 sub-redes são apresentadas e justificadas a seguir.

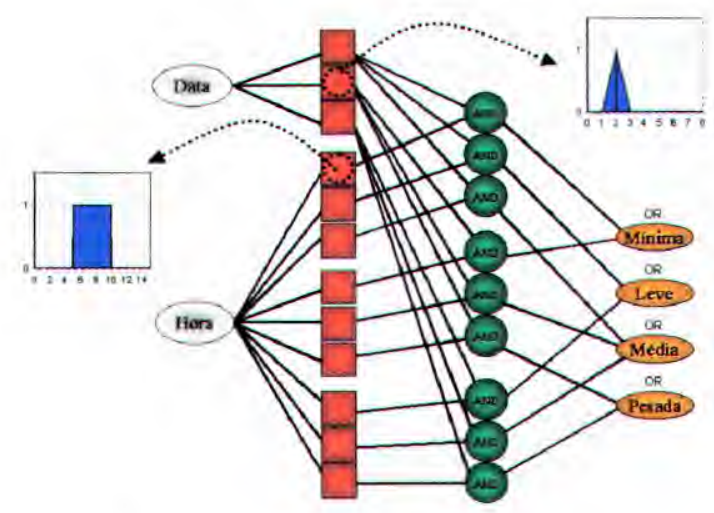

Figura 4.20: Sub-Rede 1

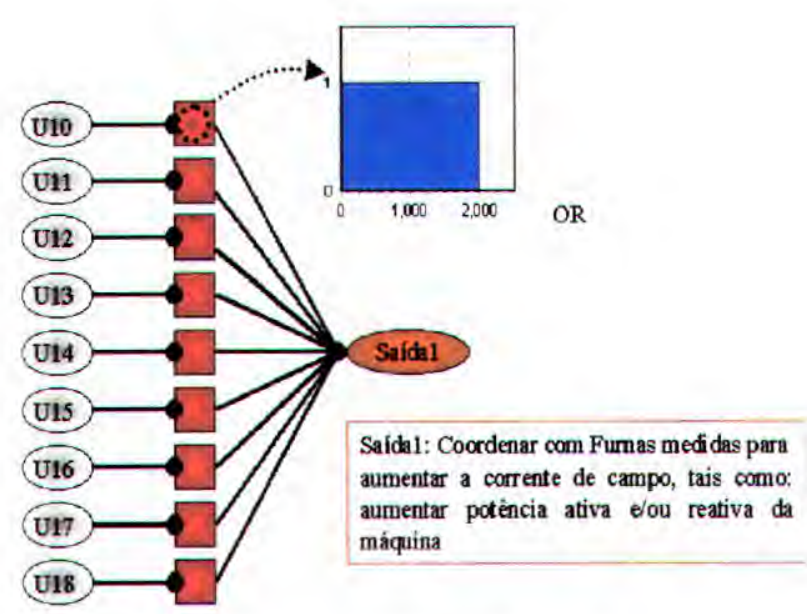

Figura 4.21: Sub-Rede 2

Na Figura 4.20 é apresentada a sub-rede 1. Esta sub-rede representa a modelagem das regras 1, 2 e 3 contidas no Apêndice A. Os neurônios de entrada caracterizam a hora e data atuais. Estes valores são fuzzificados através dos neurônios da segunda camada e nas próximas camadas são determinados os períodos de carga nos quais as entradas pertencem. Os quatro neurônios de saída simbolizam, respectivamente, as seguintes variáveis: Mínima, Leve, Média e Pesada, que são variáveis de ligação, pois outras sub-redes necessitam de período de carga como entrada.

Exemplificando a seguinte entrada: Dat $a=2$ e $H o r a=7$. Esta entrada ativa o segundo e o oitavo neurônio fuzzy da segunda camada, estes dois neurônios ativam o quinto neurônio da terceira camada, que por sua vez ativa o terceiro neurônio da camada de 
saída, que corresponde a variável Média. Logo se Data=2 e Hora=7, o Período de Carga obtido é igual a Carga Média.

A sub-rede 2 (Figura 4.21) representa às regras de 4 a 12 (Apêndice A). Todas estas regras possuem a mesma saída e portanto foram modeladas na mesma sub-rede.

A sub-rede 1 teve sua prioridade fixada em 0 (zero) pois outras sub-redes necessitam de suas saídas. Contudo, na sub-rede 2 o nível de prioridade é -1 , pois não há dependentes e nem ela própria é dependente,

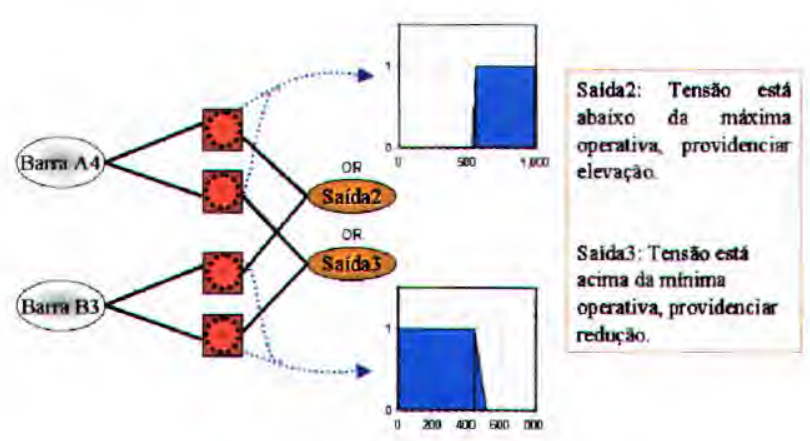

Figura 4.22: Sub-Rede 3

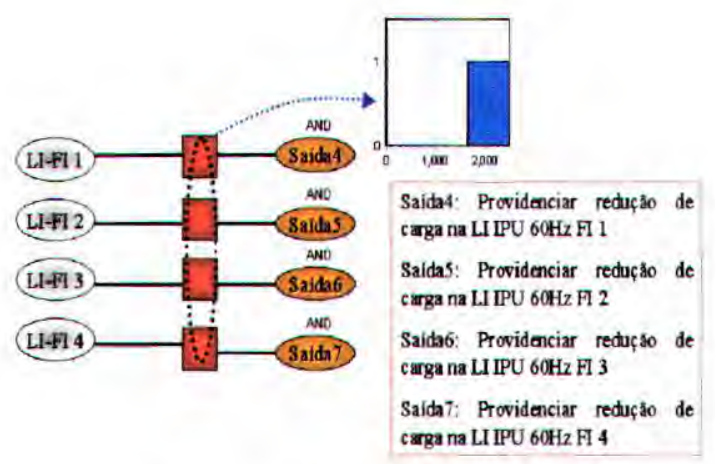

Figura 4.23: Sub-Rede 4

A sub-rede 3 da Figura 4.22 representa as regras de 13 a 16 (Apêndice A). Nestas regras têm-se duas entradas distintas, cujos valores se inferiores a 400 produzirão uma resposta, se superiores a 550 produzirão outra resposta. Caso contrário não produzirão nenhuma resposta.

Já a sub-rede 4 da Figura 4.23 refere-se às regras 17, 18, 19 e 20. Nestas regras têm-se quatro entradas e saídas distintas, e que não se relacionam.

Estas duas sub-redes possuem prioridades -1, pois elas não dependem do resultado de nenhuma outra rede para que possa ser processada.

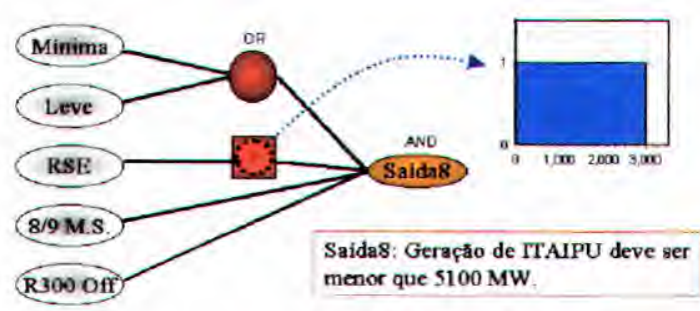

Figura 4.24: Sub-Rede 5

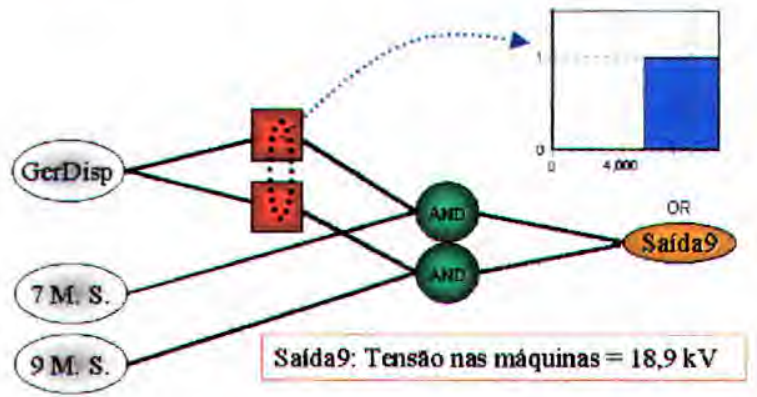

Figura 4.25: Sub-Rede 6

A sub-rede 5, exibida pela Figura 4.24, representa a modelagem da regra 21 . Os 
dois primeiros neurônios de entrada desta sub-rede referem-se às variáveis Mínima e Leve, respectivamente, que são saídas da sub-rede 1 (Figura 4.20), portanto a prioridade desta sub-rede é 1 , ou seja, deverá ser processada logo após a sub-rede 1 ter sido processada.

A sub-rede 6 ilustrada na Figura 4.25 representa às regras 23 e 24 contidas no Apêndice A, oude o primeiro neurônio refere-se a Geração Disponível em Itaipu e o segundo ao Número de Unidades (geradores) Sincronizadas de Itaipu.

A sub-rede 6 depende da sub-rede 15, que fornece à sub-rede o número de unidades sincronizadas em ITAIPU (Setor de $60 \mathrm{~Hz}$ ), portanto a prioridade desta sub-rede é 1 .

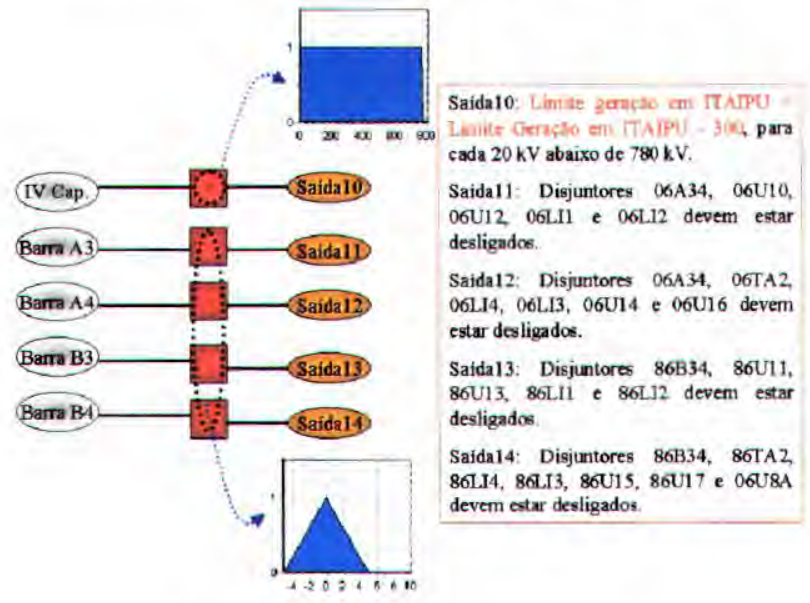

Figura 4.26: Sub-Rede 7

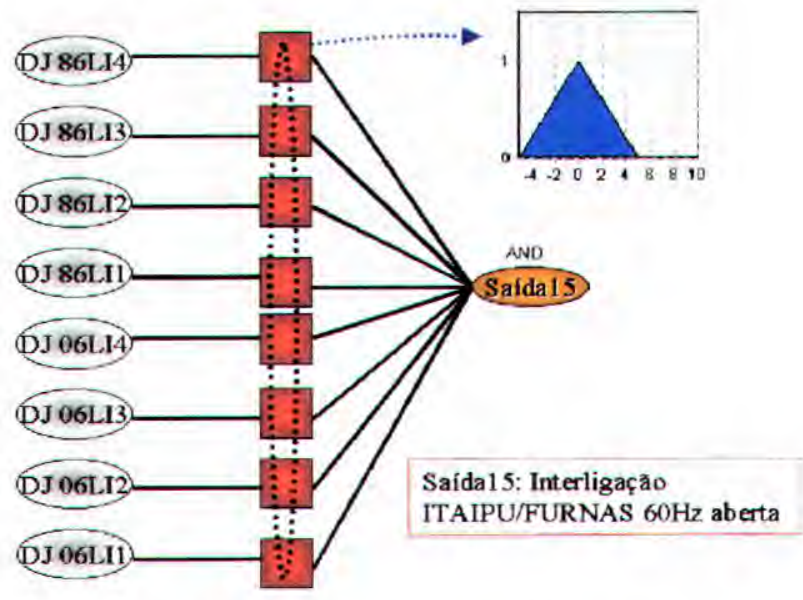

Figura 4.27: Sub-Rede 8

Na sub-rede 7 (Figura 4.26) a modelagem das regras 25 a 29 são efetuadas. O primeiro neurônio de entrada representa a Tensão presente no Capacitor de Ivaiporã. As demais entradas representam as tensões das barras A3, A4, B3 e B4 de Itaip11, no Setor de $60 \mathrm{~Hz}$. A prioridade desta sub-rede é -1 pelo fato de não ser dependente de outras sub-redes e por nâo possuir dependentes.

A sub-rede 8 (Figura 4.27) representa a regra 30. Nesta, os neurônios de entrada correspondem aos disjuntores utilizados nas linhas de transmissão. Esta sub-rede não depende de nenhuma outra para que seja processada, logo sua prioridade foi inicializada com o valor -1 .

A sub-rede 9 (Figura 4.28) apresenta a modelagem da regra 31. Nesta, os neurônios de entrada representam disjuntores. Esta sub-rede não depende de nenhuma outra para que seja processada, logo sua prioridade foi inicializada com o valor -1 .

A sub-rede 10 (Figura 4.29) representa o restante das regras, no que diz respeito às premissas, suas conchusões também foram particionadas em sub-redes para tornar o processamento e o treinamento mais rápidos. Devido a dependência das demais redes 


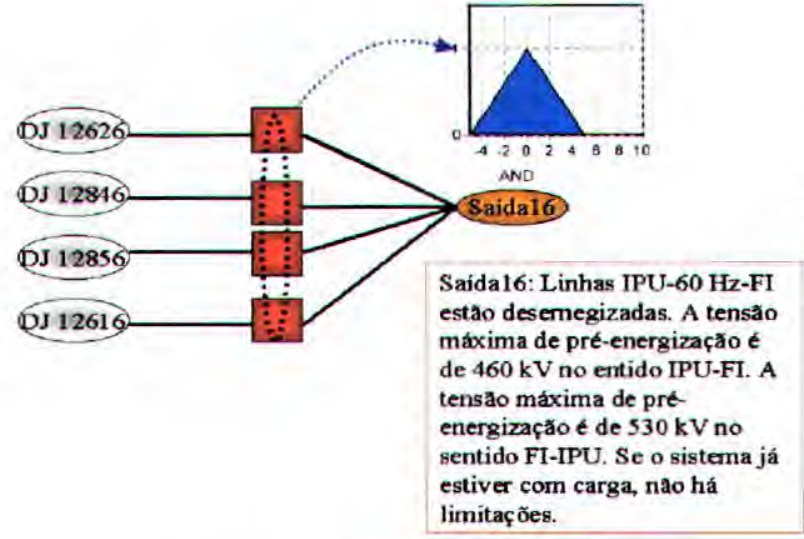

Figura 4.28: Sub-Rede 9

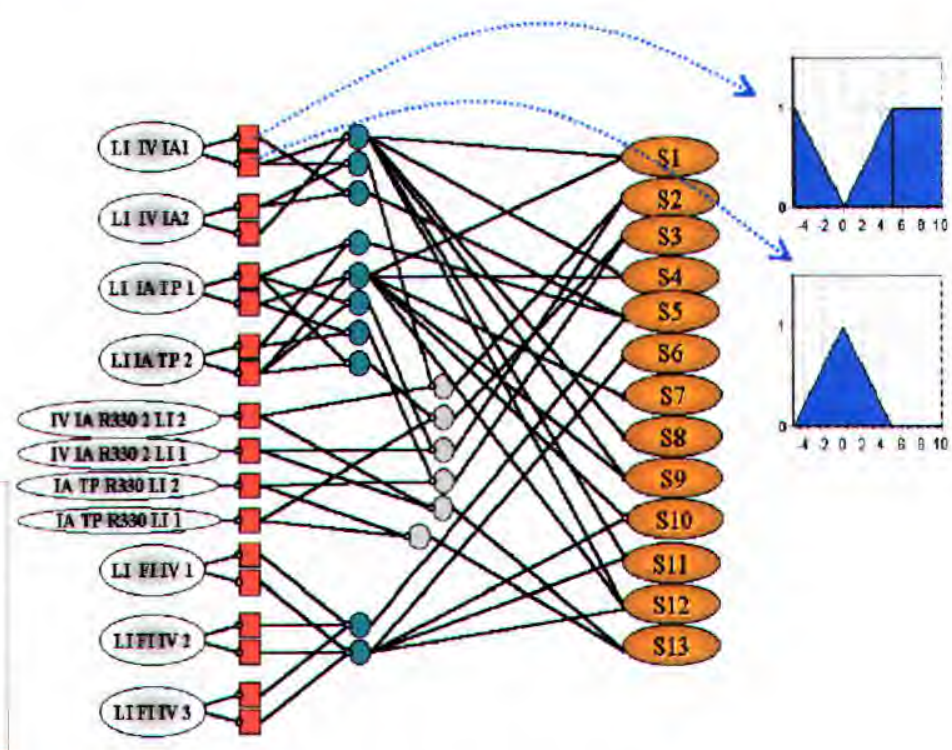

Figura 4.29: Sub-Rede 10

para com esta, foi dada a prioridade 0 (zero) para esta sub-rede.

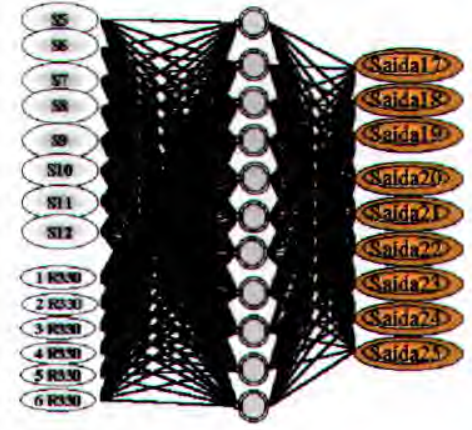

Figura 4.30: Sub-Rede 11

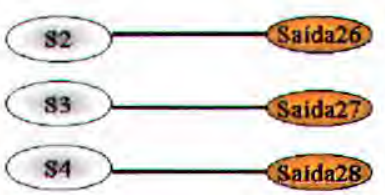

Saida26: Os reatores da barra da SE-IA (R1 e R2) devem estar ligados. Se apenas um estiver ligado, 0 limite do fluxo entre IV-IA deve ser $2400 \mathrm{MW}$.

Saida27: Devem estar ligados pelo menos 3 reatores 330 MVar em IA - de linha ou de barra. O limite de fluxo critre IV-IA deve ser $2200 \mathrm{MW}$.

Saida28: FSE deve ser $<=1900 \mathrm{MW}$. Dois reatores deverao estar ligados em barra ou em IA, podendo estar desligado até um reator de linha em IA ou TP.

Figura 4.31: Sub-Rede 12

Os primeiros 8 neurônios da sub-rede 11 (Figura 4.30) estão ligados, seqüencialmente, aos neurônios da camada de saída da sub-rede 10 que vão de 5 a 12 . Os demais neurônios representam o número de reatores desligados. Para que seja possível processar esta sub-rede deve-se antes processar a sub-rede 16, que fornece o número de reatores desligados. A prioridade desta sub-rede foi setada em 1 devido a necessidade de se utilizar dados processados pela sub-rede 16 .

A sub-rede 12 (Figura 4.31) está ligada a três neurônios (2, 3e 4 da sub-rede 10). Esta sub-rede tem como função somente fornecer a saída destes neurônios, associando-os com variáveis de saída. Da mesma forma que na sub-rede anterior, esta também depende da sub-rede 10 para ser processada, portanto sua prioridade foi fixada em 1. 


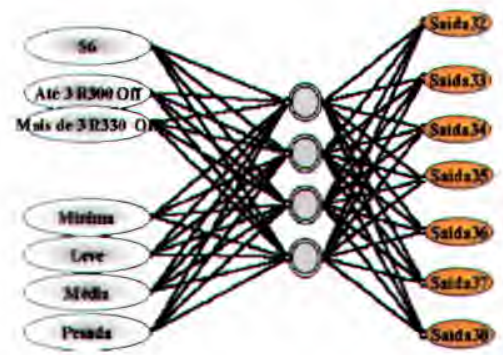

Figura 4.32: Sub-Rede 13

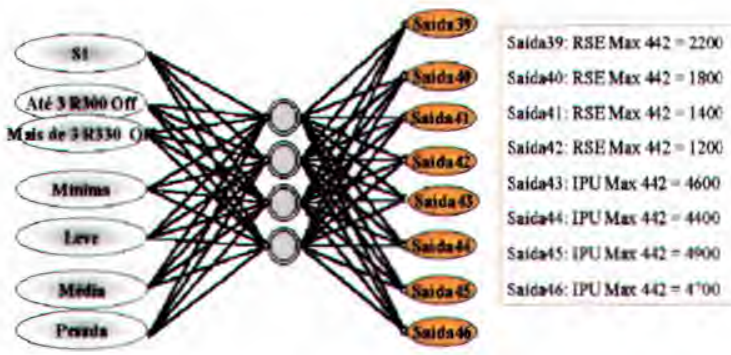

Figura 4.33: Sub-Rede 14

Na sub-rede 13 (Figura 4.32) ocorre o mesmo que nas anteriores, porém somente o sexto neurônio da sub-rede 10 é utilizado, os demais representam as seguintes informações: Número de reatores desligados (até 3 ou mais de 3), períodos de carga mínima, leve, média e pesada.

A sub-rede 14 (Figura 4.33) é semelhante a 13, exceto pelo primeiro neurônio que obtém suas informações através do primeiro da sub-rede 10.

Devido a estas dependências de informações, as prioridades destas sub-redes foram setadas em 1.

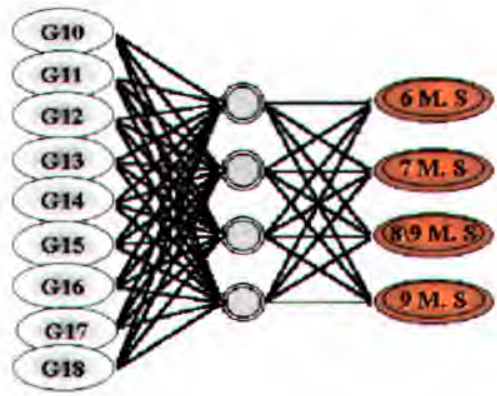

Figura 4.34: Sub-Rede 15

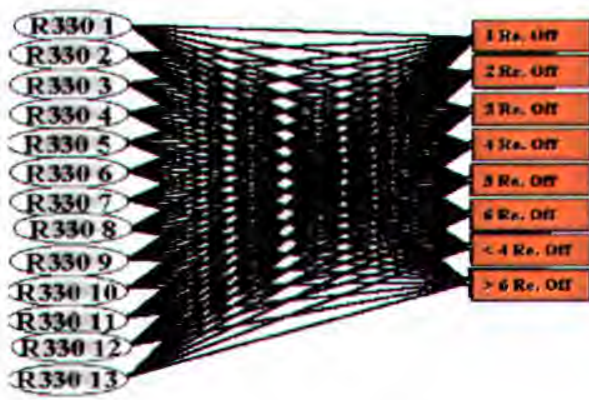

Figura 4.35: Sub-Rede 16

A sub-rede 15 representa o número de máquinas sincronizadas em ITAIPU, onde cada entrada referencia uma das máquinas do Setor de $60 \mathrm{~Hz}$. As saídas desta sub-rede são utilizadas pelas entradas de outras, portanto a prioridade desta sub-rede foi fixada em 0 ,

A sub-rede 16 indica o número de reatores de linha ou de barra que estão desligados. Cada neurônio de entrada representa um dos reatores que estão presentes no sistema de distribuição de energia que parte de Itaipu e vai até as subestações de Foz do Iguaçu, Ivaiporã, Itaberá e Tijuco Preto. Dependendo do número de reatores desligados haverá restrições na quantidade de energia despachada por Itaipu. Esta sub-rede controla o número de reatores que estão desligados, possibilitando o funcionamento de outras sub- 


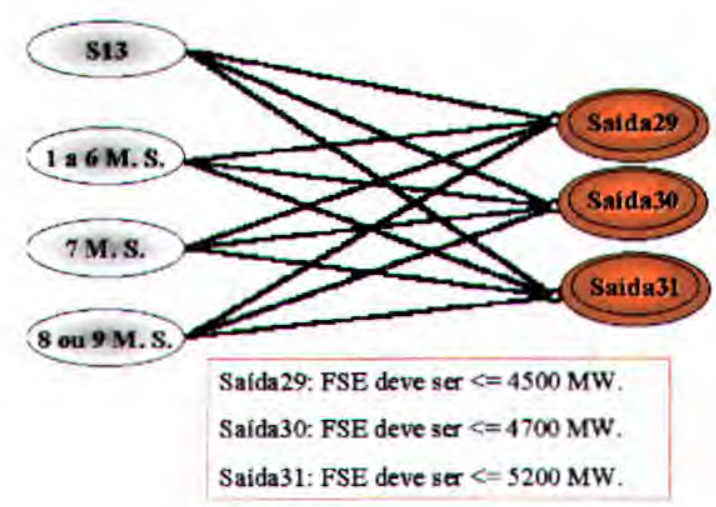

Figura 4.36: Sub-Rede 17

redes que controlam o despacho de energia de Itaipu.

Na sub-rede 17 o primeiro neurônio representa o 13 o neurônio da sub-rede 10 . Os demais neurônios estão representando o $1 \%, 2 \circ \mathrm{e} 3 \circ$ neurônios da sub-rede 15 . Esta subrede apresenta sugestões da quantidade de energia que deve ser transmitida por Itaipu, pois dependendo do número de máquinas sincronizadas em Itaipu e do número de linhas de transmissão que estão ligadas a quantidade de energia enviada para o sudeste deve ser alterada, para garantir a estabilidade do setor elétrico.

Estas foram as sub-redes consideradas necessárias para a modelagem das regras contidas no Apêndice A.

Neste capítulo não foram apresentadas as principais classes de objetos utilizadas na implementação do Simulador Neuro-Fuzzy, pois são as mesmas utilizadas no sistema NEUFI, e que são apresentadas no próximo capítulo.

\subsection{Resumo}

Neste capítulo foi apresentado o simulador desenvolvido, e como as regras do sistema especialista R-TESE foram modeladas através deste simulador. Todas as regras constituídas e suas características de modelagem também foram apresentadas.

O desenvolvimento do simulador, embora tenha consumido grande parte do tempo, facilitou a geração da Base de Conhecimento Neuro-Fuzzy construída para o presente trabalho.

O Sistema de Produção NEUFI, sistema que utiliza a base de conhecimento criada 
a partir do simulador Neuro-Fuzzy para gerar diagnósticos em tempo real, é descrito no próximo capítulo. 


\section{Capítulo 5}

\section{Sistema NEUFI}

Este capítulo apresenta o sistema de produção NEUFI, sistema de produção NEUroFuzzy para a Itaipu Binacional, voltado ao setor de geração e transmissão de energia. Este sistema processa, em tempo real, a base de conhecimento neuro-fuzzy atribuída a ele.

O Simulador Neuro-Fuzzy, apresentado no capítulo anterior, provê assistência na modelagem e no treinamento das regras numa arquitetura conexionista e fuzzy, diminuindo assim a complexidade na manutenção e no manuseio das mesmas. Além disso, ele gera a base de conhecimento final, a que contém todas as sub-redes modeladas, base esta utilizada pelo sistema NEUFI.

A arquitetura geral do sistema de produção NEUFI foi desenvolvida de modo a permitir que os próprios usuários possam modelar sua base de conhecimento conexionista. As funcionalidades e os procedimentos necessários ao funcionamento do sistema, enfatizando seus aspectos de projeto, são detalhados a seguir.

\subsection{Interfaces com os Usuários}

A interface principal do NEUFI é apresentada na Figura 5.1. Outras interfaces e a interação entre elas são apresentadas nos tópicos seguintes.

A interface principal é responsável por apresentar ao usuário os diagnósticos do sistema e permitir sua interação com ele. Nela estão disponíveis as seguintes opções:

- Rede Neural: Contém os itens de acesso às opções de carregar uma base de conhecimento, criar variáveis, relacionar variáveis, etc. 


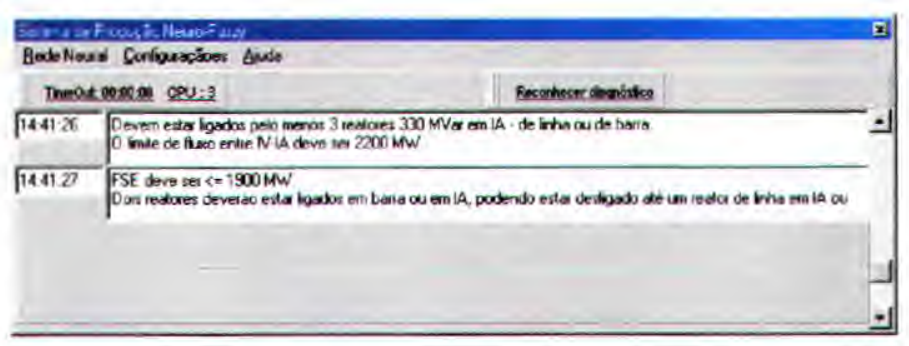

Figura 5.1: Interface Principal - NEUFI

- Ajuda: Ajuda On-line.

- Reconhecer Diagnóstico: Permite reconhecer um diagnóstico, Esta opção faz com que uma mensagem de diagnóstico deixe de ser apresentada, mas não a exclui fisicamente.

- TimeOut: Indica o intervalo de tempo decorrido desde a última leitura de dados de entrada.

- $\boldsymbol{C P U}$ : Indica o tempo de CPU utilizado para o processamento da rede neural.

- Hora: Horário em que o diagnóstico foi apresentado ao usuário.

- Descrição: Descriçâo do problema.

\subsubsection{Interface de Variáveis}

É importante atribuir uma variável a cada informação utilizada do pacote de informações, pois é ela quem disponibiliza esta informação ao neurônio de entrada correspondente.

A interface que possibilita esta associação é apresentada na Figura 5.2.

Neste formulário tem-se: ao lado esquerdo a descrição do dado de entrada; ao lado direito o nome da variável atribuída a esta informação; e na posição inferior do formulário é disponibilizado um campo para edição do nome da variável, por exemplo, o dado LT-FI-IV 2, refere-se a segunda linha de transmissão que parte de Foz do Iguaçu até a Subestação de Ivaiporã presente no pacote de dados. A este dado, uma variável chamada LI_FI_IV2 está sendo associada para representá-lo. 


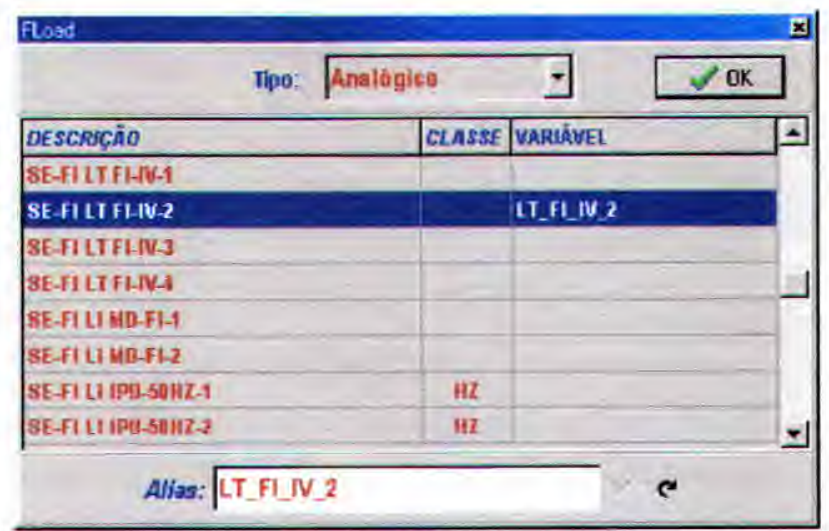

Figura 5.2: Edição de Variáveis

\subsubsection{Edição de Mensagens}

Da mesma forma que variáveis são relacionadas com dados de entrada, deve-se relacionar mensagens com variáveis que representam dados de saída. Isto facilita a compreensão das saídas emitidas pela rede, ou seja, ao invés de apresentar valores numéricos, apresenta textos descritivos.

Cada neurônio de saída que representa um diagnóstico deve ter uma variável de saída anexada e uma mensagem.

Para editar a mensagem deve-se indicar a variável de saída desejada e editar sua mensagem. Além de editar a mensagem desejada, deve-se indicar o intervalo mínimo de tempo para que a mensagem seja apresentada novamente, uma vez que ela já tenha sido apresentada. Este temporizador tem por objetivo ajudar o usuário na visualização das mensagens, pois um número de mensagens menor será apresentado.

O formulário que permite a edição de mensageus de diagnóstico é apresentado na Figura 5.3.

\subsubsection{Apresentação do Resultado}

O resultado do processo de inferência é armazenado em um pacote (tabela) de informações, além de ser apresentado na interface principal do NEUFI. Há um campo adicional na tabela que indica se aquele diagnóstico foi ou não reconhecido pelo usuário. Se reconhecido ele deixará de ser apresentado, exceto se seu neurônio for novamente ativado. A apresentação dos diagnósticos ainda não reconhecidos pode ser vista na Figura 5.4. 


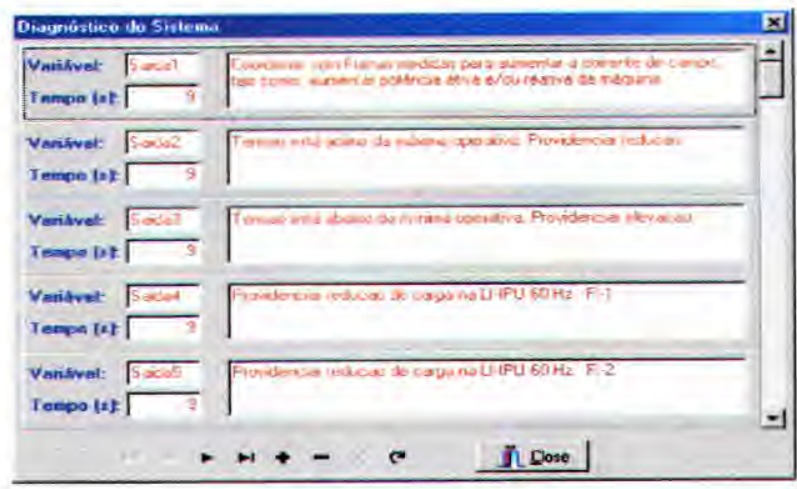

Figura 5.3: Edição de Mensagens

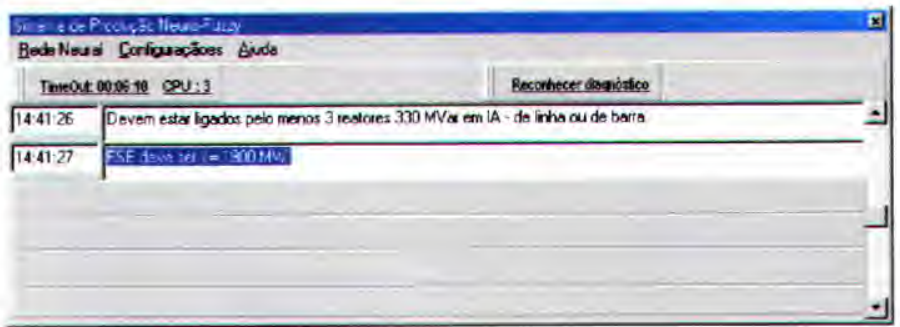

Figura 5.4: Apresentação do Resultado

A Tabela 5.1 detalha os campos presentes no pacote de informações, onde:

- Alias: Refere-se ao nome da variável;

- Temporização: Representa o intervalo de tempo de ativação da mensagem;

- Descrição: Mensagem apresentada ao usuário.

\begin{tabular}{|lll|}
\hline Nome & Formato & Tamanho \\
\hline \hline Alias & Texto & 20 caracteres \\
Temporizacao & Número & \\
Descricao & Texto & 200 caracteres. \\
\hline
\end{tabular}

Tabela 5.1: Formato do Arquivo de Mensagens

As próximas seções apresentam os detalhes de implementação inerentes ao sistema NEUFI. 


\subsection{Características de Implementação}

$\mathrm{Na}$ elaboração da base de conhecimento conexionista e fuzzy, o usuário preocupa-se somente com a modelagem das regras e com a definição das variáveis de entrada, de ligação e de saída. O próprio simulador então armazena as regras no formato requerido pelo NEUFI.

Parte-se então para o Sistema NEUFI, onde outras configurações são necessárias, tais como: associar os dados de entrada com variáveis de entrada e atribuir mensagens de diagnóstico às variáveis de saída.

Nesta seção as características de implementação do sistema NEUFI são ilustradas. O diagrama de execução principal é apresentado na Figura 5.5, onde cada módulo tem a seguinte função:

- Inicializar: Processo responsável por criar as listas de variáveis e de diagnóstico, relacionando-as com os respectivos neurônios, por carregar a base de conhecimento para sua memória, e por ativar as threads, que darão inicio ao processamento das informações.

- Mensagens de Diagnóstico: Banco de dados que contém as mensagens de diagnóstico associadas às variáveis de saída;

- Variáveis: Banco de dados que contém as variáveis de entrada, de saída e de ligação utilizadas pelo NEUFI.

- Executar (Ler Pacote - Executar a rede - Apresentar o Diagnóstico): Consiste no coração do sistema, onde novos dados são lidos, executados e o resultado é apresentado. Este processo é representado pela thread ThExecute.

- Montar Lista: Processo representado pela thread ThListaEspera, responsável por colocar em uma lista de espera os novos pacotes de dados.

- SSO: sistema que, a cada três segundos, envia pacotes de dados para serem processados;

- Pacotes de Dados: Contém as novas informações a serem processadas;

- Simulador Neuro-Fuzzy: Permite a criação e o treinamento de redes neuro-fuzzy;

- Base de Conhecimento Neuro-Fuzzy: contém o conhecimento do sistema; 


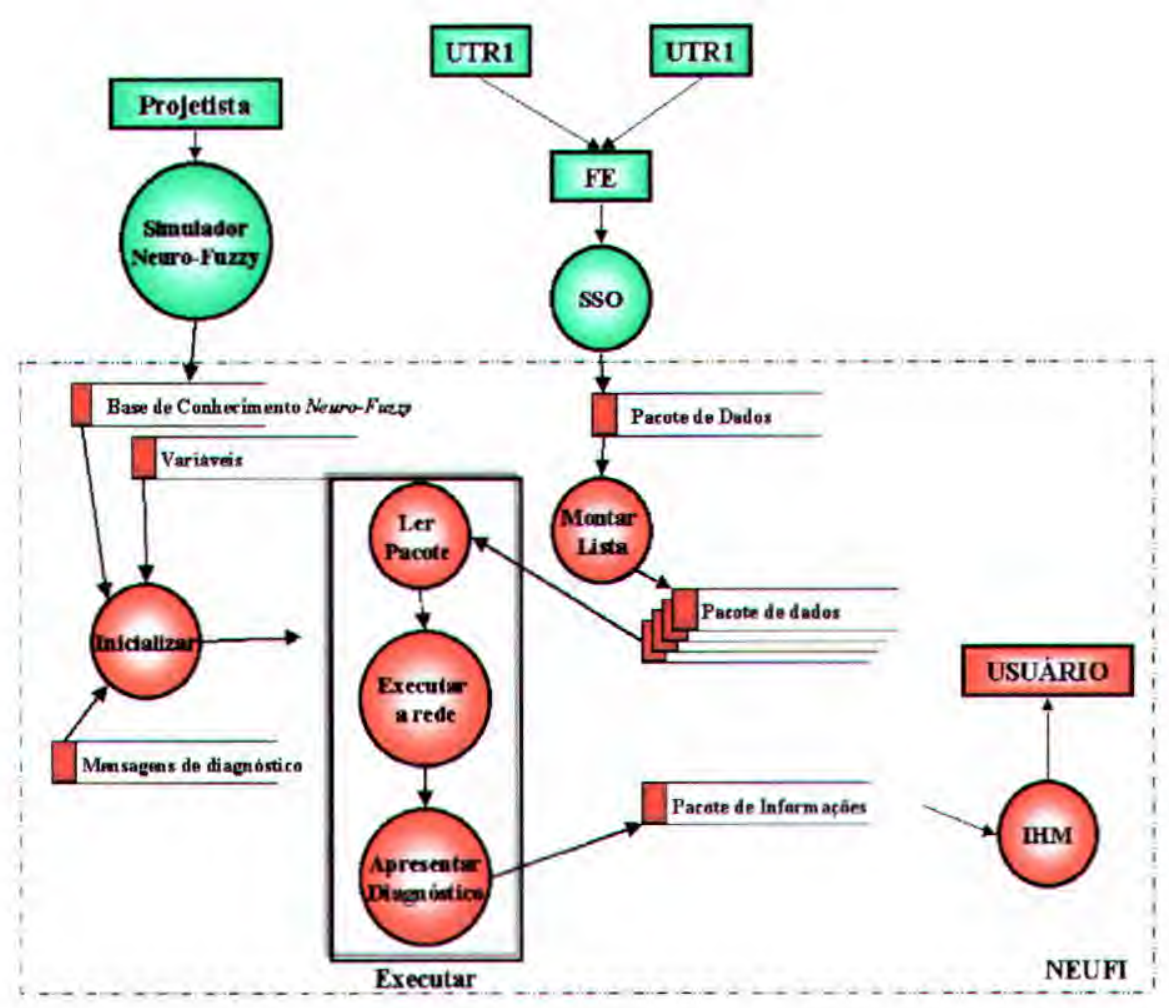

Figura 5.5: Diagrama de Execução

- Pacotes de Informações: Conclusões que foram obtidas através do processo de inferência aplicado na rede.

Quando iniciado, o NEUFI gera uma lista com as variáveis de entrada previstas, a seguir carrega a base de conhecimento neuro-fuzzy para sua memória. Em paralelo, as variáveis de ligação e de saída presentes na base de conhecimento são também criadas e adicionadas à lista de variáveis. Uma lista adicional (Saída) relacionada às mensagens de diagnóstico do sistema é criada e cada elemento desta lista é associado à sua variável de saída correspondente.

Com isso o NEUFI está pronto para iniciar seu processo de diagnóstico, que consiste na repetição exaustiva de ler os novos dados disponibilizados, processar a rede com esses dados e gerar o novo diagnóstico. Para que isso seja possível há duas threads sendo executadas em paralelo: ThListaEspera e ThExecute, descritas mais tarde neste capítulo.

A thread ThListaEspera armazena o pacote que é disponibilizado pelo SSO, a cada 3 segundos, em uma lista de espera. Esta lista contém a seqüência dos pacotes a serem inferidos pelo sistema, processo Montar Lista (Figura 5.5). 
A thread ThExecute fica constantemente retirando pacotes da lista de espera e disponibilizando seus dados ao sistema, para que possam ser processados (Figura 5.5, processo Executar).

A memória para a qual os novos dados são lidos é compartilhada com as variáveis de entrada. Isso significa que os dados lidos automaticamente atualizam estas variáveis.

Cada neurônio da camada de entrada tem uma variável designada a ele, e durante o processo de inferência sobre a rede é nessa variável que ele buscará seu valor de entrada. Os neurônios da camada de saída também têm variáveis correspondentes, onde os valores de saída do neurônio são armazenados. Assim, se houver uma dependência dos neurônios de entrada para com os de saída, a variável associada ao de entrada deverá ter o mesmo nome da variável de saída.

Ao término do processamento da rede, deve-se apresentar o diagnóstico do sistema. Como as saídas dos neurônios não são auto-explicativas, valores entre 0 e 1 , deve-se percorrer a lista adicional (Saída) que contém as mensagens correspondentes ao neurônio, verificando quais elementos desta lista estão relacionados aos neurônios que foram ativados e armazenando as mensagens num pacote de informações.

Todo esse processo é referente a um ciclo de execução, devendo terminar antes de três segundos, pois novos dados estarão sendo disponibilizados para processamento.

A seguir as principais classes de objetos implementadas no Sistema NEUFI são apresentadas e suas características descritas. Vale ressaltar que as declarações aqui expostas são particulares à linguagem de programação utilizada, que neste caso é a linguagem de programação Delphi 5.0.

Antes de apresentar as características das classes implementadas, são explicadas algumas particularidades inerentes as declarações de objetos da linguagem de desenvolvimento utilizada. São elas:

- private: um membro privado é invisível fora da biblioteca ou programa no qual a classe está sendo declarada, mesmo para suas classes descendentes;

- protected: um membro protegido é visível em qualquer módulo em que sua classe é declarada e por qualquer classe descendente, qualquer que seja o lugar de utilização;

- public: um membro público é visível onde quer que seja usado;

- published: membros publicados têm a mesma visibilidade que os membros públicos, sendo que uma das diferenças é que as declarações feitas nesta parte do código serão 


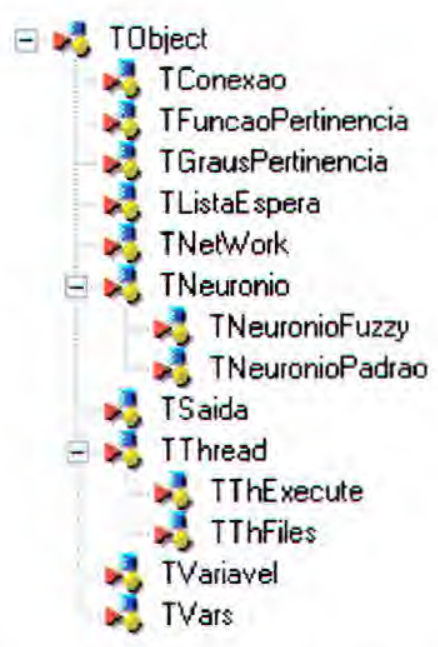

Figura 5.6: Árvore de Objetos.

exibidas no Object Inspector;

- virtual, dynamic e override: métodos virtuais e dinâmicos são semanticamente equivalentes. A única diferença é que métodos virtuais otimizam a velocidade, enquanto que os dinâmicos otimizam o tamanho do código. Ambos são utilizados para possibilitar polimorfismo.

Numa família de objetos que deve possuir polimorfismo, a classe base deverá ser declarada como virtual ou dynamic, já as descendentes deverão ser declaradas como override.

- abstract: um método abstrato é um método virtual ou dinâmico que não tem implementação na classe onde está sendo declarado. Sua implementação é feita nas classes descendentes.

A Figura 5.6 apresenta a árvore de objetos utilizada pelo NEUFI.

A seguir cada uma destas classes são apresentadas.

\subsubsection{TNeuronioBinario}

O neurônio binário (Tabela 5.2) é a classe base de todos os neurônios, devido às suas características intrínsecas de não possuir função de treinamento, os pesos de suas conexões 


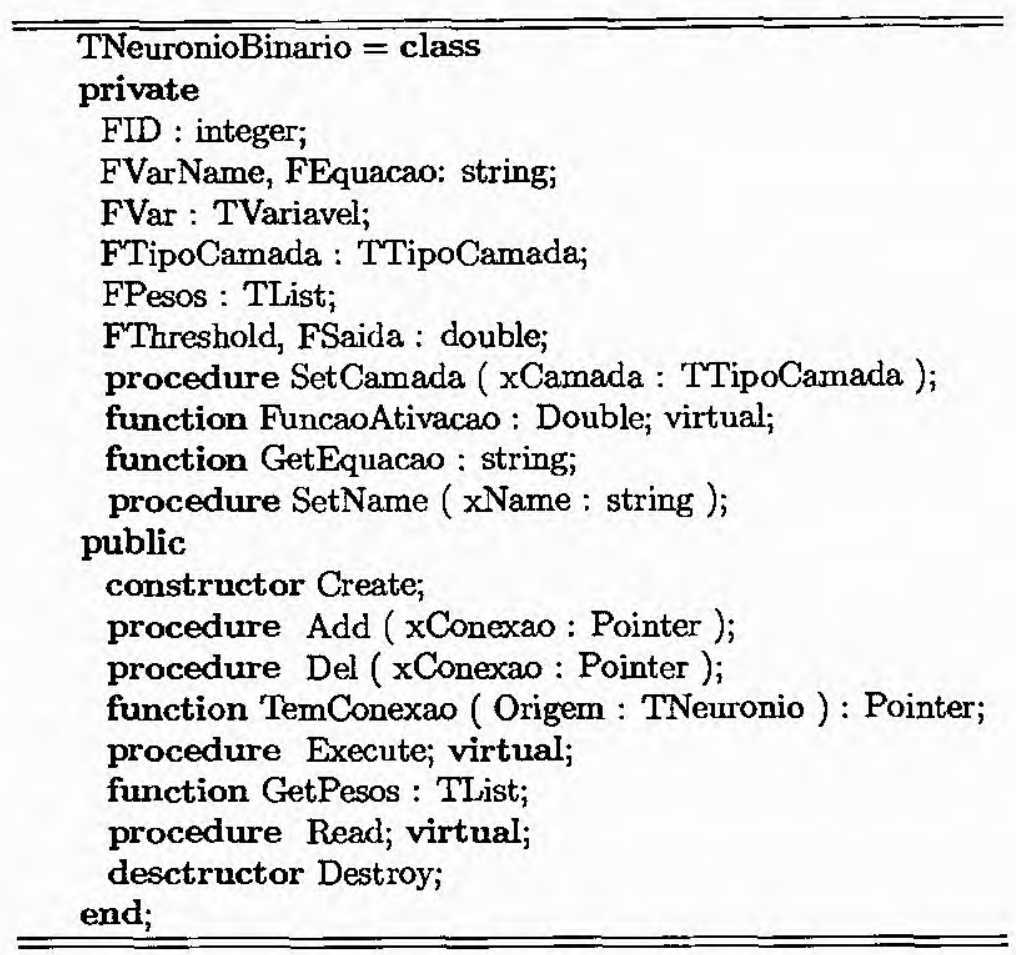

Tabela 5.2: Classe TNeuronioBinario

e seus thresholds serem inseridos diretamente em sua estrutura durante a modelagem, entre outros.

As propriedades deste neurônio são:

- FID: identificador do neurônio, não há identificadores iguais, portanto estes são chaves para o neurônio.

- FVarName e FVar: contém o nome da variável que representa o neurônio. Este nome é utilizado, durante a criação do neurônio, para procurar na lista de variáveis o endereço da respectiva variável, o qual será armazenado na propriedade FVar do neurônio.

- FEquacao: Propriedade na qual é armazenado o valor de entrada do neurônio. Esta propriedade é utilizada somente pelos neurônios que fazem parte da camada de entrada da sub-rede.

- FCamada: Propriedade que indica a camada na qual o neurônio está inserido.

- FPesos: Esta propriedade é representada por uma lista de classes TConexao (Tabela 5.7). Esta lista gerencia todas as conexões que incidem sobre o neurônio.

- FThrehold: Valor de ativação do neurônio. 
- FSaida: Valor de saída do neurônio. É o endereço desta propriedade que as variáveis de Ligação e de Saída compartilham para obterem seus valores.

Os principais métodos deste neurônio são:

- SetCamada: Insere o neurônio na camada indicada, removendo-o da antiga. Suas conexões permanecem inalteradas.

- FuncaoAtivacao: Aplica ao neurônio a função de ativação codificada nesta função. Nesta classe a função de ativação é bem simples, representada pela expressão :

$$
a=w_{1} X_{1}+w_{2} X_{2}+\ldots+w_{p} X_{p}
$$

- GetEquacao: Indica qual valor está armazenado na propriedade FEquacao.

- SetName: Associa um nome de variável ao neurônio.

- Create: Cria uma nova instância para o neurônio.

- Add: Adiciona uma conexão ao neurônio.

- Del: Exclui uma conexão do neurônio.

- TemConexao: Indica se há uma conexão entre dois neurônios.

- Execute: Realiza a inferência sobre o neurônio. Para isso, obtêm-se os dados de entrada e aplica-se a função de ativação referente ao neurônio, se o resultado for maior que o threshold então a saída do neurônio será 1, caso contrário 0 (zero).

- GetPesos: Obtém a lista de conexões incidentes ao neurônio.

- Read: Lê o neurônio da base de conhecimento.

- Destroy: Libera a memória ocupada pelo neurônio, eliminando sua instância.

O método FuncaoAtivacao é virtual, pois para cada classe de neurônios pode haver funções de ativação diferentes. 


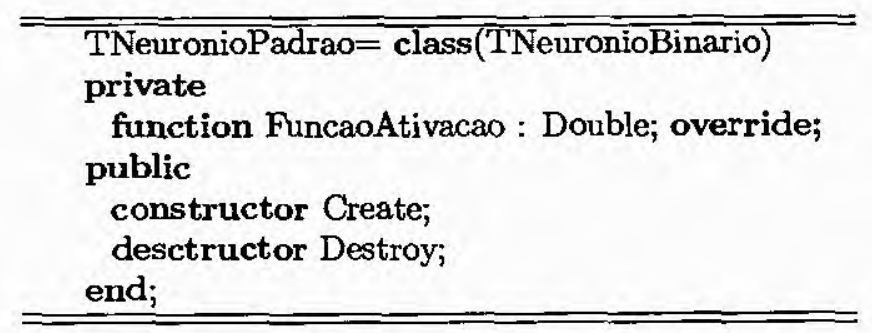

Tabela 5.3: Classe das Variáveis

\subsubsection{TNeuronioPadrao}

O Neurônio Padrão ou Perceptron (Tabela 5.3) herda todos os atributos e métodos do neurônio binário, sobrescrevendo alguns métodos.

O métodos FuncaoAtivacao, Create e Destroy são implementados novamente por apresentarem características intrínsecas à classe. Por exemplo, a função de ativação deste neurônio é representada por uma equação diferente daquela utilizada pelo neurônio binário.

\subsubsection{TNeuronioFuzzy}

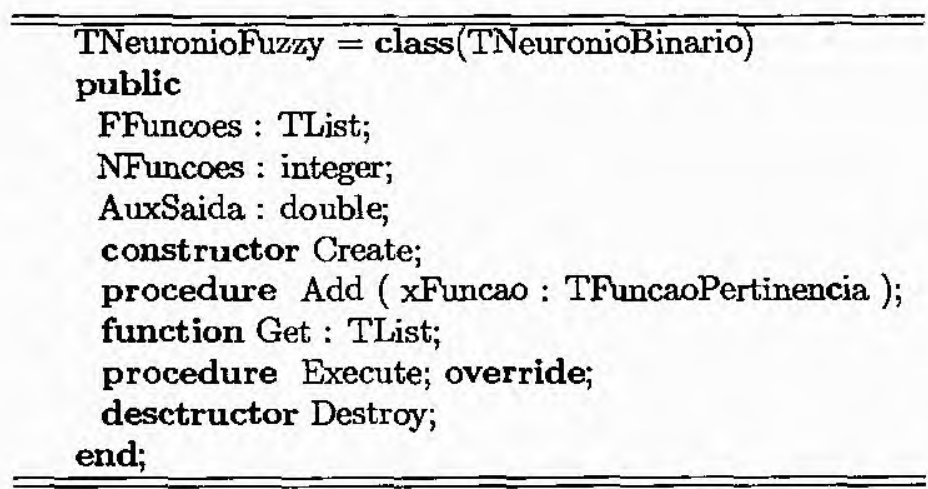

Tabela 5.4: Classe TNeuronioFuzzy

Um Neurônio Fuzzy (Tabela 5.4) é formado por um número considerável de informações, quando comparados ao neurônio binário. Cada uma destas informações são aqui descritas.

Propriedades do Neurônio Fuzzy (Tabela 5.4):

- F Funcoes: Esta propriedade é representada por uma lista dinâmica de objetos, onde cada elemento da lista é representado por uma instância da classe T FuncaoPertinencia (Tabela 5.5). 
- NFuncoes: Indica o número de funções já adicionadas à lista FFuncoes. Esta propriedade somente é utilizada durante a geração, em memória, da base de conhecimento.

- AuxSaida: Local de armazenamento temporário do valor de saída do neurônio.

Este neurônio herda também todas as propriedades do Neurônio Binário.

Os métodos implementados nesta classe de neurônio são os seguintes:

- Create: Cria uma nova instância para o Neurônio Fuzzy.

- Add: Adiciona uma nova função de pertinência para o neurônio.

- Get: Retorna as funções de pertinência atribuídas ao neurônio.

- Execute: Efetua o processo de inferência sobre o neurônio, consistindo do seguinte: obter o valor de entrada do neurônio, aplicar este valor a todas as funções de pertinência. O resultado de cada função é somado e se esta soma for superior ao threshold então o neurônio é ativado.

- Destroy: Elimina a instância atual do neurônio.

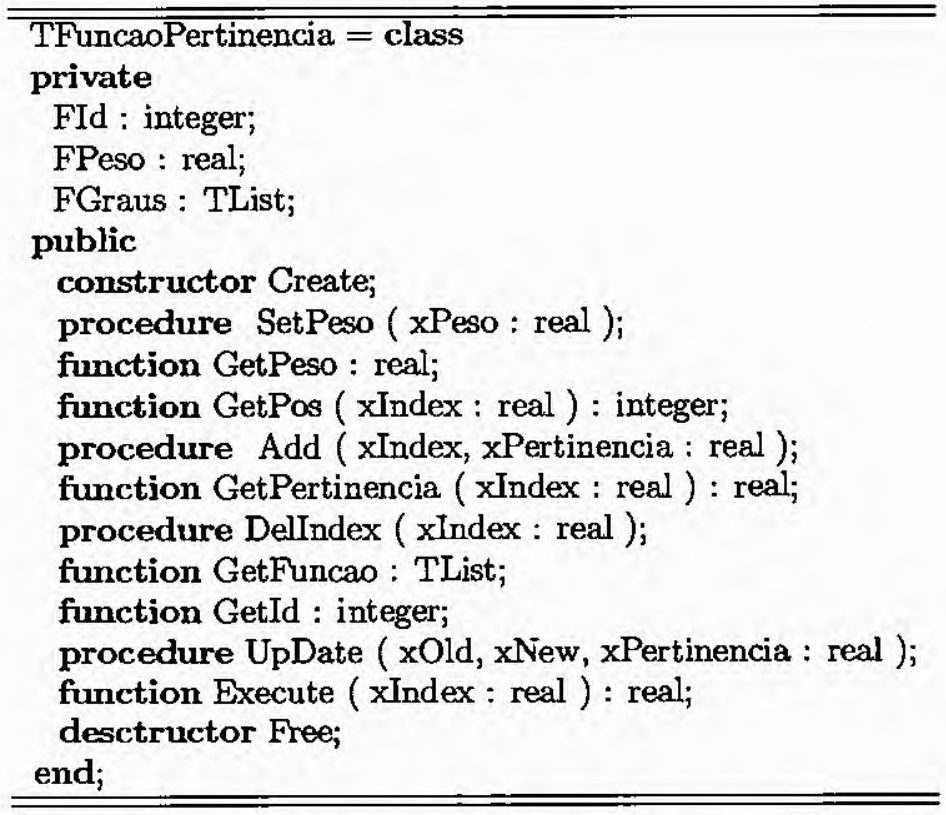

Tabela 5.5: Classe TFuncaoPertinencia

As propriedades de uma Função de Pertinência (Tabela 5.5) são apresentadas a seguir: 
- FID: Da mesma forma que cada neurônio tem um identificador único que o referencia, as funções de pertinência também os tem. Cada função de pertinência referente a um neurônio tem um identificador único.

- FPeso: Indica qual o peso $(\omega)$ associado à função.

- FGraus: Contém uma lista de todos os graus de pertinência que resultam na função de pertinência. Cada elemento desta lista é representado pela classe TGrausPertinencia (Tabela 5.6).

Abaixo são listados os métodos de uma Função de Pertinência:

- Create: Cria uma nova instância de uma classe TFuncaoPertinencia.

- SetPeso: Atribui um peso à propriedade FPeso.

- GetPeso: Indica qual o peso atual da função.

- GetPos: Obtém a posição de inserção de determinado índice.

- Add: Adiciona um novo grau de pertinência a função.

- GetPertinencia: Indica qual grau de pertinência representa um determinado índice.

- DelIndex: Elimina um grau de pertinência da função.

- GetGraus: Retorna a lista de graus de pertinência da função.

- GetId: Retorna o identificador da função.

- UpDate: Atualiza um grau de pertinência, alterando o valor do grau;

- Execute: Realiza o processo de inferência sobre as funções, retornando o resultado deste processamento.

- Free: Libera toda a memória utilizada pelas funções de pertinência.

A seguir as propriedades da classe TGrausPertinencia (Tabela 5.6) são apresentadas:

- Index: Índice do grau.

- Value: Grau representado pelo índice. Ou seja, no índice $x$ o grau é $y$. 


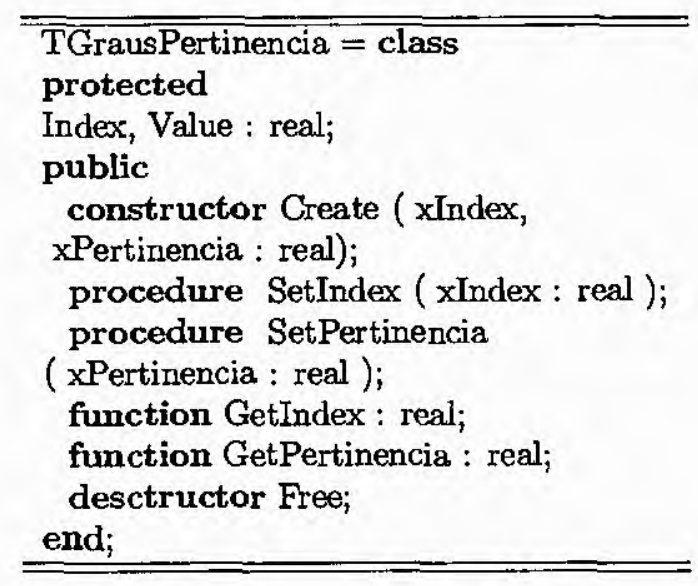

Tabela 5.6: Classe TGrausPertinencia

Métodos da classe TGrausPertinencia:

- Create: Cria uma nova instância para a classe TGrausPertinencia.

- SetIndex: Atribui um índice para o grau.

- SetPertinencia: Atribui um grau para a classe.

- GetIndex: Indica qual o valor do índice da classe.

- GerPertinencia : Indica qual o grau de pertinência da classe.

- Free: Libera a classe, eliminando sua instância.

\subsubsection{TConexao}

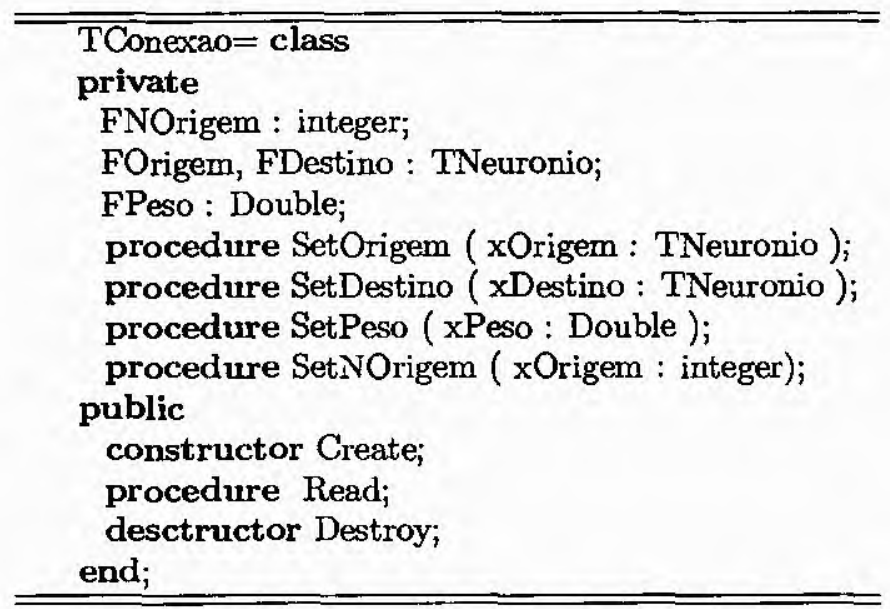

Tabela 5.7: Classe TConexao 
Cada neurônio possui uma lista de conexões, cada elemento desta lista é representado por uma classe TConexao (Tabela 5.7) .

Propriedades da classe TConexao:

- FNOrigem: Identifica o neurônio origem de uma conexão, ou seja, refere-se ao identificador do neurônio no qual parte a conexão atual. Este identificador é somente utilizado durante a criação da base de conhecimento para a memória.

- FOrigem: Indica o neurônio de origem da conexão. Ou seja, o neurônio do qual parte uma conexão para outro.

- FDestino: Indica qual é o neurônio de incidência da conexão. É na lista FPesos do neurônio de destino que a instância da conexão será inserida.

- FPeso: Indica qual é o peso da conexão. Dependendo do tipo de neurônio do qual a conexão faz parte, este peso é atualizado automaticamente por uma função de treinamento. Por exemplo, pela função backpropagation.

Métodos da classe TConexao:

- SetOrigem: Permite atualizar o neurônio de origem da conexão.

- SetDestino: Atualizar o neurônio de destino da conexão.

- SetPeso: Permite atualizar o peso da conexão.

- SetNOrigem: Permite alterar o identificador do neurônio de origem.

- Create: Cria uma nova instância de conexão.

- Read: Lê uma conexão da base de conhecimento.

- Destroy: Elimina uma instância de conexão da memória.

\subsubsection{TSubNet}

Cada sub-rede contida no projeto é armazenada numa classe TSubNet (Tabela 5.8), a qual gerencia a sub-rede contida em sua estrutura.

Propriedades da classe TSubNet: 


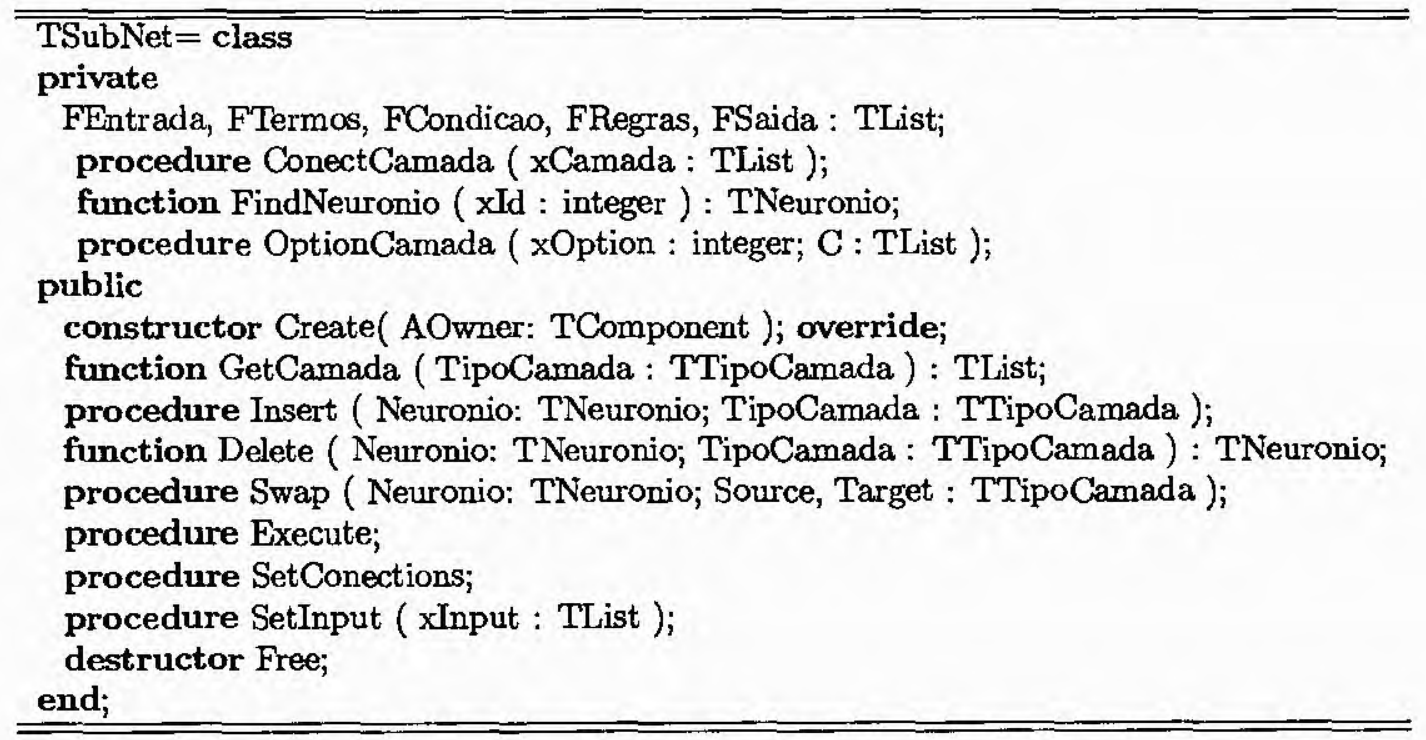

Tabela 5.8: Classe TSubNet

- FEntrada, FTermos, FCondicao, FRegras, FSaida: Cada uma destas propriedades representam listas (máximo 5), restringindo a rede a 5 camadas. Cada elemento da lista é representado por um neurônio.

Métodos da classe TSubNet:

- ConectCamada: Cria uma conexão entre dois neurônios, este neurônios podem pertencer a camadas diferentes ou a mesma camada.

- FindNeuronio: Retorna o endereço de memória de um neurônio, se o mesmo se encontrar na rede.

- Option Camada: Inicializa uma rede neural com valores aleatórios ou fixos, de acordo com as características dos neurônios que estão inseridos na rede.

- Create: Cria uma nova instância de rede neural.

- GetCamada: Retorna a lista representativa de uma determinada camada.

- Insert: Insere um novo neurônio na camada indicada.

- Delete: Exclui um neurônio da camada indicada, retornando o mesmo.

- Swap: Troca um neurônio de camada.

- Execute: Processa a rede neural. 
- SetConections: Estabelece as conexões entre os neurônios. Somente é executado durante o carregamento da base de conhecimento.

- SetInput: Atribui um determinado conjunto de dados aos neurônios que compõem a camada de entrada da sub-rede.

- Free: Libera a rede neural.

\subsubsection{TNetWork}

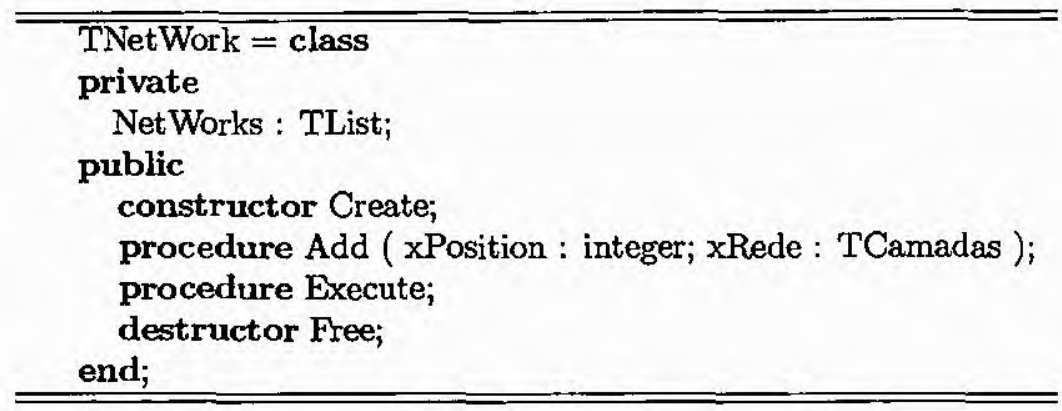

Tabela 5.9: Classe TNetWork

A classe TNetWork (Tabela 5.9) contém todas as sub-redes da base de conhecimento neuro-fuzzy. Este objeto controla as prioridades das redes, executando cada uma delas de acordo com a prioridade atribuída durante o projeto da rede.

Propriedades da classe TNetWork.

- NetWords: Esta propriedade é composta por uma lista principal que gerencia outras listas secundárias. A lista secundária gerenciada por ela contém as sub-redes com prioridade -1 , a segunda contém as sub-redes com prioridade 0 e assim sucessivamente.

Métodos da classe TNetWork:

- Create: Cria uma nova instância da classe. O sistema NEUFI possui somente uma instância desta classe, a qual representa todo o conjunto de regras armazenados na base de conhecimento neuro-fuzzy.

- Add: Adiciona uma nova classe TSubRede, na posição indicada, criando assim níveis de prioridades. 
- Execute: Percorre cada sub-rede inserida nesta classe ativando o método execute de cada uma destas sub-redes.

- Free: Libera toda a memória utilizada pela classe.

\subsubsection{TVariavel}

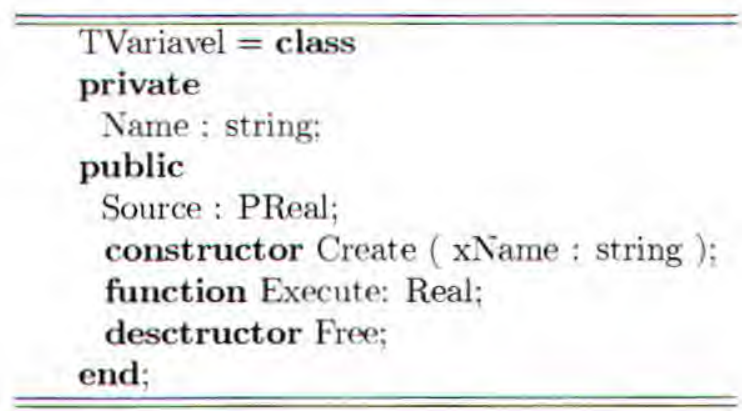

Tabela 5.10: Classe das Variáveis

Na Tabela 5.10 é apresentada a descrição da classe TVariavel.

Cada variável criada tem um Nome único que a referencia e todas são armazenadas em uma lista de variáveis, responsável pelo gerenciamento das mesmas. O método Create apenas cria uma nova variável com o nome passado como parâmetro. O método Execute retorna o valor que está armazenado no endereço que a propriedade Source referencia. Se nāo houver endereço associado o valor 0 (zero) é retornado. O método Free apenas libera a memória utilizada pela variável que está sendo destruída.

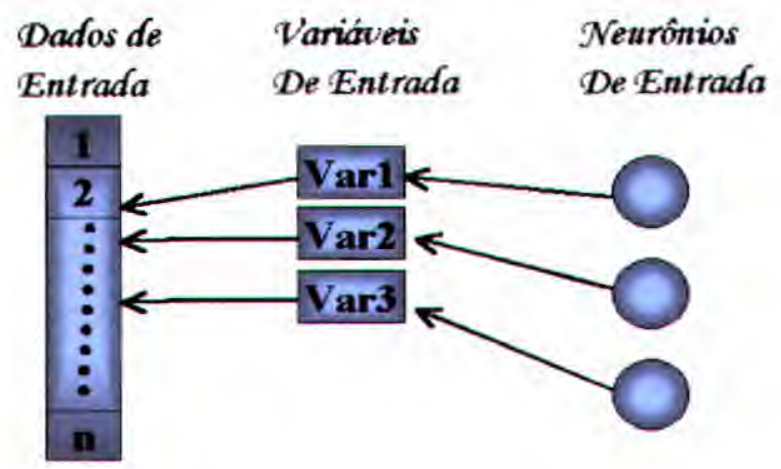

Figura 5.7: Variáveis de Entrada

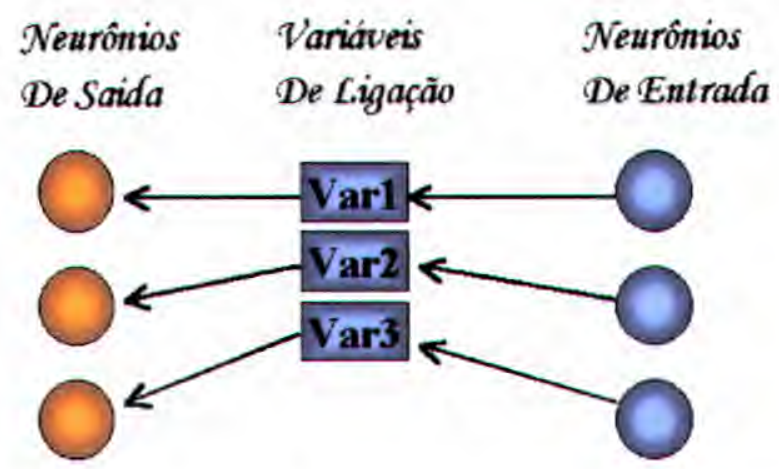

Figura 5.8: Variáveis de Ligação

Apesar das variáveis terem todas as mesmas características elas podem ser divididas em três categorias distintas:

- Variáveis de entrada: Neste tipo de variável a Propriedade Source da variável contém o endereço do dado de entrada correspondente. Quando um novo dado é 


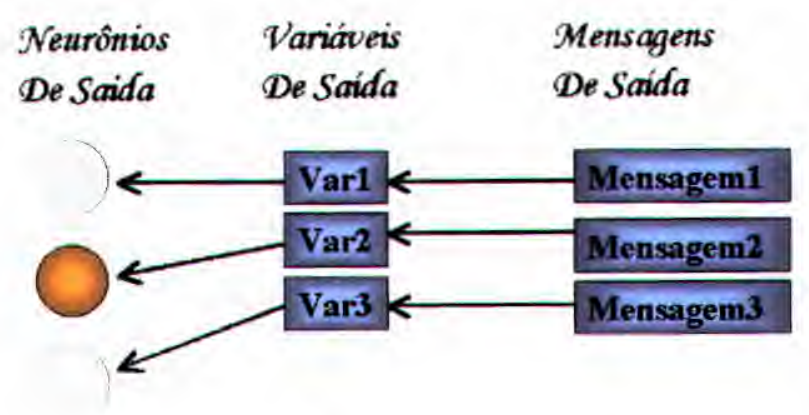

Figura 5.9: Variáveis de Saída

obtido o valor desta variável automaticamente é alterado, pois eles compartilham o mesmo endereço. A Figura 5.7 apresenta como isso é feito. O neurônio da camada de entrada contém o endereço da variável correspondente a ele, que contém o endereço do valor de entrada;

- Variáveis de Ligação: Aqui a Propriedade Source da variável contém o endereço da saída do neurônio na qual ela busca informações. Quando o neurônio de saída for processado ele armazenará seu resultado neste endereço, já atualizando a variável. A Figura 5.8 apresenta como isso é feito. O neurônio da camada de entrada contém o endereço da variável correspondente a ele, que contém o endereço da saída do neurônio da camada de saída da outra sub-rede;

- Variáveis de Saída: A Propriedade Source da variável (Tabela 5.9) contém o endereço da saída do neurônio na qual ela busca informaçôes. Está variável é utilizada pela lista que contém as mensagens de diagnóstico do sistema. Esta lista contém índice para todas as variáveis de saída necessárias para o diagnóstico, isto é, a lista de mensagens referenciam variáveis que, por sua vez, referenciam neurônios.

\subsubsection{TSaida}

Esta classe de objetos é responsável por apresentar mensagens textuais ao usuário, não somente números. Para isso, no projeto da rede, a cada neurônio da camada de saída é associado um nome de variável e uma mensagem, que corresponderá ao diagnóstico do respectivo neurônio, se o mesmo for ativado. A classe TSaida simplesmente monta uma lista com estas mensagens.

As características do registro TInformacao (Tabela 5.11) são as seguintes: 


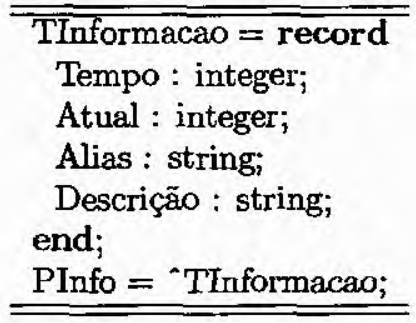

Tabela 5.11: Registro TInformacao

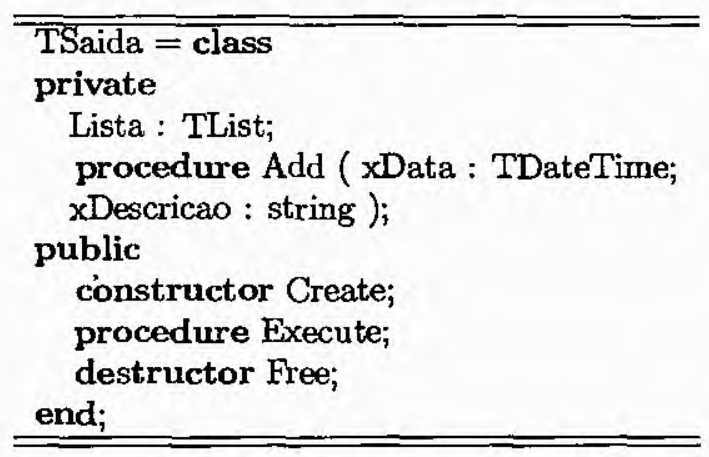

Tabela 5.12: Classe TSaida

- Tempo: Para que não ocorra uma avalanche de informações, no caso do mesmo neurônio ser ativado diversas vezes consecutivas, foi criado esta variável que indica o tempo mínimo de espera para se mostrar novamente uma descrição.

- Atual: Está variável controla o intervalo de tempo decorrido desde a última ativação do neurônio. Quando o neurônio correspondente deixa de ser ativado, esta variável é setada para zero. Toda vez que ele é ativado, ela é acrescida de 1. Se ela alcança o valor contido na variável Tempo, a descrição é apresentada e é também atribuído o valor zero a está variável.

- Alias: Contém o nome da variável que deverá ser verificada para determinar se a mensagem deve ou não ser apresentada.

- Descricao: Descrição (diagnóstico) apresentada se o neurônio for ativado.

Propriedades da classe TSaida (Tabela 5.12):

- Lista: Esta propriedade representa uma lista, onde cada item dela é composto por um registro TInformacao.

Métodos da classe TSaida:

- Add: Este método adiciona um novo registro à lista.

- Create: Cria uma nova instância da classe TSaida.

- Execute: Executa a lista, ou seja, percorre elemento por elemento da lista verificando quais tiveram suas saídas ativadas.

- Free: Libera a lista de registros. 


\subsubsection{TThFiles}

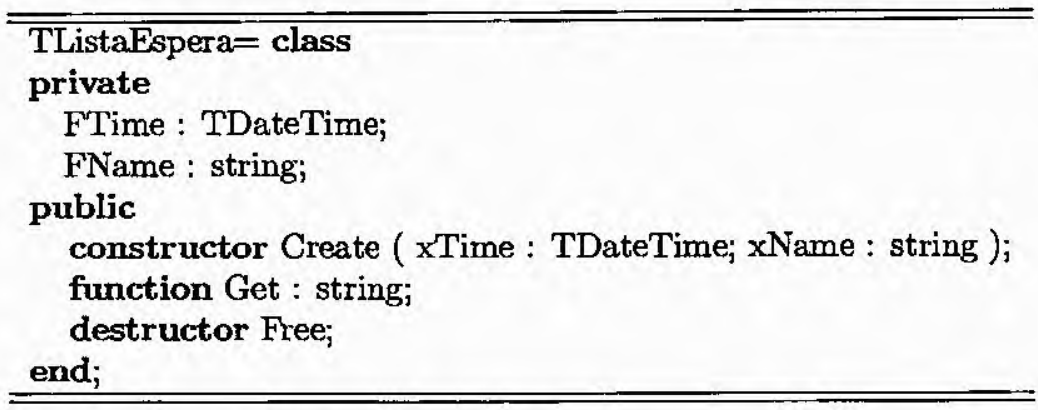

Tabela 5.13: Classe TListaEspera

A classe T ListaEspera (Tabela 5.13) contém as informações referente a um pacote a ser processado.

Propriedades da classe TListaEspera:

- FTime: Horário em que a informação foi inserida na lista.

- FName: Nome do arquivo que contém a informação.

Métodos da classe TListaEspera:

- Create: Cria uma nova instância da classe TListaEspera, de acordo com os parâmetros indicados.

- Get: Retorna as informações da classe referenciada.

- Free: Libera a classe.

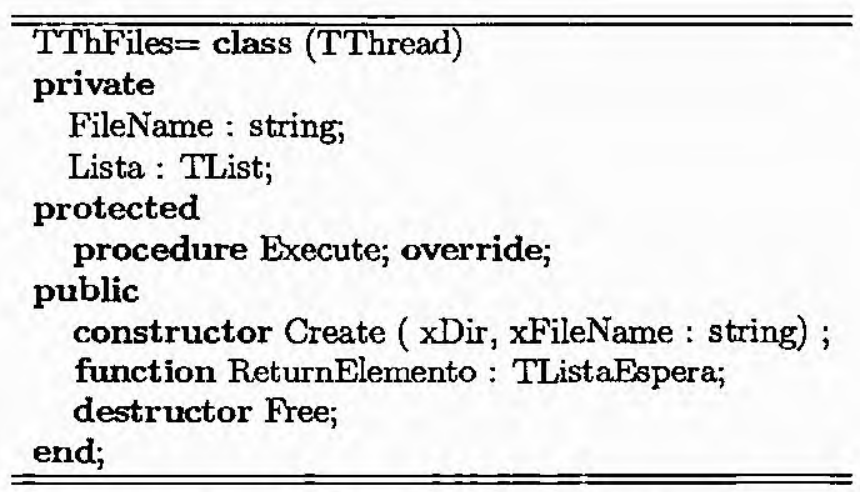

Tabela 5.14: Classe TThFiles 
A classe TThFiles (Tabela 5.14) é a thread responsável pela constante verificação da chegada de informações a serem processadas. Quando uma nova informação chega (na forma de arquivos), a mesma é inserida na lista de espera.

Propriedades da classe TThFiles:

- FileName: Nome do arquivo que contém as novas informações para processamento.

- Lista : Lista de objetos TListaEspera. Normalmente esta lista estará vazia ou contendo um elemento. Quando houver mais elementos na lista significa que o tempo de processamento da rede está sendo muito grande e que muitos dados de processamento estão ficando pendentes.

Métodos da classe TThFiles:

- Execute: Este método fica constantemente verificando a existência do arquivo FileName. Se este arquivo existir ele é renomeado, e um objeto TListaEpera é criado para comportar este arquivo, e ele é armazenado na propriedade Lista.

- Create: Cria a thread TThFiles.

- ReturnElemento: Retorna o primeiro elemento da Lista, para que o mesmo possa ser processado pela thread TTHExecute.

- Free: Destrói a thread.

\subsubsection{TThExecute}

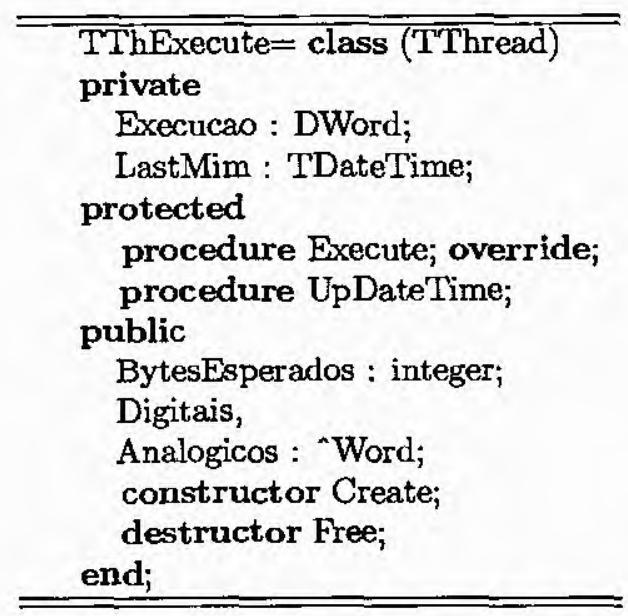

Tabela 5.15: Classe TThExecute 
Esta thread (Tabela 5.15) é responsável pelo funcionamento do sistema, determinando a ordem de execução das operações. Seu código principal é apresentado a seguir:

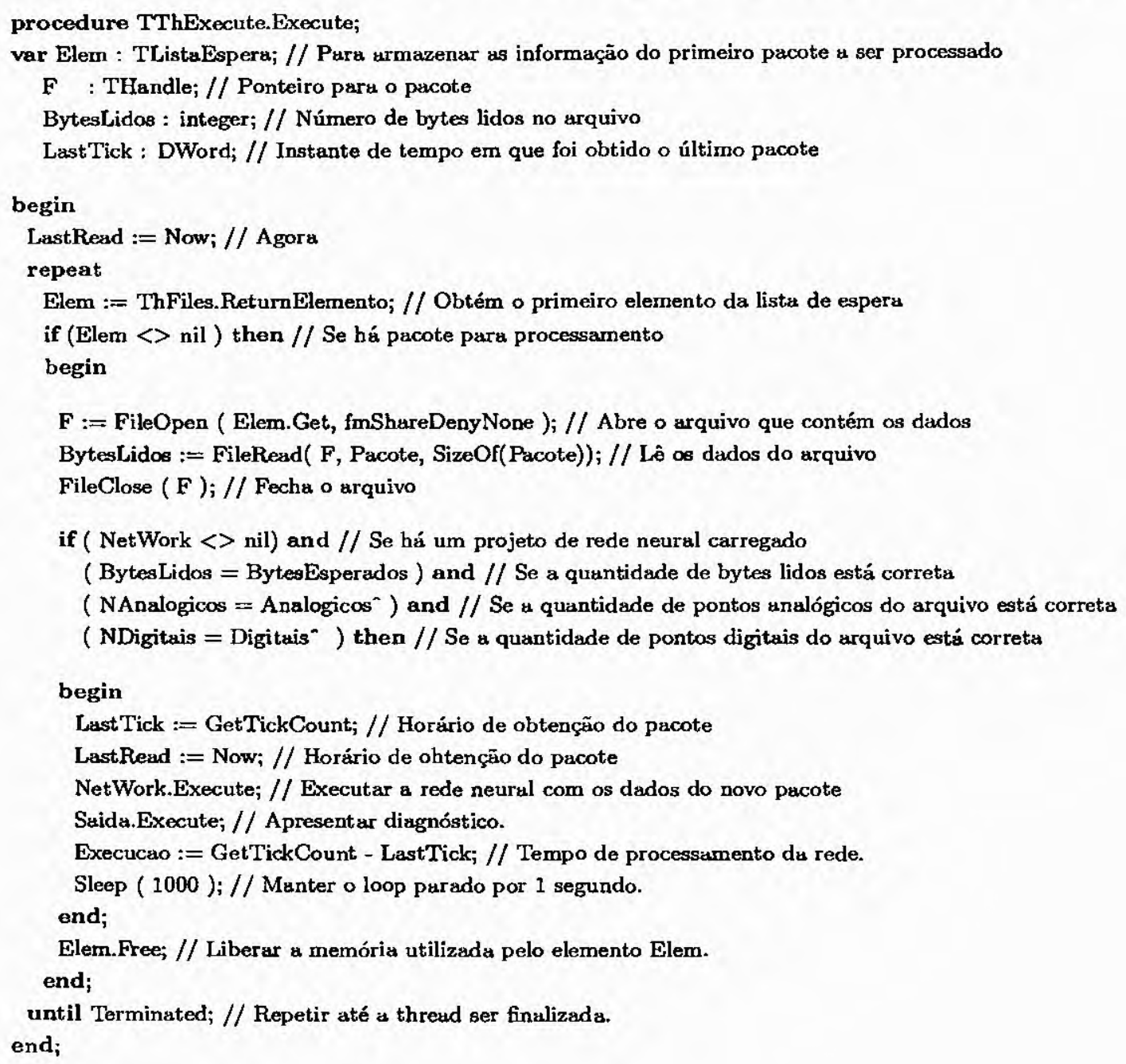

Propriedades da classe TThExecute:

- Execucao: Nesta propriedade é armazenado o tempo de CPU utilizado para o processamento da rede neural.

- LastRead: Horário da obtenção do último pacote de informações.

- BytesEsperados: Números de bytes esperados no pacote de informações.

- Analogicos: Número de pontos analógicos que o pacote deverá conter para que esteja com informações compatíveis.

- Digitais: Número de pontos digitais que deverão estar presentes no pacote de informações. 


\subsection{Testes e Validação dos Resultados}

Durante a implementação do NEUFI, testes foram realizados com o propósito de garantir a confiabilidade dos resultados obtidos.

A validação do SSO já foi realizada em trabalhos anteriores (Capanema, 1997), ficando explícito que o SSO disponibiliza dados confiáveis aos operadores, e as ações sobre estes dados são processadas adequadamente.

Para validar o funcionamento do software NEUFI seus módulos foram testados separadamente, bem como a integração entre eles.

Com este propósito, os testes foram divididos em testes de unidades e de interação entre o SSO e o NEUFI, como apresentados a seguir.

\subsubsection{Testes de Unidade}

Os testes de unidade foram executados desde o início da construção do software, destinandose a detectar erros no programa executável, e em achar falhas na sua concepção.

A seguir são apresentados os principais destes de unidades realizados.

\section{Testes com o SSO}

- Leitura do pacote de dados disponibilizados pelo SSO: verificou-se que as grandezas analógicas e digitais contidas no pacote foram lidas corretamente.

- Envio de pacote com dados inválidos (checksum inválido): o NEUFI lê o pacote, detecta o problema e descartaro. A seguir espera por outro pacote que contenha dados corretos.

- Tempo entre a leitura de cada pacote: verificou-se que este tempo é, em média, de 3 segundos. Se a inferência sobre a rede ultrapassar este valor o pacote é mantido numa lista, aguardando processamento.

- Perda de comunicação com o SSO: O NEUFI continua ativo, deixando de executar a rede. Em sua interface principal é apresentado o time-out do sistema, o que permite ao usuário perceber a perda da comunicação. 


\section{Testes com as Sub-Redes}

- Validação das sub-redes: Cada sub-rede foi testada individualmente, onde foi a cada entrada fornecida, verificava-se se a saída estava próxima da saída desejada. Este teste foi efetuado diretamente no simulador.

\section{Testes com a Base de Conhecimento Final}

- Validação da Base de Conhecimento: Aqui todas as sub-redes foram unidas, formando uma única rede neural. Verificou-se o desempenho da rede como um todo, onde para cada entrada fornecida foi observada sua saída. Este teste foi efetuado através do NEUFI, utilizando-se dados obtidos em tempo real.

- Validação do Tempo de Resposta: A cada ciclo de processamento, o tempo de resposta do sistema foi observado, para garantir que sua velocidade de processamento se enquadrasse nos requisitos de tempo de resposta desejados. O maior tempo médio obtido foi de 20 milissegundos, para um total de 15 sub-redes.

\subsubsection{Testes de Interação entre o SSO e o NEUFI}

Os testes de interação entre o SSO e o NEUFI validam o sistema final como um todo, ou seja, uma determinada entrada de dados fornecida pelo SSO é avaliada e uma resposta é apresentada.

Vários testes de interação foram efetuados, a seguir três destes testes são apresentados.

\section{Teste 1}

Aumento da tensão da barra de $500 \mathrm{kV}$ da Subestação Isolada a Gás (GIS). Com este aumento a sub-rede 3 (Figura 4.22, Capítulo 4) é ativada. Esta sub-rede engloba a regra abaixo (regra - 13 apêndice $A$ ):

SE

$$
\text { ("IPU-60 BARRA A4-KV.VALOR" > 550) }
$$

ENTÃo ("Tensão está acima da máxima operativa. Providenciar redução.)

A Figura 5.11 apresenta como o resultado da ativação desta sub-rede é apresentado no sistema. Como pode ser visto, quando a tensão da barra é alterada, de forma manual 
ou automática, a mesma é processada e um diagnóstico é apresentado, se necessário.

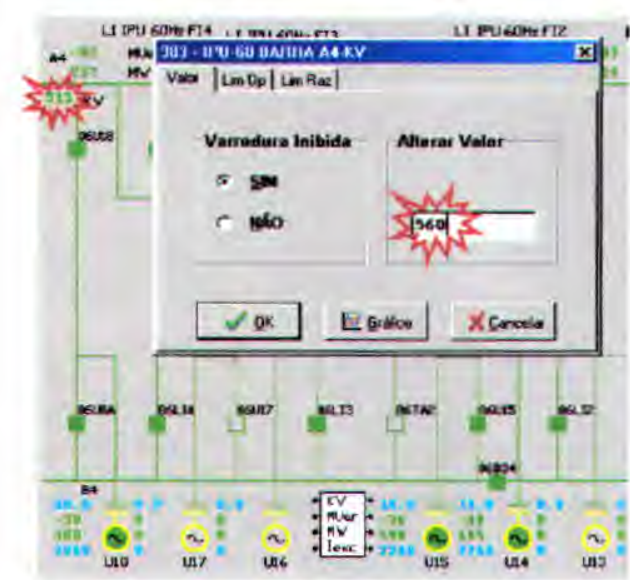

Figura 5.10: Mudança efetuada no SSO na Barra A4, de 515 para $560 \mathrm{kV}$

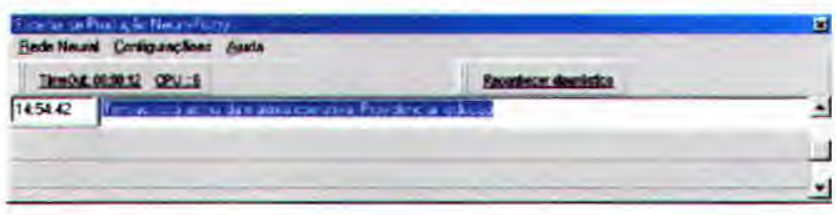

Figura 5.11: Diagnóstico apresentado pelo NEUFI quando a tensão da Barra A4 foi aumentada no SSO

\section{Teste 2}

Testes foram realizados levando-se em consideração o dia da semana e a hora, pois dependendo destes, o período de carga assume valores diferentes.

\begin{tabular}{|c|c|c|}
\hline \hline \multirow{2}{*}{$\begin{array}{c}\text { PERÍODO DE } \\
\text { CARGA }\end{array}$} & $2^{a}$ FEIRA A SÁBADO & DOMINGO E FERIADOS \\
\cline { 2 - 3 } & DE-ATE (horas) & DE - ATE (horas) \\
\hline MÍNIMA & $00: 00-07: 00$ (Segunda-Feira) & $05: 00-10: 00$ \\
\hline & & $00: 00-05: 00$ \\
LEVE & $00: 00-07: 00$ & $10: 00-17: 00$ \\
& & $22: 00-24: 00$ \\
\hline MÉDIA & $00: 00-07: 00$ & $17: 00-22: 00$ \\
\hline PESADA & $22 ; 00-24: 00$ & \\
\hline
\end{tabular}

Tabela 5.16: Períodos de Carga

A Tabela 5.16 apresenta, de forma sintetizada, às regras 1, 2 e 3 contidas no Apêndice A. Os resultados obtidos para cada um dos testes realizados é apresentado na tabela abaixo.

\begin{tabular}{|c|l|c|l|}
\hline \hline \multicolumn{3}{|c|}{ Testes } & \multirow{2}{*}{ Resultados } \\
\hline Teste no & DIA & HORÁRIO & \\
\hline \hline $\mathbf{1}$ & Segunda & $06: 00$ & Carga Mínima \\
\hline $\mathbf{2}$ & Terça & $06: 00$ & Carga Leve \\
\hline $\mathbf{3}$ & Terça & $18: 00$ & Carga Pesada \\
\hline $\mathbf{4}$ & Quarta & $08: 00$ & Carga Média \\
\hline $\mathbf{5}$ & Quinta & $23: 00$ & Carga Média \\
\hline $\mathbf{6}$ & Sexta & $02: 00$ & Carga Leve \\
\hline $\mathbf{7}$ & Sábado & $06: 00$ & Carga Mínima \\
\hline $\mathbf{8}$ & Domingo & $11: 00$ & Carga Leve \\
\hline $\mathbf{9}$ & Domingo & $21: 00$ & Carga Média \\
\hline
\end{tabular}


Como pôde ser visto, todos os testes realizados para determinar o período de carga foram bem sucedidos. Por exemplo, se o sistema receber como entrada Dia = Segunda e Hora $=06: 00 \mathrm{~h}$, ele fornece a resposta Carga Minima. Um outro exemplo, se sistema receber como entrada $D i a=$ Domingo e Hora $=11: 00 \mathrm{~h}$, a resposta do sistema é Carga Leve.

\section{Teste 3}

Outro teste é o que se refere a dependência entre as sub-redes, por exemplo, a regra 21 apresentada no Apêndice A:

\begin{tabular}{|c|c|}
\hline SE & 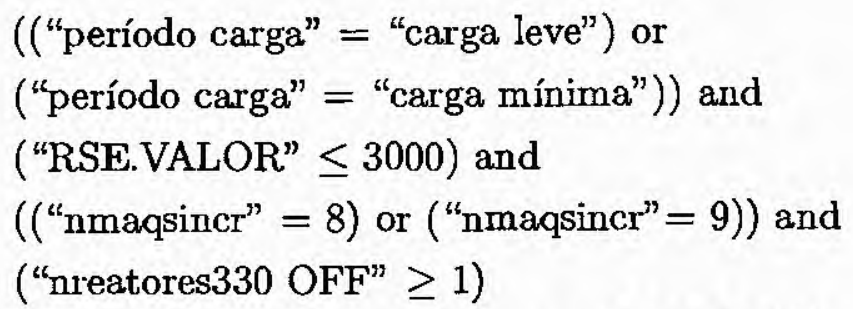 \\
\hline & ("Geração de ITAIPU deve ser $\leq 5100 \mathrm{MW"}$ \\
\hline
\end{tabular}

Para se determinar o diagnóstico desta regra, deve-se primeiro determinar o período de carga em vigor, o número de máquinas sincronizadas e o número de reatores de 330 $\mathrm{kV}$ que estão desligados, para então poder-se efetuar a inferência sobre a rede e obter um diagnóstico confiável.

Os testes efetuados sobre esta sub-rede obtiveram resultados ótimos, conforme pode ser visto no quadro abaixo:

\begin{tabular}{|c|c|c|c|c|c|}
\hline \multicolumn{5}{|c|}{ Testes } & \multirow{2}{*}{ Resultado } \\
\hline Teste no & Carga & RSE & NMaqSinc. & NReatoresOFF & \\
\hline 1 & Leve & 3000 & 8 & 1 & Geração de ITAIPU deve ser $\leq 5100 \mathrm{MW}$ \\
\hline 2 & Leve & 3000 & 8 & 0 & - \\
\hline 3 & Leve & 3000 & 9 & $\mathbf{I}$ & Gerução de ITAIPU deve ser $\leq 5100 \mathrm{MW}$ \\
\hline 4 & Mínima & 3000 & 9 & 0 & - \\
\hline $\mathbf{5}$ & Mínima & 3100 & 8 & 1 & 一 \\
\hline 6 & Mínima & 3100 & 9 & 0 & - \\
\hline 7 & Pesada & 3000 & 9 & 1 & - \\
\hline 8 & Média & 3000 & 9 & 1 & 二 \\
\hline
\end{tabular}

Com a realização destes testes foi possível validar, também, a dependência entre as sub-redes, onde sub-redes cujas entradas dependem das saídas de outras somente podem ser processadas quando suas entradas já tiverem sido atualizadas. 


\subsection{Resumo}

Este capítulo apresentou o funcionamento do Sistema de Produção NEUFI, destacando suas interfaces com o usuário, detalhes de implementação e testes realizados.

Conclui-se assim o trabalho proposto, onde se procurou utilizar conhecimentos e técnicas de inteligência artificial para criar um sistema híbrido, com uma base de conhecimento neuro-fuzzy, dentro dos requisitos exigidos.

Além disso, incorpora-se a vantagem de utilização de orientação a objetos, que facilitou na implementação do sistema, devido às suas características de reusabilidade, facilidade de implementação, polimorfismo, entre outras. 


\section{Capítulo 6}

\section{Conclusões e Trabalhos Futuros}

No presente trabalho foi proposta uma metodologia voltada ao desenvolvimento de sistemas híbridos para previsão e detecção de falhas na Usina Hidrelétrica de Itaipu Binacional.

O Sistema NEUFI desenvolvido utiliza uma base de conhecimento neuro-fuzzy para realizar diagnósticos. Na inicialização do sistema, a base de conhecimento é carregada para a memória, variáveis são associadas a neurônios da camada de entrada e de saída, mensagens são associadas a algumas das variáveis, quando estas representam neurônios de saída. A cada ciclo do processo de execução são fornecidos dados em tempo real pelo sistema de potência utilizado em ITAIPU, estes dados são distribuídos aos neurônios da camada de entrada, e então é aplicado um mecanismo de inferência para processá-los. Após este passo, as mensagens dos neurônios da camada de saída ativados serão apresentadas aos despachantes de carga. A apresentação destas mensagens são também controladas por um temporizador, o qual não permite que uma mensagem seja apresentada duas ou mais vezes sem que haja transcorrido um intervalo de tempo determinado, eliminando assim, possíveis avalanches de uma mesma mensagem.

Um simulador neuro-fuzzy também foi desenvolvido. Este simulador permite a modelagem e o treinamento de redes neurais, que podem ou não incorporar lógica fuzzy, dependendo da aplicação a que se destina. Este simulador foi projetado para a modelagem de redes a partir de regras. Para isso ele permite que haja o particionamento de uma rede em diversas sub-redes, de acordo com as características das regras, onde regras similares foram agrupadas e treinada em uma mesma sub-rede. Ao final de todo o processo é acionado um método que agrupa todas as sub-redes numa única, denominada base de conhecimento neuro-fuzzy, base esta utilizada pelo sistema NEUFI.

A fase de reconhecimento de padrões é efetivada, neste trabalho, através do uso 
de três neurônios distintos:

- Padrão (perceptron) : O perceptron é o modelo mais simples dentre os neurônios que possibilitam treinamento.

- Binário: O neurônio binário é um perceptron simplificado, pois o conhecimento é diretamente inserido em sua estrutura, sem haver posterior treinamento.

- Fuzzy: O neurônio fuzzy, normalmente utilizado nas camadas de entrada das redes, fuzzifica suas entradas crisp em ordens de veracidade (quantização), repassando estas ordens para as próximas camadas de neurônios. A incorporação de lógica Fuzzy no tratamento de algumas variáveis permitiu maior flexibilidade ao sistema.

Existem muitos outros modelos e muitas outras funçôes que podem ser utilizadas para gerar a saída de um neurônio. Estes modelos são capazes de resolver alguns problemas que teriam alto grau de dificuldade se não fossem utilizadas técnicas de IA.

O objetivo deste trabalho foi o desenvolvimento do Sistema de Produção NEUFI, possuindo as seguintes características:

- Interface amigável com os usuários.

- Alta velocidade de processamento, sendo capaz de obter dados do SSO, analisálos e formular um conjunto de ações que fornecerá uma configuração (dentro dos parâmetros desejáveis) ao sistema elétrico.

- Armazenamento, em arquivos diários, de todos os diagnósticos apresentados aos despachantes, horário de ocorrência e status de reconhecimento.

- Indicação do status de comunicação com o SSO.

O NEUFI, através de mecanismos de threads, possibilita que o usuário fique interagindo com o sistema enquanto outras informações estão sendo processadas "paralelamente", ou seja, as threads ficam constantemente verificando a existência de dados para serem lidos e processados, enquanto o usuário fica interagindo com o sistema.

A principal utilidade do NEUFI é prover informações consideradas relevantes no caso de situações emergenciais aos despachantes de carga, sugerindo, de forma rápida e segura, alternativas de configuração do sistema elétrico.

Além do NEUFI, os seguintes produtos foram gerados no deçorrer deste trabalho: 
- Simulador Neuro-Fuzzy: Este simulador foi desenvolvido com o objetivo de facilitar a modelagem da base de conhecimento neuro-fuzzy.

- Base de Conhecimento Neuro-Fuzzy: Base de conhecimento construída a partir de regras de produção. Esta base é formada por neurônios fuzzy, padrão e binário.

O sistema NEUFI tem diversas vantagens em relação ao sistema especialista $R$ TESE.

A primeira delas refere-se a diminuição do número de regra. Isso se deve ao fato das regras serem semelhantes, possibilitando suas modelagens em uma mesma sub-rede. Outra vantagem é a flexibilidade de visualização das regras graficamente, o que permite mostrar quais regras estão sendo ativadas num dado instante de tempo e, com isso, ter-se idéia do funcionamento do sistema NEUFI. O tempo de processamento também foi melhorado, pelo fato de não se trabalhar com variáveis lingüísticas, as quais consomem tempo considerável de processamento. Além disso, pode-se trabalhar com dados imprecisos, proporcionando maior flexibilidade ao sistema.

O tempo médio de resposta do sistema foi de 20 milissegundos, para um total de 15 sub-redes. Este tempo pode ser melhorado através da utilização de bases de dados em formato próprio, pois os existentes consomem mais tempo processamento.

O estado atual do trabalho permite abordar os seguintes tópicos como extensões futuras:

- Construção de uma base de conhecimento completa, pois até o momento somente um subconjunto das regras foi modelado (em torno de 50 de 250 regras). Para o presente trabalho, este subconjunto foi considerado suficiente pelo fato de possuírem características presentes no conjunto todo.

- Aumentar as funcionalidades do Sistema NEUFI, tal como, fornecer explicação a respeito de um determinado diagnóstico.

- Ampliar as funcionalidades implementadas no Simulador, tais como: inclusão de algoritmos de treinamento, adição de outros tipos de neurônios, melhorias nas interfaces com o usuário.

Baseando-se nos resultados obtidos e nos aspectos descritos, salienta-se que o projeto é estratégico no sentido de utilizar uma abordagem híbrida, apresentando uma aplicação bem sucedida desta abordagem a um problema real. 
O estudos apresentados neste trabalho, bem como os aplicativos desenvolvidos sāo de extrema importância devido a aplicação, na prática, dos estudos realizados.

De forma sintetizada, este trabalho abordou a modelagem de um sistemas híbrido através dos paradigmas fuzzy e conexionista, com enfoque para o setor de geração e transmissão de energia.

O importante, afinal, é conseguir uma melhora contínua de todo o processo de tomada de decisões, auxiliando para que esta seja feita de forma rápida e eficaz. O Sistema de Produção NEUFI compreende um sistema que pode ser usado para este propósito.

Todas as informações aqui expostas nos levam a crer que o campo de redes neurais artificiais e lógica fuzzy são, acima de tudo, extremamente vastos e promissores. Por ser um assunto que surgiu há muito tempo atrás, ganhou muita credibilidade, e as novas descobertas relacionadas tornaram-nas bastante atrativas para profissionais de domínios distintos, tornando-se um assunto interdisciplinar. 


\section{Bibliografia}

Braga, A. P., de Leon F. De Carvalho, A. P., and Ludemir, T. B. (1999). Redes Neurais Artificiais: Teoria e Aplicações. LTC Press, Rio de Janeiro.

Brown, M. (1994). Elements of Machine Learning. Prentice Hall.

Brule, J. F. (1985). Fuzzy systems - a tutorial. Disponível em http://austinlinks.com /Fuzzy/tutorial.html, 07/02/2000.

Capanema, I. F. (1997). Desenvovimento de um sistema de supervisão em tempo real. Universidade Federal de Santa Catarina, Monografia de Graduação.

Capanema, I. F. (1999). Ambiente para a construção de sistemas especialistas em tempo real para a itaipu binacional. Master's thesis, Universidade Federal de Santa Catarina, Florianópolis, SC. Dissertação de Mestrado.

Carvalho, A. P. L. F. (1999). Redes neurais artificiais. Disponível em http://www.icmsc.sc.usp.br/ andre/neural1.html, 04/02/2000.

Cybenko, G. (1988). Continuos valued neural networks with two hidden layers are sufficient. Technical report, Department of Computer Science, Thufts University.

Cybenko, G. (1989). Approximation by superpositions of a sigmoid function. Mathematics of Control, Signals and Systems, 2:303-314.

Fabro, J. A. (1998a). Redes neurais. Disponivel em http://www.dcc.unioeste-foz.br/ jfabro/cap0022.html, 09/02/2000.

Fabro, J. A. (1998b). Sistemas nebulosos. Disponível em http://www.dcc.unioestefoz.br/ ${ }^{\sim}$ jfabro/cap0023.html, 09/02/2000.

Fullér, R. (1995). Neural Fuzzy Systems. Abo Akademi. Disponível em http://austinlinks.com /Fuzzy/tutorial.html, 07/02/2000. 
Goonatilake, S. and Khebbal, S. (1995). Intelligent Hibrid Systems. University College London, UK.

Haykin, S. (1999). Neural Networks: a Comprehensive Fondation. Prentice Hall.

Kasabov, N. K. (1996). Foundations of Neural Networks, Fuzzy Systems, and Knowledge Engeneering. MIT Press, Cambridge, Mass.

Keller, J. M., Yager, R. R., and Tahani, H. (1992). Neural network implementation of fuzzy logic. Fuzzy Sets and Systems, 45:1-12.

Khouri, J. H. H. E. (1991). Proposta e processo de desenvolvimento para sistemas de comando e controle. Master's thesis, Instituto Tecnológico da Aeronáutica, São José dos Campos, SP. Dissertação de Mestrado.

Khouri, J. H. H. E. (1993). Sistemas especialistas de apoio ao despacho de carga da usina de itaipu. In $V$ Encontro Reginal Latino Americano da Cigre, Ciudad del Este, Paraguay.

Lin, C.-T. and Lu, Y.-C. (1995). A neural fuzzy system with linguistc teaching signals. IEEE Transactions on Fuzzy Systems, 3(2):169-189.

Lin, Y. and Cunningham, G. A. (1995). A new approach to fuzzy-neural system modeling. IEEE Transactions on Fuzzy Systems, 3(2):190-197.

McCulloch, W. S. and Pitts, W. (1943). A logical calculus of the ideas immanent in nervous activity. Bulletin of Mathematical Biophysics, 5:115-133.

Omlin, C. W., Thornber, K. K., and Giles, C. L. (1998). Fuzzy finite-state automata can be deterministically encoded into recurrent neural networks. IEEE Transactions on Fuzzy Systems, 6(1):76-89.

Pressman, R. S. (1995). Engenharia de Software. Mackrom Books, São Paulo.

Rodrigues, M. A. P., Souza, J. C. S., and Schilling, M. T. (1999). Building local neural classifiers for alarm handling and fault location in electrical power systems. In Torres, G. L. and da Silva, A. P. A., editors, The Intenational Conference on Intelligent System Apllication to Pawer System, pages 157-161, Rio de Janeiro.

Rumelhart, D. E., Hinton, G. E., and Williams, R. J. (1986). Learning representations by back-propagating errors. Nature, 323:740-746. 
Wang, H. and Keerthipala, W. W. L. (1998). Fuzzy-neuro aproach to fault classification for transmission line protection. IEEE Transactions on Power Dilivery, 13(4):10931104.

Weber, A. L. (1997). Sistemas em tempo real - sistemas inteligentes em tempo real. Disponivel em http://www.geocities.com/SiliconValley/Setor 1010/temporeal.html, 06/08/1998.

Widrow, B. and Hoff, M. E. (1960). Adaptative switching circuits. Institute of Radio Engineers, Western Electronic Show and Convention.

Yager, R. R. (1992). Implementing fuzzy logic controllers using a neural network framework. Fuzzy Sets and Systems, 48:53-64.

Yamakawa, T., Uchino, E., Miki, F., and et al. (1992). A neo fuzzy neuron and its application to system indentification and prediction of the system behaviour. In Proceedings of the Second International Conference on Fuzzy Logic and Neural Networks, pages 477-483, lizuka, Japan.

Zadeh, L. A. (1965). Fuzzy sets. Information on Control, (8):338-353.

Zell, A. (1995). SNNS - stuttgart neural network sumulator user manual version 4.1. Technical Report 6/95, University of Stuttgart, Institute of Parallel and Distributed High Performance Systems. 


\section{Apêndice A}

\section{Base de Conhecimento Real (notação no R-TESE)}

01. SE $((\mathrm{DATA}=1)$ or $(\mathrm{DATA}=8))$

ENTÃO SE $(($ HORA $\geq 5)$ and $($ HORA $<10))$

ENTÃo ("Período Carga" := "Carga Mínima");

SE $((($ HORA $\geq 0)$ and $($ HORA $<5))$

or $(($ HORA $\geq 10)$ and $($ HORA $<17))$

or $(($ HORA $\geq 22)$ and $($ HORA $<24)))$

ENTÃO ("Período Carga" := "Carga Leve");

SE $((($ HORA $\geq 17)$ and $($ HORA $<22))$

ENTÃO ("Período Carga" := "Carga Média");

02. SE $\quad(\mathrm{DATA}=2)$

ENTÃO SE ((HORA $\geq 7)$ and (HORA < 17))

or ((HORA $\geq 22)$ and (HORA < 24)))

ENTÃO ("Período Carga" := "Carga Média");

SE $(($ HORA $\geq 0)$ and (HORA $<7))$

ENTÃO ("Periodo Carga" := "Carga Mínima");

SE $(($ HORA $\geq 17)$ and (HORA < 22))

ENTÃo ("Período Carga" := "Carga Pesada"); 
03. SE $\quad((\mathrm{DATA} \geq 3)$ and $(\mathrm{DATA} \leq 7))$

ENTÃO SE ((HORA $\geq 0)$ and (HORA $<7)$ )

ENTÃO ("Período Carga" := "Carga Leve");

SE $(($ HORA $\geq 7)$ and $($ HORA $<17))$

or $(($ HORA $\geq 22)$ and (HORA $<24))$ )

ENTÃO ("Período Carga" := "Carga Média");

SE $(($ HORA $\geq 17)$ and (HORA $<22))$

ENTÃO ("Período Carga" := "Carga Pesada");

04. SE (ICAMPO U10.VALOR" < 2000)

ENTÃO ("Coordenar com Furnas medidas para aumentar a corrente de campo, tais como: aumentar potência ativa e/ou reativa da máquina.")

05. SE ("ICAMPO U11.VALOR" < 2000)

ENTÃo ("Coordenar com Furnas medidas para aumentar a corrente de campo, tais como: aumentar potência ativa e/ou reativa da máquina.")

06. SE (ICAMPO U12.VALOR" < 2000)

ENTĀO ("Coordenar com Furnas medidas para aumentar a corrente de campo, tais como: aumentar potência ativa e/ou reativa da máquina.")

07. SE ("ICAMPO U13.VALOR" < 2000)

ENTÃO ("Coordenar com Furnas medidas para aumentar a corrente de campo, tais como: aumentar potência ativa e/ou reativa da máquina.")

08. SE ("ICAMPO U14.VALOR" < 2000)

ENTÃO ("Coordenar com Furnas medidas para aumentar a corrente de campo, tais como: aumentar potência ativa e/ou reativa da máquina.")

09. SE ("ICAMPO U15.VALOR" < 2000)

ENTÃo ("Coordenar com Furnas medidas para aumentar a corrente de campo, tais como: aumentar potência ativa e/ou reativa da máquina.")

10. SE ("ICAMPO U16.VALOR" < 2000)

ENTÃO ("Coordenar com Furnas medidas para aumentar a corrente de campo, tais como: aumentar potência ativa e/ou reativa da máquina.")

11. SE ("ICAMPO U17.VALOR" < 2000)

ENTÃO ("Coordenar com Furnas medidas para aumentar a corrente de campo, tais como: aumentar potência ativa e/ou reativa da máquina.")

12. SE ("ICAMPO U18.VALOR" < 2000)

ENTÃO ("Coordenar com Furnas medidas para aumentar a corrente de campo, tais como: aumentar potência ativa e/ou reativa da máquina.")

13. $\mathrm{SE}$ ("IPU-60 BARRA A4-KV.VALOR" > 550)

ENTÃo ("Tensão está acima da máxima operativa. Providenciar redução.) 
14. SE ("IPU-60 BARRA B3-KV.VALOR" > 550)

ENTĀO ("Tensão está acima da máxima operativa. Providenciar redução.)

15. SE ("IPU-60 BARRA A4-KV.VALOR" < 480)

ENTÃo ("Tensão está abaixo da mínima operativa. Providenciar elevação.)

16. SE ("IPU-60 BARRA B3-KV.VALOR" < 480)

ENTÃo ("Tensão está abaixo da mínima operativa. Providenciar elevação.)

17. SE ("IPU-60 LI-FI-1 MW.VALOR" > 1650)

ENTÃO ("Providenciar redução de carga na LI-IPU-60Hz-FI-1")

18. SE ("IPU-60 LI-FI-2 MW.VALOR" > 1650)

ENTÃO ("Providenciar redução de carga na LI-IPU-60Hz-FI-2")

19. SE ("IPU-60 LI-FI-3 MW.VALOR" > 1650)

ENTÃO ("Providenciar redução de carga na LI-IPU-60Hz-FI-3")

20. SE ("IPU-60 LI-FI-4 MW.VALOR" > 1650)

ENTÃO ("Providenciar redução de carga na LI-IPU-60Hz-FI-4")

21. SE (("período carga" = "carga leve") or

("período carga" = "carga mínima")) and

("RSE.VALOR" $\leq 3000$ ) and

$((" n m a q s i n c r "=8)$ or $(" n m a q s i n c r "=9))$ and

("nreatores330 OFF" $\geq 1$ )

ENTÃO ("Geração de ITAIPU deve ser $\leq 5100$ MW")

22. SE ("IV-IA RE 330 2-LI2.VALOR" = OFF) or

("IV-IA RE 330 2-LI1.VALOR" = OFF)) and

(("IA-TP RE 330 2-LI2.VALOR" = OFF) or

("IA-TP RE 330 2-LI1.VALOR" = OFF))

ENTÃO if(("nmaqsincr" $\leq 6)$, ("FSE dever ser $\leq 4500 \mathrm{MW}$ "),

(if(("nmaqsincr" $=7$ ), ("FSE dever ser $\leq 4700 \mathrm{MW}$ "),

(if(("nmaqsincr" $\geq 8$ ), ("FSE dever ser $\leq 5200 \mathrm{MW}$ "),

("Verificar número de máquinas síncronas"))))))

23. SE (("GER DISP 60.VALOR" $\geq 4400)$ and ("nmaqsincr" = 7))

ENTÃO ("Tensão nas máquinas $=18,9$ kV")

24. SE (("GER DISP 60.VALOR" $\geq 4700$ ) and ("mmaqsincr" > 8))

ENTÃO ("Tensāo nas máquinas $=18,9 \mathrm{kV}$ ")

25. SE ("IV CAPACITOR KV.VALOR" < 780)

ENTÃO ("Limite geração em ITAIPU = Limite Geração em ITAIPU - 300, para cada $20 \mathrm{kV}$ abaixo de $780 \mathrm{kV}$ ") 
26. SE ("IPU-60 BARRA A3-KV.VALOR" = 0)

ENTÃO ("Disjuntores 06A34, 06U10, 06U12, 06LI1 e 06LI2 devem estar desligados")

27. SE ("IPU-60 BARRA A4-KV.VALOR" = 0)

ENTÃO ("Disjuntores 06A34, 06TA2, 06LI4, 06LI3, 06U14 e 06U16 devem estar desligados")

28. SE ("IPU-60 BARRA B3-KV.VALOR" =0)

ENTÃO ("Disjuntores 86B34, 86U11, 86U13, 86LI1 e 86LI2 devem estar desligados")

29. SE ("IPU-60 BARRA B4-KV.VALOR" = 0)

ENTÃO ("Disjuntores 86B34, 86TA2, 86LI4, 86LI3, 86U15, $86 \mathrm{U} 17$ e 06U8A devem estar desligados")

30. SE (("DJ 86LI4.VALOR" = OFF) and

("DJ 86LI3.VALOR" = OFF) and

("DJ 86LI2.VALOR" = OFF) and

("DJ 86LI1.VALOR" = OFF) and

("DJ 06LI4.VALOR" = OFF) and

("DJ 06LI3.VALOR" = OFF) and

("DJ 06LI2.VALOR" = OFF) and

("DJ 06LI1.VALOR" = OFF))

ENTÃO ("Interligação ITAIPU/FURNAS 60Hz aberta")

31. SE ((DJ 12626.VALOR" = OFF) and

("DJ 12646.VALOR" = OFF) and

("DJ 12656.VALOR" = OFF) and

("DJ 12616.VALOR" = OFF)

ENTĀO ("Linhas IPU-60 Hz-FI estāo desernegizadas") and

("A tensão máxima de pré-energização é de $460 \mathrm{kV}$ no sentido IPU-FI")

and ("A tensão máxima de pré-energização é de $530 \mathrm{kV}$ no sentido FI-IPU")

and ("Se o sistema já estiver com carga, não há limitações.")

32. SE (("LT-FI-IV 2.VALOR" = OFF) or

("LI FI-IV 2.VALOR" = OFF) or

("LI FI-IV 3.VALOR" = OFF))

ENTĀO If ((("nreatores330 OFF" $\leq 3)$ and ("período carga"="carga pesada")),

(("IPUMAX 441":=2700) and ("RSEMAX441":=4000)),

(If ((" "nreatores330 OFF" $\leq 3$ ) and ("período carga" = "carga média")),

(("IPUMAX441":=2500) and ("RSEMAX441":=4000)),

(If ((" "nreatores330 OFF" $\leq 3$ ) and ("período carga" = "carga leve")),

(("IPUMAX441":=1800) and ("RSEMAX441":= 4000)),

(If ((("nreatores330 OFF" $\leq 3$ ) and ("período carga" = "carga mínima")),

(("IPUMAX441":=1500) and ("RSEMAX441":=4000)),

(If (("nreatores330 OFF" $\geq 4)$ and ("período carga" = "carga pesada")),

(("IPUMAX441":=2700) and ("RSEMAX441":=4200)),

(If ((("nreatores330 OFF" $\geq 4)$ and ("período carga" = "carga média")), 
(("IPUMAX441":=2500) and ("RSEMAX441":=4200)),

(If (( ("nreatores330 OFF" $\geq 4)$ and ("período carga"="carga leve")),

(("IPUMAX441":=1800) and ("RSEMAX441":=4300)),

(If (( ("nreatores330 OFF" $\geq 4$ ) and ("período carga" ="carga mínima")),

$((($ IPUMAX441":=1500) and ("RSEMAX441":=4300)), (Erro)))))))))))))))))

33. SE (("LI IV-IA 1.VALOR" = OFF) or

("LI IV-IA 2.VALOR" = OFF) or

("LI IA-TP 1.VALOR" = OFF) or

("LI IV-TP 2.VALOR" = OFF))

ENTÃO If ((("nreatores330 OFF" $\leq 3)$ and ("período carga"="carga pesada")),

(("IPUMAX442":=4600) and ("RSEMAX442":=2200)),

(If ((("nreatores330 OFF" $\leq 3$ ) and ("período carga" = "carga média")),

(("IPUMAX442":=4600) and ("RSEMAX442":=1800)),

(If (( ("nreatores330 OFF" $\leq 3$ ) and ("período carga" = "carga leve")),

(("IPUMAX442":=4400) and ("RSEMAX442":=1400)),

(If ((("nreatores330 OFF" $\leq 3$ ) and ("período carga"="carga mínima")),

(("IPUMAX442":=4400) and ("RSEMAX442":=1200)),

(If ((" "nreatores330 OFF" $\geq 4)$ and ("período carga" = "carga pesada")),

(("IPUMAX442":=4900) and ("RSEMAX442":=2200)),

(If ((("nreatores330 OFF" $\geq 4$ ) and ("período carga" = "carga média")),

(("IPUMAX442":=4900) and ("RSEMAX442":=1800)),

(If ((("nreatores330 OFF" $\geq 4$ ) and ("período carga" = "carga leve")),

(("IPUMAX 442":=4700) and ("RSEMAX442":=1400)),

(If ((("nreatores330 OFF" $\geq 4$ ) and ("período carga"="carga mínima")),

$(($ (IPUMAX442":=4700) and ("RSEMAX442":=1200)), (Erro))))))))))))))))

34. SE (("LI IV-IA 1.VALOR" = OFF) and

("LI IV-IA 2.VALOR" = ON) and

("IV-IA RE 330 2-LI2.VALOR"=OFF)) or

( ("LI IA-TP1.VALOR" = ON) and

("LI IA-TP 2.VALOR" = OFF) and

("IV-IA RE 330 2-LI1.VALOR" = OFF))

ENTÃO ("Os reatores de barra da SE-IA (R1 e R2) devem estar ligados") and

("Se apenas um estiver ligado, o limite do fluxo entre IV-IA deve ser

$2400 \mathrm{MW}$ ),

35. SE (("LI IA-TP 1.VALOR" = OFF $)$ and

("LI IA-TP 2.VALOR" = ON) and

("IA-TP RE 330 LI2.VALOR" = OFF)) or

(("LI IA-TP 1.VALOR" = ON) and

("LI IA-TP 2.VALOR" = OFF) and

("IA-TP RE 330 LI1.VALOR" = OFF))

ENTÃO ("Dievem estar ligados pelo menos 3 reatores 330 MVar em IA - de linha ou de barra) and ("O limite do fluxo entre IV-IA deve ser $2200 \mathrm{MW")}$ 
36. SE

(("I,I IV-IA 1.VALOR" = OFF) or

("LI IV-IA 2.VALOR" = OFF)) and

(("LI IA-TP 1.VALOR" = OFF) or

("LI IA-TP 2.VALOR" = OFF))

ENTĀO ("FSE deve ser $\leq 1900$ ") and ("Dois reatores deverão estar ligados em

barra em IA, podendo estar desligado até um reator de linha em IA ou TP")

37. SE

$$
\begin{aligned}
& \text { ("LI FI-IV 1.VALOR" }=\mathrm{ON} \text { ) and } \\
& \text { ("LI FI-IV 2.VALOR" = ON) and } \\
& \text { ("LI FI-IV 3.VALOR" = ON) and } \\
& \text { ("LI IV-IA 1.VALOR" = ON) and } \\
& \text { ("LI IV-IA 2.VALOR" = ON) and } \\
& \text { ("LI IA-TP 1.VALOR" = ON) and } \\
& \text { ("LI IA-TP 2.VALOR" = ON)) }
\end{aligned}
$$

ENTÃo If ((("nreatores OFF" $\leq 2)$, ("Número de máquinas sincronizadas = 3"),

(If (("nreatores OFF" $\leq 3)$, ("Número máquinas sincronizadas $=4$ "),

(If (("nreatores OFF" $\leq 4)$, ("Número máquinas sincronizadas $=5$ "),

(If (("nreatores OFF" $\leq 5)$, ("Número máquinas sincronizadas $=6$ "),

(If (("nreatores OFF" $\leq 6)$, ("Número máquinas sincronizad as $=6$ ") and

("Pelo menos um dos reatores deve ser Tijuco Preto")), (Erro))))))))))

38. SE ("LI FI-IV 1.VALOR" = OFF) or

("LI FI-IV 2.VALOR" = OFF) or

("LI FI-IV 3.VALOR" = OFF))

ENTĀO If (( ("nreatores OFF" $\leq 3)$, ("Número de máquinas sincronizadas $=3$ "),

(If ( "nreatores OFF" $\leq 4)$, ("Número máquinas sincronizadas $=4$ "),

(If (("nreatores OFF" $\leq 5)$, ("Número máquinas sincronizadas $=5$ "),

(If (("nreatores OFF" $\leq 6)$, ("Número máquinas sincronizadas $=6$ ") and

("Pelo menos um dos reatores deve ser Tijuco Preto")), (Erro))))))))

39. SE (("LI IA-TP 1.VALOR" = OFF) or

("LI IA-TP 2.VALOR" = OFF))

ENTÃO If ((("nreatores OFF" $\leq 3)$, ("Número de máquinas sincronizadas $=3 ")$, (If (("nreatores OFF" $\leq 4)$, ("Número máquinas sincronizadas $=4$ "),

(If (("nreatores OFF" $\leq 5)$, ("Número máquinas sincronizadas $=5$ "),

(If (("nreatores OFF" $\leq 6)$, ("Número máquinas sincronizadas $=6$ ") ) and

("Pelo menos um dos reatores deve ser Tijuco Preto")), (Erro))))))))

40. SE

(("LI IV-IA 1.VALOR" = OFF) or

("LI IV-IA 2.VALOR" = OFF))

ENTÃo If ((" "nreatores OFF" $\leq 2)$, ("Número de máquinas sincronizadas = 3"),

(If (("nreatores OFF" $\leq 3)$, ("Número máquinas sincronizadas $=4$ "),

(If (("nreatores OFF" $\leq 4)$, ("Número máquinas sincronizadas $=5$ "),

(If (("nreatores OFF" $\leq 5$ ), ("Número máquinas sincronizadas $=6$ "),

(If (("nreatores OFF" $\leq 6)$, ("Número máquinas sincronizadas $=6$ ") and

("Pelo menos um dos reatores deve ser Tijuco Preto")), (Erro)))))))))) 
41. SE (("LI IV-IA 1.VALOR" = OFF) or

("LI IV-IA 2.VALOR" = OFF)) and

(("LI IA-TP 1.VALOR" = OFF) or

("LI IA-TP 2.VALOR" = OFF))

ENTÃO If ((" "nreatores OFF" $\leq 4)$, ("Número de máquinas sincronizadas = 3"),

(If (("nreatores OFF" $\leq 5$ ), ("Número máquinas sincronizadas = 4"),

(If (("nreatores OFF" $\leq 6$ ), ("Número máquinas sincronizadas $=5$ ") and

("Pelo menos um dos reatores deve ser Tijuco Preto")), (Erro))))))))

42. SE (("LI FI-IV 1.VALOR" = OFF) or

("LI FI-IV 2.VALOR" = OFF) or

("LI FI-IV 3.VALOR" = OFF)) and

(("LI IA-TP 1.VALOR" = OFF) or

("LI IA-TP 2.VALOR" = OFF))

ENTĀO If ((" "nreatores OFF" $\leq 3)$, ("Número de máquinas sincronizadas $=2$ "),

(If (("nreatores OFF" $\leq 4$ ), ("Número máquinas sincronizadas = 3"),

(If (("nreatores OFF" $\leq 5$ ), ("Número máquinas sincronizadas =4"),

(If (("nreatores OFF" $\leq 6)$, ("Número máquinas sincronizadas = 5") and

("Pelo menos um dos reatores deve ser Tijuco Preto")), (Erro))))))))

43. SE (("LI FI-IV 1.VALOR" = OFF) or

("LI FI-IV 2.VALOR" = OFF) or

("LI FI-IV 3.VALOR" = OFF)) and

(("LI IV-IA 1.VALOR" = OFF) or

("LI IV-IA 2.VALOR" = OFF))

ENTÃO If (( "nreatores OFF" $\leq 1)$, ("Número de máquinas sincronizadas = 2"),

(If (("nreatores OFF" $\leq 2)$, ("Número máquinas sincronizadas = 3 "),

(If (("nreatores OFF" $\leq 3$ ), ("Número máquinas sincronizadas $=4$ "),

(If (("nreatores OFF" $\leq 4)$, ("Número máquinas sincronizadas $=5$ "),

$($ Erro $)))))))$ )

44. SE (("LI FI-IV 1.VALOR" = OFF) or

("LI FI-IV 2.VALOR" = OFF) or

("LI FI-IV 3.VALOR" = OFF)) and

(("LI IV-IA 1.VALOR" = OFF) or

("LI IV-IA 2.VALOR" = OFF)) and

("LI IA-TP 1.VALOR" = OFF) or

("LI IA-TP 2.VALOR" = OFF))

ENTÃO If ((("nreatores OFF" $\leq 2)$, ("Número de máquinas sincronizadas = 1") and ("Reatores de FI-IV devem estar conectados"),

(If (("nreatores OFF" $\leq 4)$, ("Número máquinas sincronizadas =2") and

("reator da LT IA-TP deve estar em operação")), (Erro)))) 